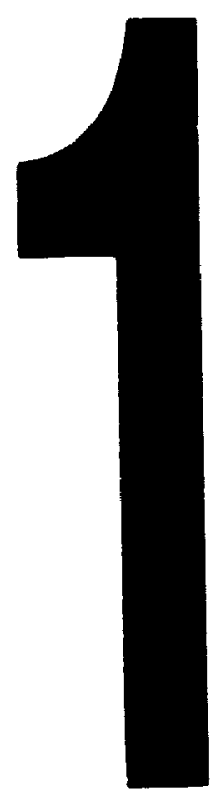

PM-1 31/2" $x 4 "$ PHOTOGRAPHIC MICAOCOPY TARGET MES 1010A ANSI/ISO "2 EQUIVALENT

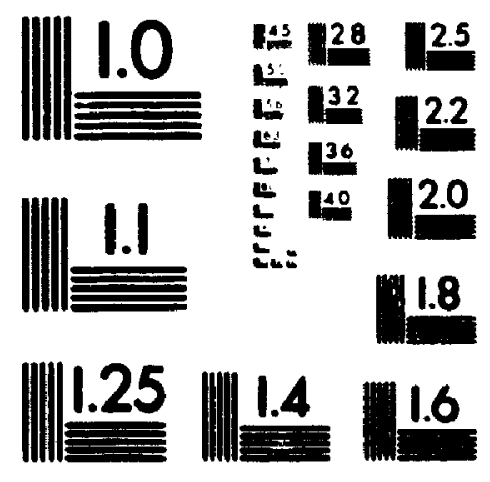

PRECISIONEM RESOLUTION TARGETS 
National Library

of Canada

Acquisitions and

Bibliograptic Services Branch

395 Weitroton Street

Onawa. Ontano

KIAONA
Bibliotheque nationale

du Canada

Direction des acquisitions et

des services bibliographiques

395. ne Wellington

Onawa (Ontano)

KIA ON4
The quality of this microform is heavily dependent upon the quality of the original thesis submitted for microfilming. Every effort has been made to ensure the highest quality of reproduction possible.

If pages are missing, contact the university which granted the degree.

Some pages may have indistinct print especially if the original pages were typed with a poor typewriter ribbon or if the university sent us an inferior photocopy.
La qualité de cette microforme dépend grandement de la qualité de la thèse soumise au microfilmage. Nous avons tout fait pour assurer une qualité supérieure de reproduction.

S'il manque des pages, veuillez communiquer avec l'université qui a conféré le grade.

La qualité d'impression de certaines pages peut laisser à désirer, surtout si les pages originales ont été dactylographiées à l'aide d'un ruban usé ou si l'université nous a fait parvenir une photocopie de qualité inférieure.

La reproduction, même partielle, de cette microforme est soumise à la Loi canadienne sur le droit d'auteur, SRC 1970, c. C-30, et ses amendements subséquents.
Reproduction in full or in part of this microform is governed by the Canadian Copyright Act, R.S.C. 1970, C. C-30, and subsequent amendments. 


\title{
Performance Evaluation of Handover Process in Personal Communication System using fuzzy algorithm
}

\author{
by
}

Chiku H. Mlonja, B. Sc.

\author{
A tilesis submitted to \\ the Faculty of Graduate Studies and Research \\ in partial fulfilment of \\ the requirements for degree of
}

\section{Master of Engineering}

Oitawa-Carleton Institute for Electrical Engineering

Faculty of Engineering

Department of Systems and Computer Engineering

Catleton University

January 1996

- Copyright

1996, Chiku Mlonja 
National Libran

of Canada

Acquisitions and

Bibliographic Senvices Branch

395 Weington Street

Onawa Onlario

KIA ONA

\section{Bibliotheque nationale}

ou Canada

Direction des acquisitions et

des services bibliographiques

395. ne Welingtion

Onswa (Ontario)

KiA ois

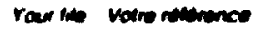

The author has granted an irrevocable non-exclusiye licence allowing the National Library of Canada to reproduce, loan, distribute or sell copies of his/her thesis by any means and in any form or format, making this thesis available to interested persons.
L'auteur a accordé une licence irrévocable ef non exclusive permettant à la Bibliothèque nationale du Canada de reproduire, prêter, distribuer ou vendre des coples de sa these de quelque manière et sous quelque forme que ce solt pour mettre des exemplaires de cette these a la disposition des personnes intéressées.

L'auteur conserve la propriété du droit d'auteur qui protoge sa these. Ni la thèse ni des extraits substantiels de celle-ci ne doivent être imprimés ou autrement reproduits sans son autorisation.

ISBN $\quad 0-612-08982-7$ 
Nom Claikn Whisaica

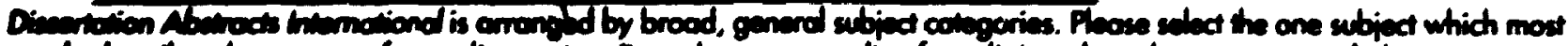

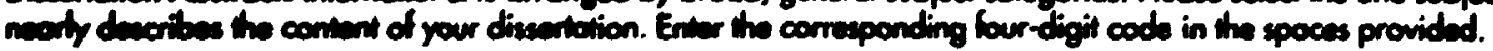

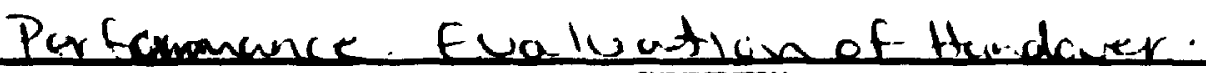

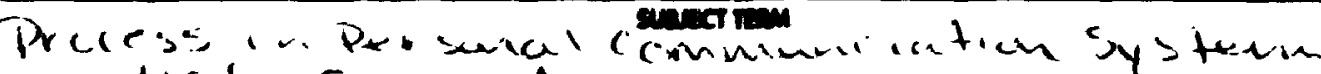 salind disitid, Fuz 4 A igurith}

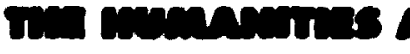

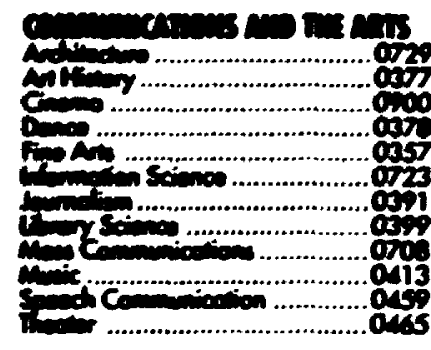

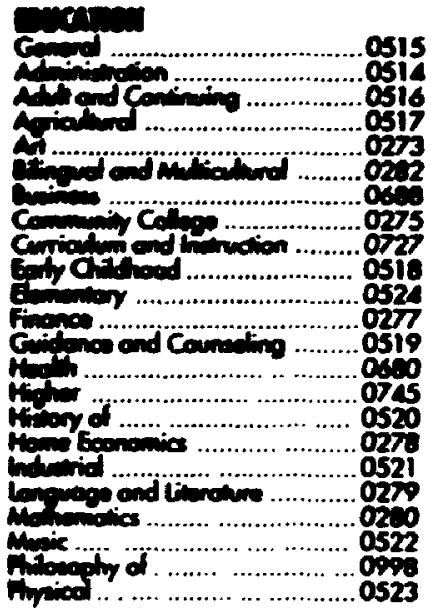
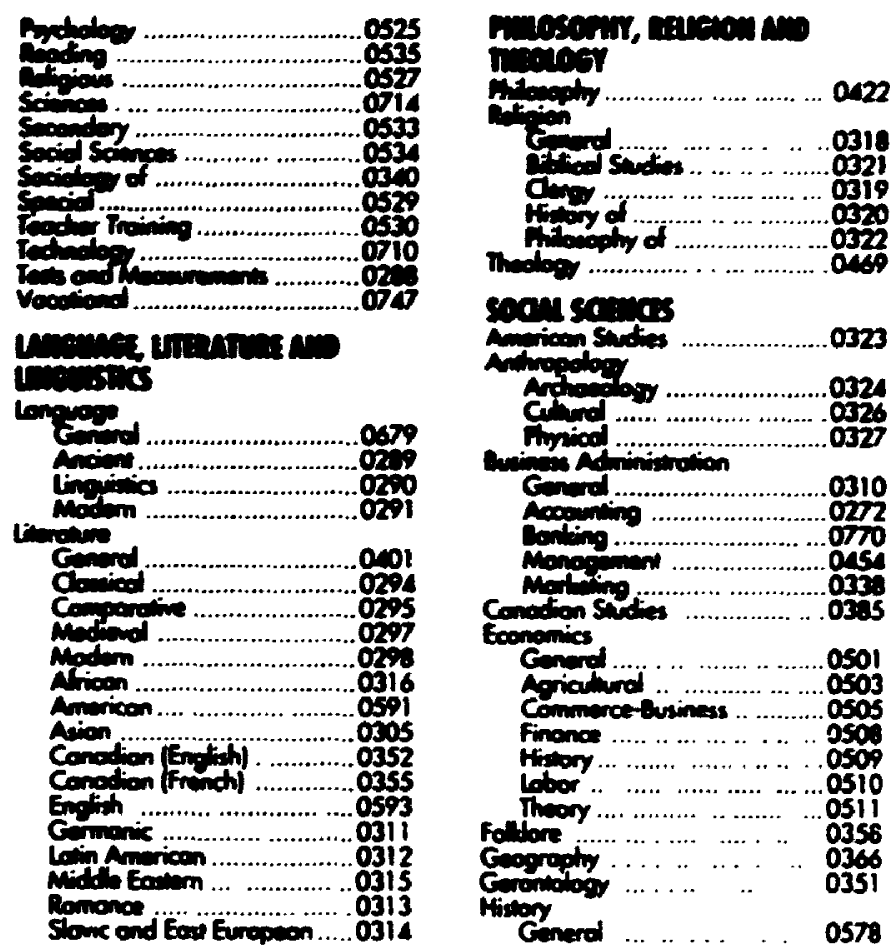

G $79910 \cdot \mathbf{U} \cdot \mathbf{M} \cdot \mathbf{I}$ ancesere

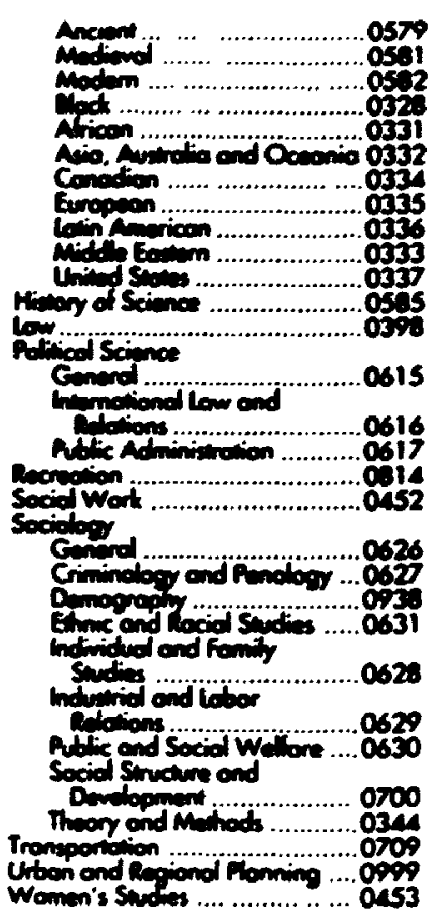

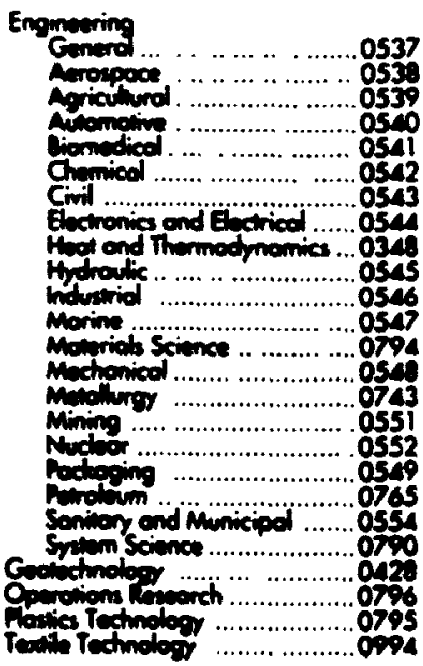

estapueser

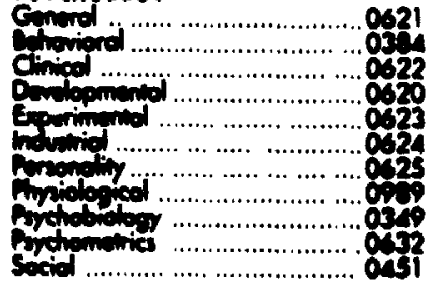

ose

542

(5)

0340

0546

0794

874

0551

0552

0765

050

ga.

0795

21

22

32 5 25 34 atsi

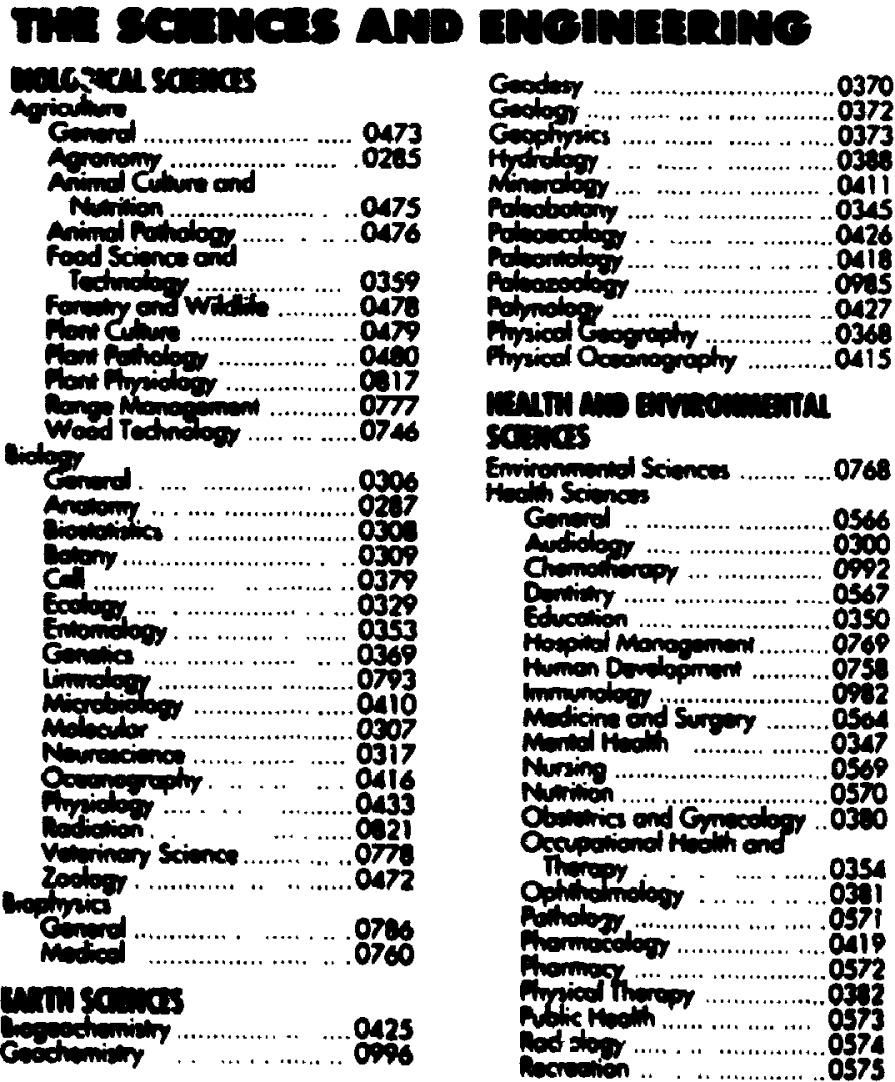

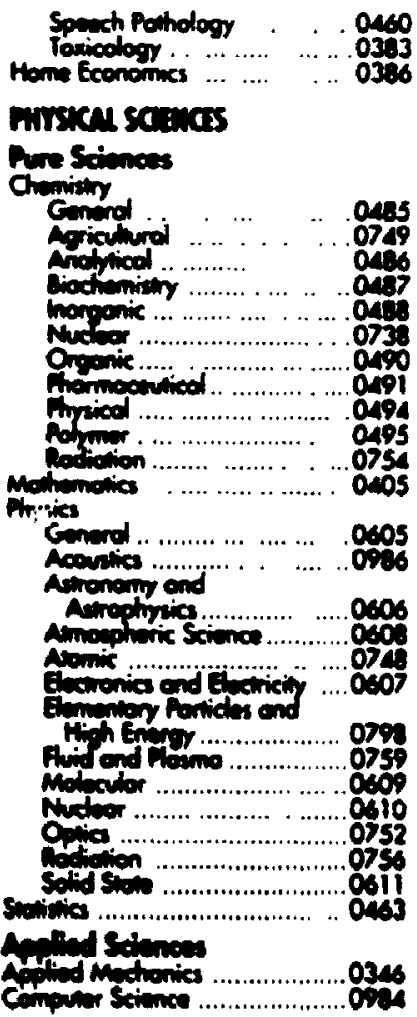


The undersigned recommend to the Faculty of Graduate Studies and Research acceptance of the thesis

\section{Performance Evaluation of Handover Process in Personal Communication System using fuzzy algorithm}

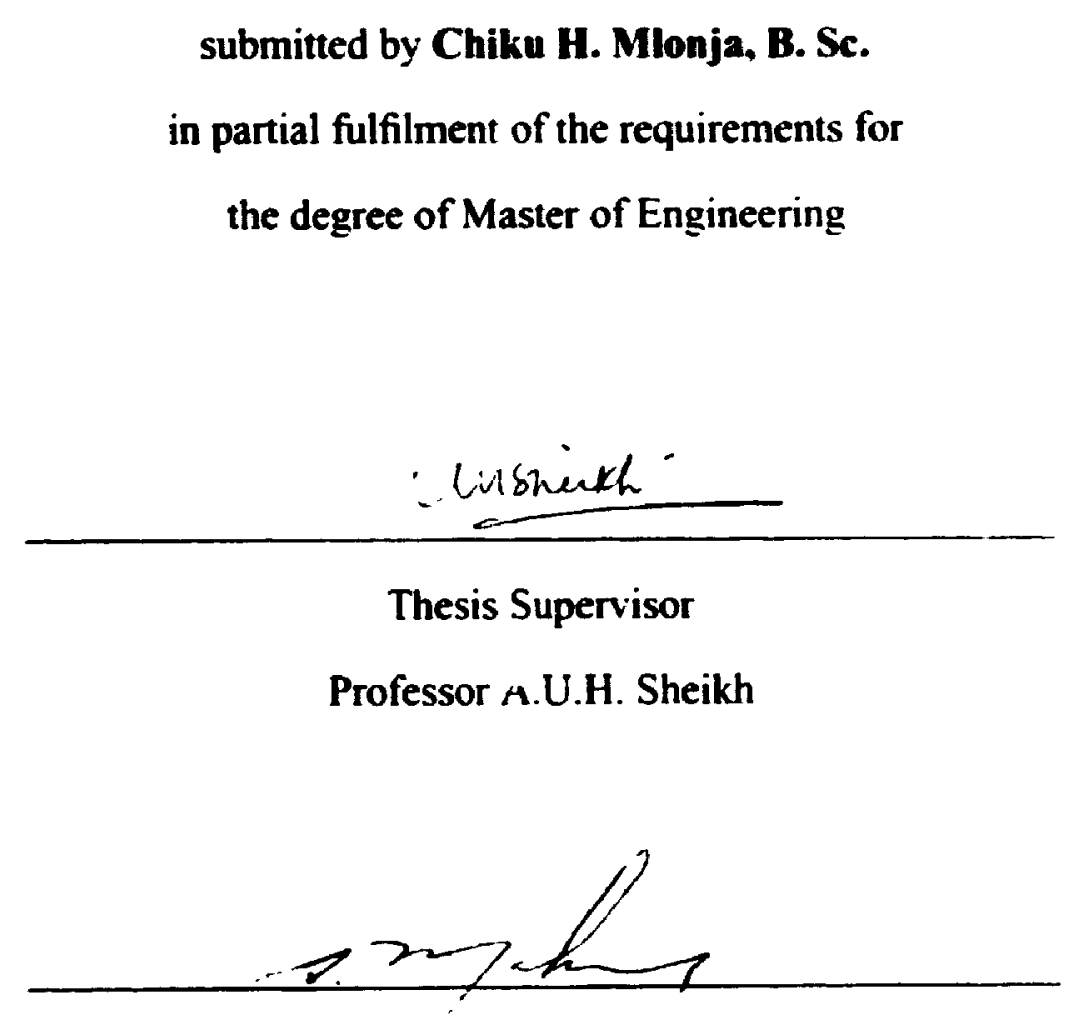

Chair. Department of Systems and Computer Engineering

Professor S.A. Mahmoud

Carleton University

January 9, 1996 


\section{Abstract}

The increasing demand for wireless communication has led to the emerging technology of Universal Personal Communication System (UPCS). Universal PCS will provide more flexible and convenient communication services than presently available at an affordable cost and without mobility restriction. To suppon the combination of high user density, high mobility and enhanced network capabilities required in PCS, higher spectrum ciffciency will be required which can be achieved using microcellular systems. One of the major problems of microcellular systems is that the mobile will be crossing cell boundaries very frequently leading to an increase in the number of handovers.

This thesis investigates the use of fuzzy handover algorithm in microcellular environment. The study was performed by considering signal strength and carrier to interference ratio measurements and comparison was done between existing (conventional) algorithms and fuzzy algorithm. It is observed that fuzzy algorithm has a marked impact in reducing the number of handovers as compared to the conventional algorithms. It is also indicated that fuzzy techniques can be implemented to combine two decision parameters. This is shown by combining signal strength and carrier to interference measurements in a fuzzy based handover algorithm. It is also observed that fuzzy logic based handover algorithm is more sensitive to channel shadowing which means that the handover is no longer restricted to regions in proximity to the cell boundaries. 
To My Dear Parents 


\section{Acknowledgments}

I wish to express my sincere gratitude to my thesis supervisor Prof. A. U. H. Sheikh for his time, guidance and continuous encouragement throughout the duration of the research work and in the preparation of this thesis.

I would like to thank all my fellow students in PCS laboratory especially Faramarz Handessi, Syed Abbas, Mohamed Eltarhuni and Shahid Chaudry for their support and friendly advice during the course of this thesis.

Finally, I gratefully acknowledge the generous financial support provided by the Canadian Commonwealth. 


\section{Table of Contents}

Abstract

Acknowledgments

Table of Contents

List of Figures viii

List of Tables $\quad$ xi

List of Abbreviations and Acronyms xii

Special Mathematical Notations $\quad$ xiii

Chapter 1

Introduction

1.1 Introduction 1

1.2 Thesis Motivation 2

1.3 Thesis Scope 3

1.4 Thesis Organization 3

Chapter 2

A Brief Review of Handover Process 5

2.1 Introduction 5

2.2 Handover Process 5

2.3 Handover Criterion 14

2.3.1 Distance Measurement 14

2.3.2 Signal Strength Measurement 16

2.3.3 Carrier to Interizrence Ratio Measurement 17

2.3.4 Network Criterion 18

2.4 State of the Art in Handover Algorithm 18 


\section{Chapter 3}

Fuzzy Sets Theory and its Application in Handover Process 22

3.1 Basics of Fuzzy Set 22

3.1.1 Definition and Operations 22

3.1.2 Fuzzy Relations 27

3.1.3 Measure of Fuzziness 27

3.2 Fuzzy Pattern Recognition 29

3.2.1 Supervised Classification 29

3.2.1.1 Recognition by Fuzzy Decision Tree 29

3.2.1.2 Recognition by Weighted Distance 31

3.2.1.3 Recognition by Similarity Vectors 31

3.2.2. Unsupervised Classification 32

3.2.2.1 Clustering by Fuzzy Partition 32

3.2.2.2 Fuzzy ISODATA 33

3.2.2.3 Fuzzy Algorithm 34

3.2.3 Fuzzy Algorithm Application to Handover Process 35

Chapter 4

Performance Analysis and Simulation Results 37

4.1 Experimental Analysis of Handover Process 37

4.1.1 Analysis using Signal Strength Measurements 38

4.1.2 Analysis using CIR Measurements 43

4.1.3 Multiple Criteria using Signal Strength and CIR 45

4.1.4 Performance Measure 47

4.2 Performance with Signal strength Measurements 47

4.2.1 Handover Distribution 48

4.2.2 Total Number of Handovers $\quad 56$

4.2.3 Evaluation of Short Term Handovers 70

4.3 Performance with Signal Strength and CIR 89

\section{Chapter 5}

Conclusions $\quad 94$

5.1 Conclusions 94

5.2 Suggestions for Future Investigations 95

References $\quad 97$ 


\section{List of Figures}

Figure 2.1 A mobile in the boundary of two cells requiring handover

Figure 2.2 MSC originated handover process

Figure 2.3 Message exchange in the handover procedure

Figure 2.4 Mobile originated handover process

Figure 2.5 Frame format for common control channel

Figure 2.6 Relative distance measurements

Figure 2.7 Received signal fluctuations due to propagation characteristics

Figure 2.8 Hysteresis margin

Figure $3.1 \quad$ Fuzzy decision tree

Figure 4.1 Handover model

Figure 4.2 Long term median of the received signal strength

Figure 4.3 A mobile outside handover region of cell $C_{1}$ and cell $C_{2}$

Figure 4.4 A mobile in cellular system of cluster size three

Figure 4.5 SIR versus distance

Figure 4.6 Handover distribution with Rayleigh using conventional algorithm

Figure 4.7 Handover algorithm with Rayleigh using fuzzy algorithm

Figure 4.8 Handover distribution with shadowing parameter $\mathrm{S}=9 \mathrm{~dB}$ using conventional algorithm.

Figure 4.9 Handover distribution with shadowing parameter $S=9 \mathrm{~dB}$ using fuzzy algorithm 
Figure 4.10 Handover distribution for different shadowing parameters using conventional algorithm

Figure 4.11 Handover distribution for different shadowing parameters using fuzzy algorithm

Figure 4.12 Total number of handovers with Rayleigh fading

Figure 4.13 Total number of handovers with shadowing parameter $S=6 \mathrm{~dB}$

Figure 4.14 Total number of handovers with shadowing parameter $S=9 \mathrm{~dB}$

Figure 4.15 To:al number of handovers with shadowing parameter $S=12 \mathrm{~dB}$

Figure 4.16 Total number of handovers for averaging distance $d_{\text {ave }}=5 \mathrm{~m}$

Figure 4.17 Total number of handovers for averaging distance $d_{\text {ave }}=10 \mathrm{~m}$

Figure 4.18 Total number of handovers for averaging distance $d_{\text {ave }}=15 \mathrm{~m}$

Figure 4.19 Total number of handovers for averaging distance $d_{a v e}=5 \mathrm{~m}$ with hysteresis

Figure 4.20 Total number of handovers for averaging distance $d_{\text {ave }}=10 \mathrm{~m}$ with hysteresis

Figure 4.21 Total number of handovers for averaging distance $d_{\text {ave }}=15 \mathrm{~m}$ with hysteresis

Figure 4.22 Handovers for different intervals with Rayleigh fading using conventional algorithm

Figure 4.23 Handovers for different intervals with Rayleigh fading using fuzzy algorithm

Figure 4.24 Handovers for different intervals using conventional algorithm with shadowing parameter $S=6 \mathrm{~dB}$

Figure 4.25 Handovers for different intervals using fuzzy algorithm with shadowing parameter $S=6 \mathrm{~dB}$

Figure 4.26 Handovers for different intervals using conventional algorithm with shadowing parameter $S=9 \mathrm{~dB}$ 
Figure 4.27 Handovers for different intervals using fuzzy algorithm with shadowing parameter $S=9 \mathrm{~dB}$

Figure 4.28 Handovers for different intervals using conventional algorithm with shadowing parameter $S=12 \mathrm{~dB}$

Figure 4.29 Handovers for different intervals using fuzzy algorithm with shadowing parameter $S=12 \mathrm{~dB}$

Figure 4.30 Short term and long term handovers with Rayleigh fading using conventional algorithm

Figure 4.31 Short term and long term handovers with Rayleigh fading using fuzzy algorithm

Figure 4.32 Short term and long term handover using conventional algorithm for shadowing parameter $S=6 \mathrm{~dB}$

Figure 4.33 Short term and long term handover using fuzzy algorithm for shadowing parameter $S=6 \mathrm{~dB}$

Figure 4.34 Short term and long term handover using conventional algorithm for shadowing parameter $S=9 \mathrm{~dB}$

Figure 4.35 Short term and long term handover using fuzzy algorithm for shadowing parameter $S=9 \mathrm{~dB}$

Figure 4.36 Short term and long term handover using conventional algorithm for shadowing parameter $S=12 \mathrm{~dB}$

Figure 4.37 Short term and long term handover using fuzzy algorithm for shadowing parameter $S=12 \mathrm{~dB}$

Figure 4.38 Handover variation with shadowing using conventional algorithm for signal strength measurements

Figure 4.39 Handover variation with shadowing using conventional algorithm for CIR measurements

Figure 4.40 Handover variation with shadowing for combined signal strength and CIR measurements using fuzzy technique. 


\section{List of Tables}

Table 4.1 Comparison of the number of handovers with Rayleigh fading

Table 4.2 Comparison of the number of handovers with stadowing parameter $\mathrm{S}=6 \mathrm{~dB}$

Table 4.3 Comparison of the number of handovers with shadowing parameter $S=9 \mathrm{~dB}$

Table 4.4 Comparison of the number of handovers with shadowing parameter $S=12 \mathrm{~dB}$

Table 4.5 Percentage increase of the number of handovers over Rayleigh fading 


\section{List of Abbreviations and Acronyms}

Abbreviations

\section{Acronym}

a

BER

BS

C-450

CIR

CT-2

CT-3

$d_{\text {ave }}$

DECT

GSM

$\mathrm{H}$

ISODATA

MSC

NMT

PCN

R

S

SIR

TDMA

UPCS
Meaning

Propagation constant

Bit Error Rate

Base Station

German Cellular System

Carrier to Interference Ratio

Second Generation Cordless Telephone

Third Generation Cordless Telephone

Averaging distance

Digital European Cordless Telecommunication

Global Service for Mobile Telecommunication

Hysteresis margin

Iterative Self Organizing Data Analysis Technique A

Mobile Switching Center

Nordic Mobile Telephone

Personal Communication Networks

Protection ratio

Shadowing parameter

Signal to Interference Ratio

Time Division Multiple Access

Universal Personal Communication Systems 


\section{Special Mathematical Notations}

\begin{tabular}{|c|c|}
\hline Notation & Meaning \\
\hline$=$ & is equal to \\
\hline$\epsilon$ & is an element of \\
\hline$\varnothing$ & an empty set \\
\hline$\Leftrightarrow$ & if and only if \\
\hline$\cup$ & union \\
\hline n & intersection \\
\hline$c$ & is the subset of \\
\hline$\leq$ & is less than or equal to \\
\hline$\geq$ & is greater than or equal to \\
\hline$\mu_{1}(x)$ & membership function of $x$ in $A$ \\
\hline $\min : i$ & is the minimum function \\
\hline $\max : 1$ & is the maximum function \\
\hline$A \times B$ & cartesian product of $A$ and $B$ \\
\hline$f \oplus B$ & bounded sum of $A$ and $B$ \\
\hline$f \Theta B$ & bounded difeerence of $A$ and $B$ \\
\hline$A \cdot B$ & is the algebraic product of $A$ and $B$ \\
\hline $\operatorname{CON}(A)$ & is the concentration of $\mathrm{A}$ \\
\hline $\operatorname{DIL}(A)$ & is the dilation of $\mathrm{A}$ \\
\hline INT(A) & is the contrast intensificatiı . of $\mathrm{A}$ \\
\hline I(A) & index of fuzziness of set $A$ \\
\hline$H(A)$ & entropy of fuzzy set \\
\hline$r$ & is the norm of $x$ \\
\hline
\end{tabular}




\section{Chapter 1}

\section{Introduction}

\subsection{Introduction}

The introduction of telephone over a century ago marked a major step towards the field of telecommunications. During the past decade, there have been growing advancements in communication systems technologies particularly in the area of wireless communication. The development was due to the popularity of mobile communication services such as cordless telephones, mobile radio telephones and radio pagers. However, each of the above services satisfies a limited number of portable communication needs. With an increasing demand for flexible and convenient communication services, the telecommunication industry is moving to a higher level of wireless technological revolution. The new technologies aim to provide systems that will allow integration of portable telephones and data terminals via a very small portable handset at an affordable cost and will allow a large number of people to communicate wherever they are. Such systems have come to be known as Universal Personal Communication Systems (UPCS).

The concept of Universal PCS was initially proposed by D.C Cox [1] and later on discussed by a number of authors [2-6]. The main objectives of the proposed systems are to make a variety of telecommunication services available at affordable rates to the users without mobility restriction and to have reasonable operating and maintenance costs. The assortment of services that may be provided by several forms of Universal PCS are, for 
example, Personal Communication Networks (PCN), the second and the third generation Cordless Telephone (CT-2, CT-3), Digital European Cordless Telecommunication (DECT) $[4,7,8]$.

Today, the demand for personal communication services is rapidly growing. Research done in 1991 indicated that, the number of subscribers using mobile radio services in North America alone is about 37 millions [9]. With the promise of personal convenience and freedom of mobility through wireless, lightweight. low power and portable iandset at relatively low cost, the market for personal communication services is expected to increase to more than 50 millions in the United States [10]. A similar trend is also observed in other parts of the world e.g. Europe [11] and Japan [12].

\subsection{Thesis Motivation}

In order to support the combination of high user density, high mobility and enhanced network capabilities required in PCS, higher spectrum efficiency is essential. However, the spectrum available for use is very limited and the best possible way to accommodate more customers is to reuse the frequency more extensively. This necessitates very low power and very small cell operation. It is generally accepted that a reduction in cell size towards microcellular system in heavily crowded areas, will bring a significant improvement in the spectrum efficiency [13].

One of the major problem encountered in microcellular environments is that of very frequent crossing of cell boundaries by the operating mobiles. This leads to an increase in the number of handovers. Obviously, we need to limit the number of such handovers to reduce burden on the system management. Therefore, suitable strategies must be found in order to achieve consistently successful handovers while limiting the number of unnecessary 
handovers to a minimum. The main motivation behind this thesis is to investigate whether implementation of Fuzzy algorithm will facilitate better performance in the handover control process while maintaining call continuity.

\subsection{Thesis Scope}

In this thesis, the study of the performance of handover process is achieved by dividing the problem into the following four steps:

(i) A review of handover processes evolving to the currently available technology including service concepts and control procedures is presented. The concept of fuzzy theory and its applications are introduced. These will provide us with the baseline on which to apply fuzzy algorithm technique in handover process.

(ii) Handover technique using fuzzy algorithm is described. Handover incdels and the propagation characteristics in which the handover process takes place are also presented.

(iii) The performance of the models is assessed by computer simulations and compared with the baseline handover procedure of step (i). The performance is further analyzed by investigating a number of handover scenarios and types which occur in the system.

(iv) Finally, the computer simulated performance results are presented and discussed. Recommendation for future work are also made.

\subsection{Thesis Organization}

The thesis is organized into five chapters including the current chapter. 
Chapter 2 describes background information on the handover process. It begins with an introduction to the handove- process and discusses different handover criteria and handover algorithms that are currently used in cellular wireless communications. The chapter also describes problems encountered with existing algorithms which led to the motivation for fuzzy approach.

Chapter 3 describes the theory of fuzzy sets and its applications in pattem recognition techniques. It also explains how pattern recognition technique using fuzzy algorithm can be implemented in the system to improve the performance of handover process.

Propagation characteristics, models used, various assumptions considered and list of parameters used in the simulations are presented in chapter 4 . The chapter also presents the results of the performance evaluation by computer simulation of handover process using fuzzy algorithm.

Chapter 5 summarizes the research findings and suggests topics for future investigations. 


\section{Chapter 2}

\section{A Brief Review of Handover Process}

\subsection{Introduction}

In the near future, microcellular systems using very small cells with radius of $0.2-1 \mathrm{~km}$ will be introduced in high density traffic areas. Smaller cell size operation in a microcellular systems leads to more frequent cell migrations by the mobile. Whenever a mobile enters a new cell, the currently used radio channel must be transferred to a new channel which is assigned in the new cell. This change of radio channel is commonly known as handover process.

In this chapter, we review salient aspects of the handover process and briefly describe different criteria that are available to perform the handover process.

\subsection{Handover Process}

Handover is an important feature of cellular systems. It allows continuity of service as the mobile moves through a wireless network. One of the most important feature of handover lies in the concept of frequency reuse in order to attain high spectrum efficiency. Although it was originally designed as the automatic call control transfer process from one base station to another, it is now considered as a more general process with the following functions [14]: 
(i) to control the signal quality throughout the duration of the call,

(ii) to allow the continuation of the call as the mobile moves through the boundary of two adjacent cells,

(iii) to control the traffic loading in the cellular structure in order to avoid congestion,

(iv) to prevent the use of a channel outside the planned cellular area.

Thus, basically, handover is the change of $R F$ channel during the call without causing any disruption to it. There are two basic handover modes:

The first handover mode is known as Intra-cell handover. This occurs when the interference in the currently used radio channel becomes unacceptable and therefore new channel must be assigned inside the same cell to maintain the call quality.

The second handover mode in known as Inter-cell handover. This is the common type of handover which occurs in cellular communication systems. It is affected when the mobile terminal moves from one cell to the adjacent one where a previously used channel is not available and therefore a new channel must be assigned in order to maintain the call.

The most important factor in the initiation of handover process is unacceptable degradation in the quality of communication in the currently used radio channel. As the mobile moves in a cellular system, the quality of the radio channel is continuously changing; the quality is monitored by using a certain physical parameter such as signal strength, carrier to interference ratio or bit efror rate (BER). Any of these parameters or a combination thereof may be used to make a handover decision. When the selected parameter drops below a specified threshold, a message is sent to the mobile switching center (MSC) that 
the mobile in question is probably nearing the edge of the cell and requires a handover to another base station (BS). This situation represents a typical inter-cell handover and is illustrated in figure 2.1 [15].

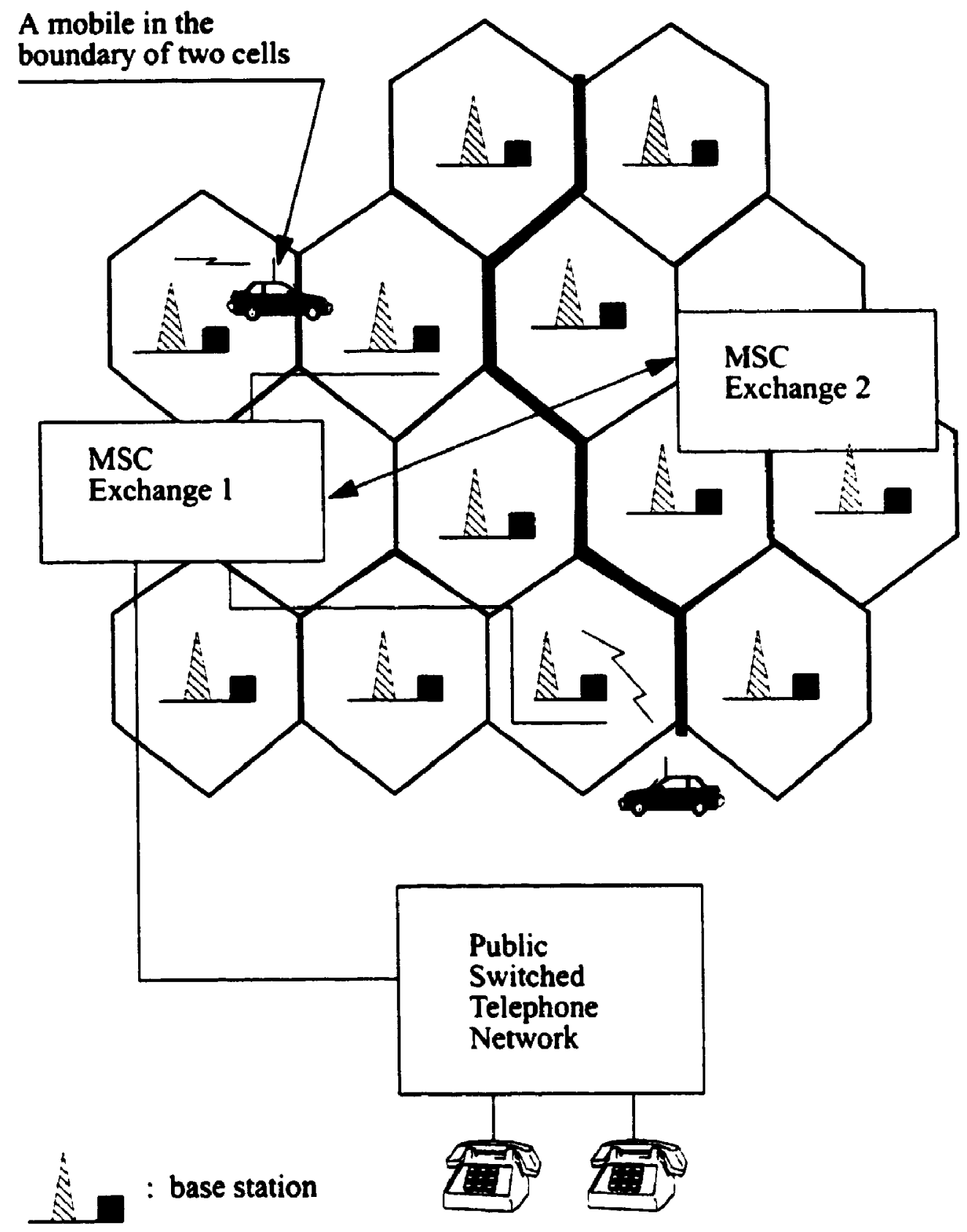

Figure 2.1 A mobile in the boundary of two cells requiring handover 
Handover process can be originated either from the MSC or from the mobile [13]. In MSC originated handover process, when the serving BS notices a degradation of the radio channel from the mobile, it sends a report to the MSC. The MSC will in turn request the current BS and its surrounding base stations to measure the signal or other parameter and report the measurements. From the reported results the MSC will select the base station which will best serve the mobile in terms of link quality and will instruct it to be ready for handover. This process is illustrated in figure 2.2. It will also send a short message to the mobile to switch to the new set of frequencies. The mobile blanks the voice message and tunes to new frequencies. It will also send an acknowledgment to MSC that it has switched to the new channel. Similarly, the new base station switches to the new frequencies specified by the MSC.

The Overall handover process requires exchange of messages between the MSC, BS and the mobile. The exchange of messages is performed very fast so as to ensure that the subscriber does not notice any quality degradation.

A complete handover sequence is shown in figure 2.3 [24] where the mobile is initially served by base station A (figure 2.3 (a)) and later handed over to base station B (figure 2.3(b)) due the degradation of the signal quality as described below:

When the base station (BS-A) currently serving the mobile realizes the degradation of signal quality and therefore the mobile needs to be handed over to another base station, it sends a handover required message (HO-REQD) o the MSC. Upon receiving the handover required message, the MSC performs measurements to determine which base station to serve the mobile. The MSC then sends a handover request message (HO-REQST) to the selected base station (BS-B). 

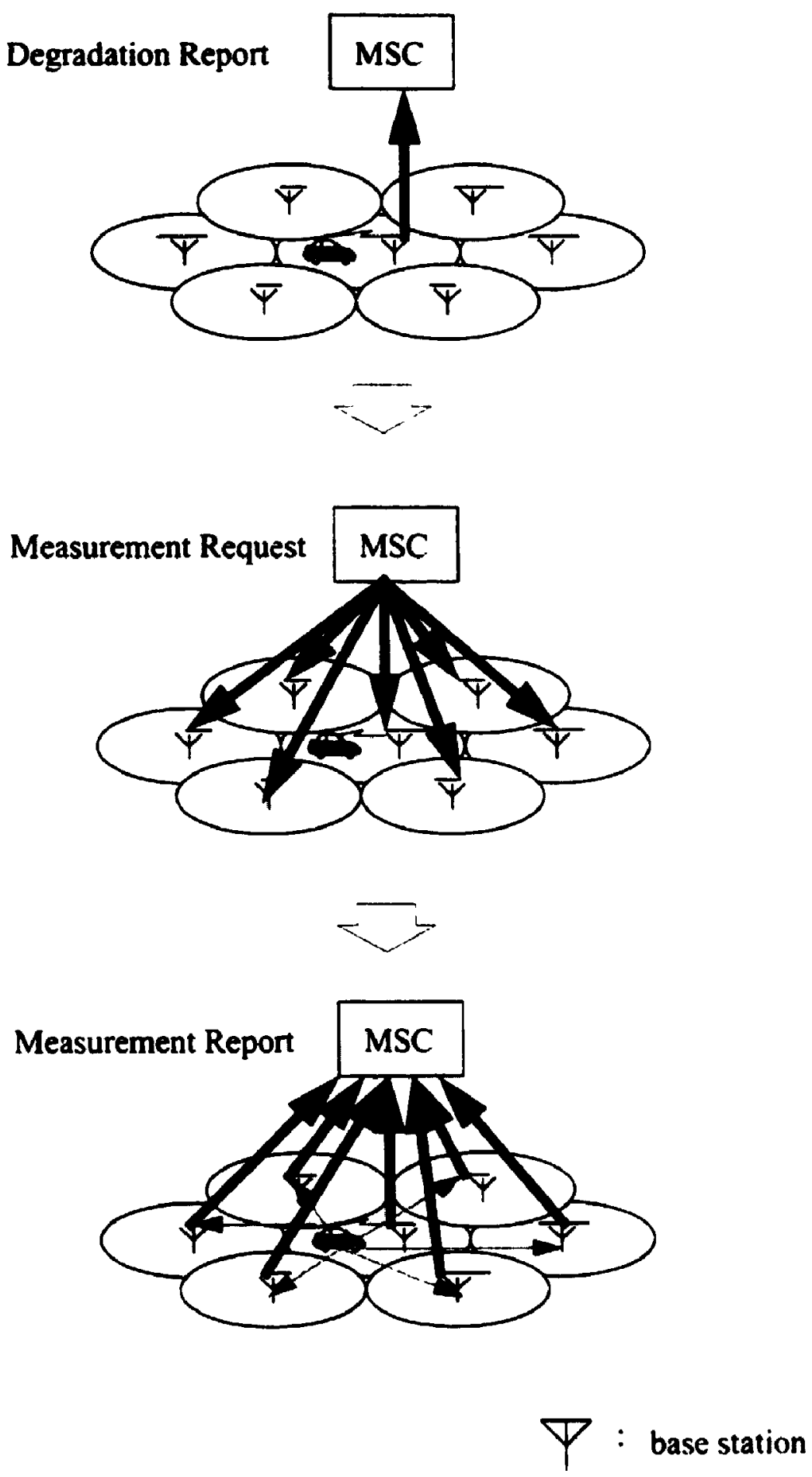

Figure 2.2 MSC originated handover process 
When BS-B receives the handover request, it takes the necessary action to allow the mobile to access its radio resources. After BS-B completes the resolrce allocation process, it sends a handover request acknowledgment (HO-REQST-ACK) to the MSC. When the MSC receives the acknowledgment from BS-B, it begins the process of instructing the mobile to tune to a new dedicated radio resources.

This is achieved by MSC sending a handover command (HO-COMM) to BS-A. When BS-A receives the handover command message, it sends a radio interface handover command message (RI-HO-COMM) which contains a reference number previously allocated by the BS-B to the mobile.

Upon receiving the radio interface message, the mobile will then access the new radio resources using the handover reference number contained in the radio interface handover access message (RI-HO-ACC). The reference number will be checked by BS-B to ensure it is expected and the correct mobile has been captured. When the verification of mobile is completed, BS-B sends a handover detect message (HO-DET) to MSC.

When the mobile is successfully communicating with the BS-B, it sends a radio interface handover complete message (RI-HO-COMP) to BS-B. The base station (BS-B) will then send a handover complete message (HO-COMP) to the MSC. After receiving the handover complete message, the MSC releases the resources allocated to BS-A by sending a clear command (CLEAR-COMM) to BS-A. BS-A will complete the release of resource allocation by sending a clear complete message (CLEAR- COMP). 


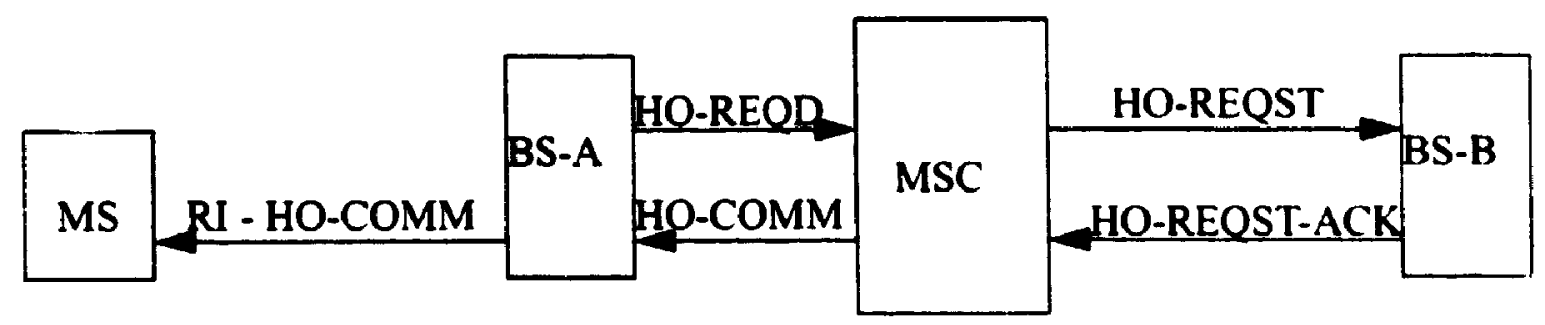

(a) Mobile at frequency $f_{1}$ served by base station $A$.

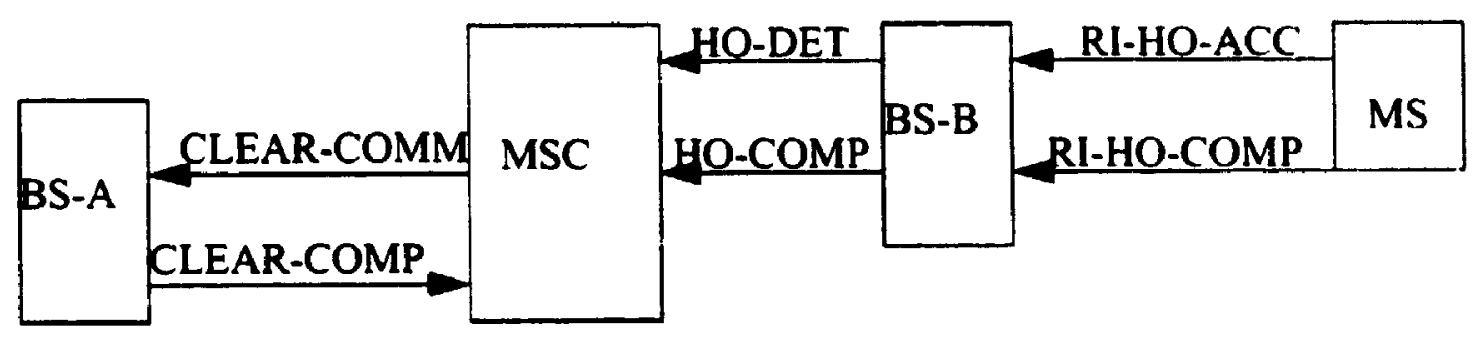

(b) Mobile at frequency $f_{2}$ served by base station $B$. 
Mobile originated handover process is achieved by equipping the mobile with suitable measurement function for handover. In this process, the mobile measures the quality of the radio channel from the current BS and its surrounding base stations and determines the appropriate BS in case a handover is necessary. It will then send a handover request to the MSC with information on BS as a handover candidate. This process can be illustrated as shown in figure 2.4. The MSC will then reassign a radio channel of the new BS to the mobile.
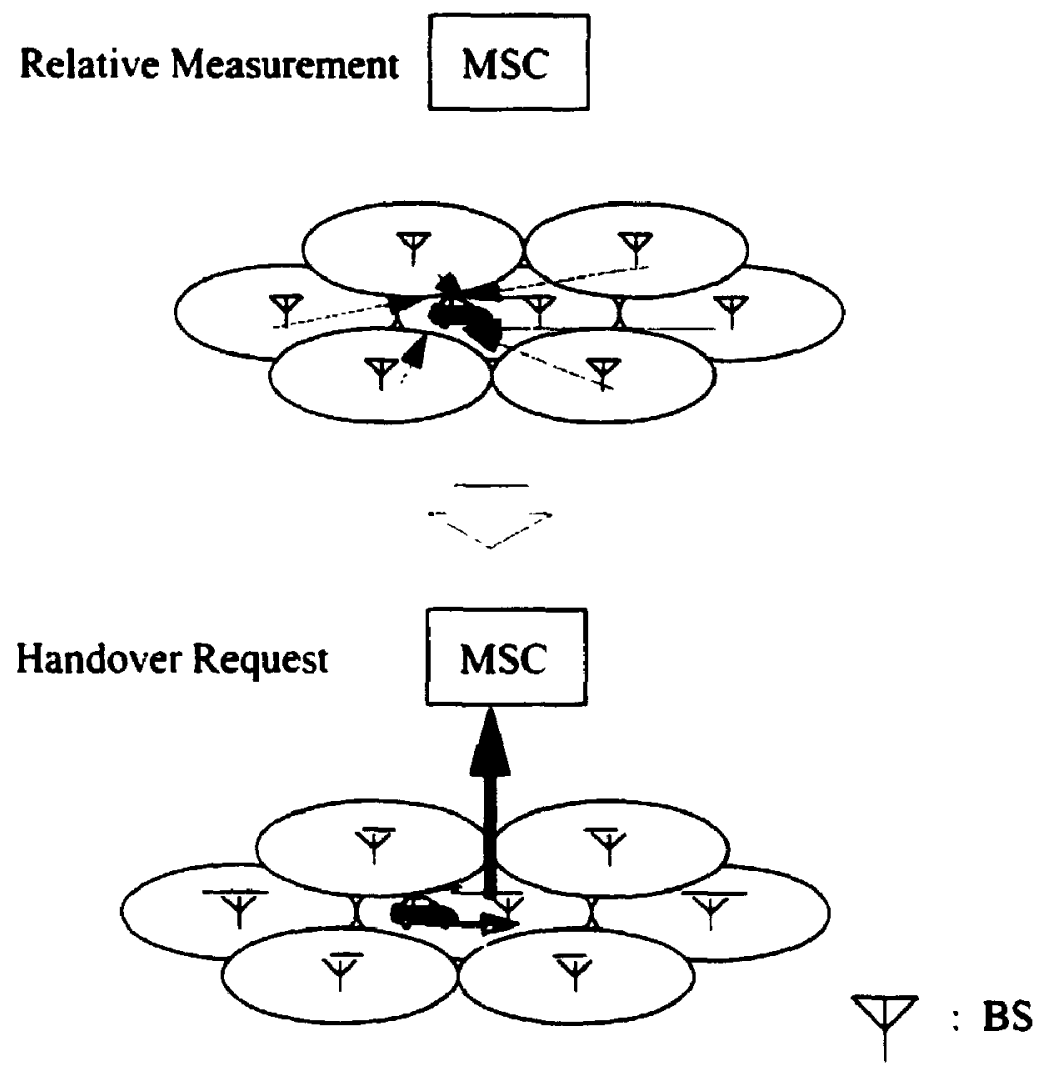

Figure 2.4 Mobile originated handover process 
In order to monitor the signal quality from the base stations, a TDMA system is adopted where common control channels of all base stations are multiplexed on the same carrierfrequency with frame format as shown in figure 2.5. In this case, the radio channel transmits at a rate of $270.88 \mathrm{~kb} / \mathrm{s}$. Therefore, one time slot with 156.25 bits will have a time duration of $0.577 \mathrm{~ms}$ and one TDMA frame with eight time slots will have a time duration of $4.615 \mathrm{~ms}$. It has been observed that, mobile originated handover process allows the reduction of heavy processing load at the MSC and BS and also reduces the time required for handover [16].

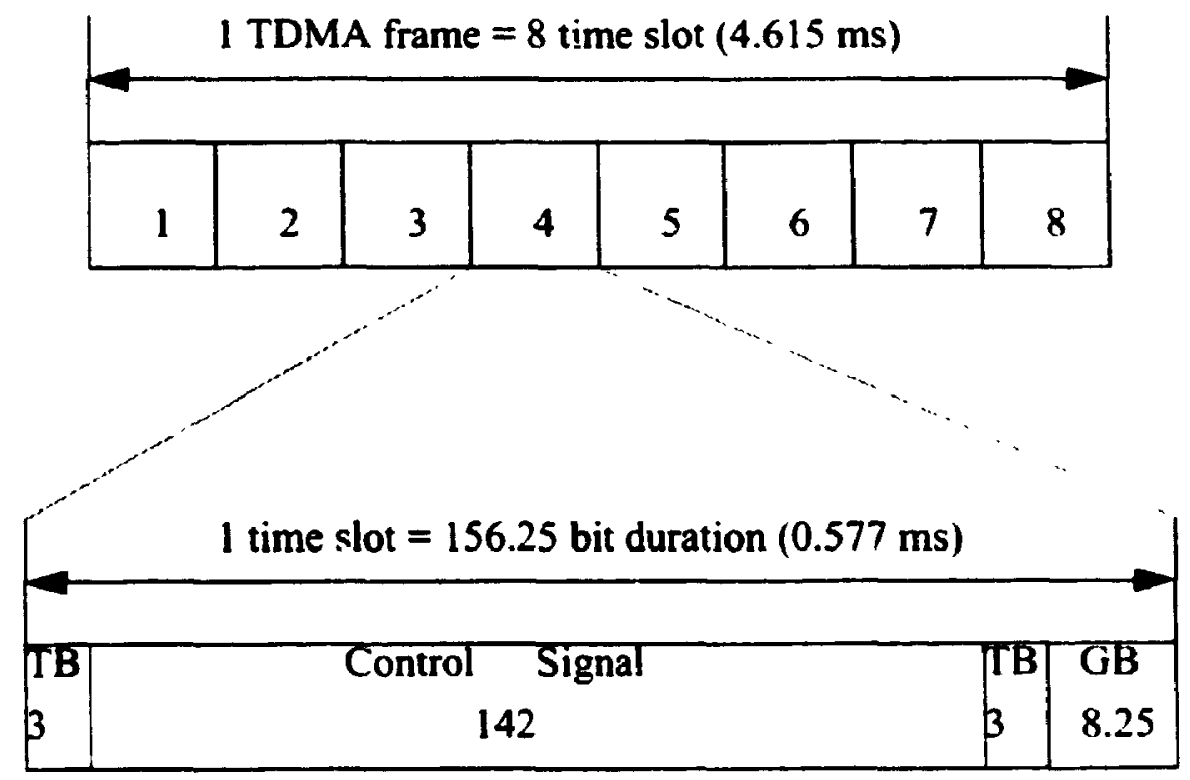

TB: Tail bits

GB: Guard bits

Figure 2.5 Frame format for common control channel 


\subsection{Handover Criterion}

This is a measure on a physical parameter that is used to initiate handover.

There are four parameters which have so far been used in handover initiation. These are described in the following sub-sections.

\subsubsection{Distance Measurement}

This criterion selects the BS nearest to the Mobile as a handover candidate by comparison of propagation delay times between signals transmitted from the surrounding base stations [18].

Distance can be estimated by measuring propagation delay times of the signals [21]. When the handover procedure is being conducted by MSC, the mobile transmits a signal to the serving and the surrounding base stations. Each base station measures the arrival time of the signal and reports the measurement to the MSC. In the case where handover is conducted by the mobile. signals are transmitted simultaneously by the serving and the surrounding base stations. The mobile receiver then masures the arrival times of the signals. Figure 2.6 shows the relative distance measurements done by the mobile. A mobile is at location $p$ and receives signals from both BS-1 and BS-2. The signals from the two base stations arrive with delay times $t_{1}$ and $t_{2}$. Since radio waves propagate at a known velocity, the delay times obtained are used to determine the distances $d_{1}$ and $d_{2}$. Errors in this estimation are primarily due to reflections and shadowing.

By using the distance based criterion, it is possible to control the cell structure as was planned thus avoiding the cases in which the mobile nuns away using a channel outside their planned cell boundaries. In selecting the BS which will best serve the mobile, measurements are made on the narrowband voice channel while speech is present. This mini- 
mizes the channels required and unnecessary disnuption of the conversation. Economically, it is desirable that the mobile plays an important role in the measurement procedure. German cellular system C 450 and European GSM system adopt this criterion $[22,23]$.

When the mobile is travelling through a cellular territory, distance measurement is carried out continuously on each speech channe' between the serving BS and the Mobile using that channel. A handover is initiated as the mobile approaches the defined boundary between the cells.

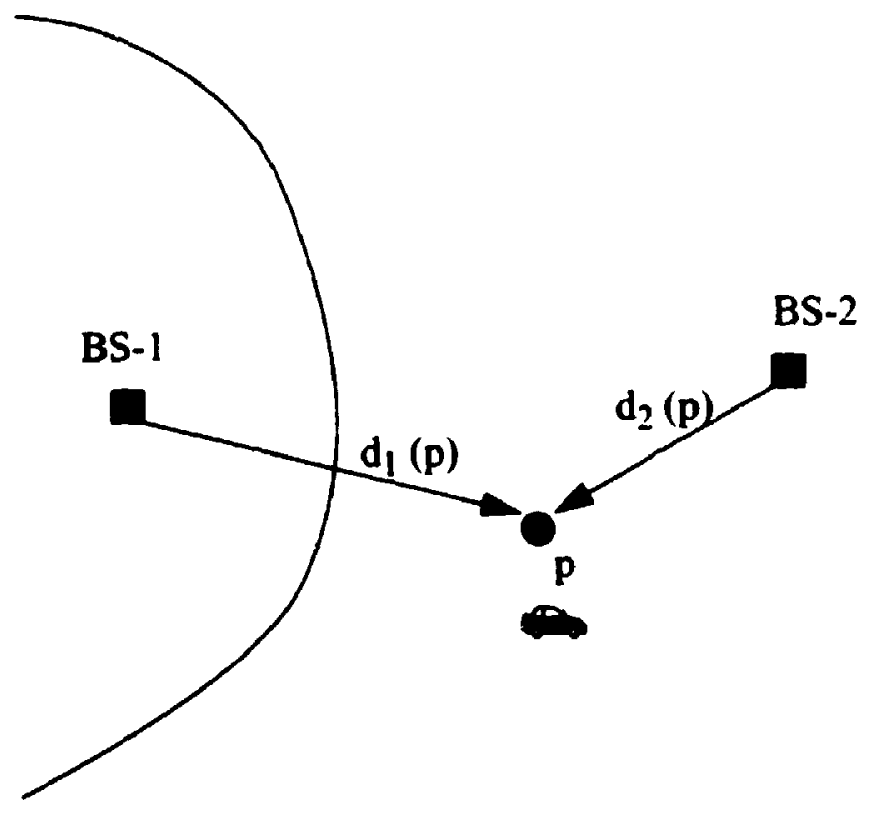

Figure 2.6 Relative distance Measurement 
Distance measurements can also be estimated using received signal level [17]. Statistically, it has been shown that signal level is proportional to $d^{-\alpha}[19-201$. Therefore, if $\alpha$ is known distance can be estimated using the received signal level. The signal strength is also used as a parameter in handover and is described in the following section.

\subsubsection{Signal Strength Measurement}

This criterion selects the base station which receives the strongest signal from the mobile as the handover candidate. It is the most widely studied criterion and is mostly adopted in the existing systems because field strength can be easily measured.

Signal strength is always monitored from a reverse voice channel as the mobile moves through a cellular territory. It is observed that signal transmission between the BS and the Mobile usually experiences the multipath phenomenon because of the scatters, the terrain and the effect of other obstacles [17]. Due to this phenomenon, the received signal has fluctuations as illustrated in figure 2.7. These fluctuations cause the mean of the signal to be lower over a short distance causing unnecessary handover to occur and as a results the number of handover increases.

During measurement, the received signal is sampled within a specified observation period and the average value of the signal strength is recorded. When the average signal strength measurement falls below a specified threshold, a request is sent to the MSC for handover on the call. 

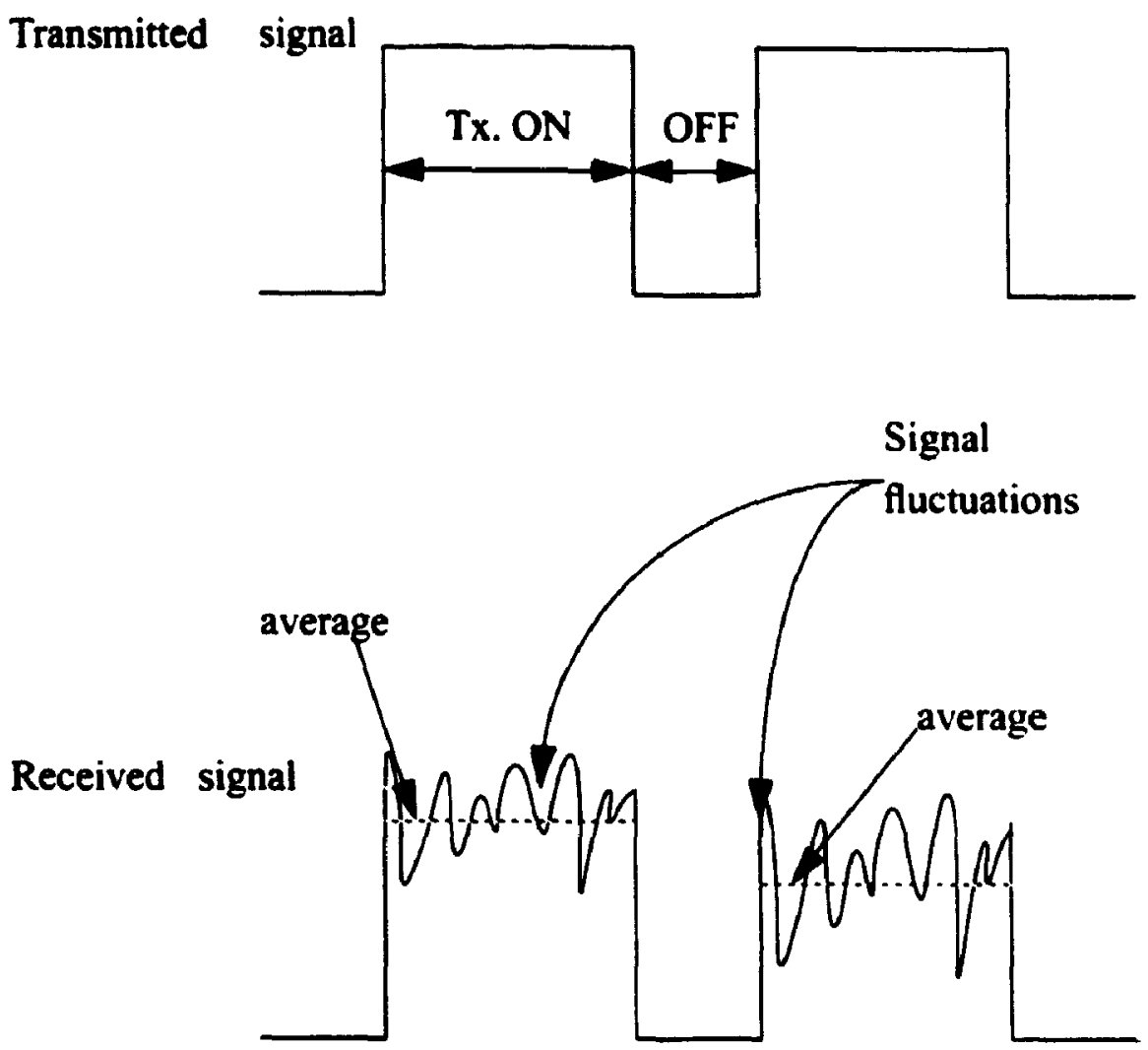

Figure 2.7 Received Signal fluctuations due to propagation Characteristics

\subsubsection{Carrier to Interference Ratio Measurement}

Carrier to interference ratio (CIR) is an important parameter in the design of cellular systems. It determines the frequency reuse distance and hence the cluster size and spectrum efficiency. It also allows determination of the signal quality which is closely related to the bit error rate (BER). This method is used in some European Systems like nordic mobile telephone (NMT) where a supervisory tone outside the band is sent continuously from the base station to the mobile which retums it without any modification. The base station will then determine the transmission quality by measuring the carrier to interference ratio of 
the reflected tone received. The obtained information is sent to the MSC to check for the degradation in the signal quality. In case the degradation of the signal quality is observed. handover is initiated and the mobile is handed over to the base station with the best signal quality.

Theoretical studies have been done on this criterion by considering signals received at the mobile from the serving BS as the desired signal and from the surrounding base stations as the interference signals [14]. The mobile is assumed to suffer cochannel interference if the desired signal does not exceed the interference signals by a certain value called protection ratio. The probability of cochannel interference for a given system protection ratio is calculated and it was assumed that handoff probability at a point is closely related to this value.

In practice, a training sequence is transmitted during the voice transmission and the BER is detennined which is closely related to carrier to interference ratio. The decision for handover is based on this information.

\subsubsection{Network Criterion}

In this criterion, the handover procedure is done by reasoning besides considering the degradation of the signal quality discussed in the proceeding criteria. The decision to perform handover is done at the management centre of the system by considering measurements such as current traffic loading per cell, number of handover between cells and future traffic loading per cell. This criterion is usually used in combination with one of the other criteria discussed earlier in order to obtain effective performance.

\subsection{State of the Art in Handover Algorithm}

Handover decision algorithm is very important for overall functioning of handover pro- 
cess in communication system. It is mostly implemented in software in order to easily adapt to any system. Although there is no absolute measure to determine the quality of handover decision algorithm. a number of criteria may be defined which provide the relative performance measures. Some general demands which should be met are:

(i) the number of handovers per unit distance covered should be as smal' as possible,

(ii) to ensure that each handover is successfully completed and unnecessary handovers are reduced,

(iii) the new base station should be chosen carefully by selecting the one which provides the best signal quality,

(iv) handover should respect the planned cellular boundary,

In microcellular systems, handover processing should be ver $/$ fast as the mobile may remain in a particular cell for only a small duration of time. The user should be unaware of the handover process which might be taking place and minimum number of channel resources should be used in the handover process.

In existing cellular communication systems, the decision to perform handover is being carried out by using different approaches which are mainly based on the signal strength measurements. Approaches based on other decision parameters have also been investigated and in some cases used together with signal strength measurements. So far, the main approaches considered are evaluation of handover decision algorithm using signal strength where the mobile is handed over from one base station to another when: 
- the average signal strength measurement of the new base station is greater than that of the old (serving) base station.

- the average signal strength measurements of the new base station exceeds that of the old base station by a certain value which is known as Hysteresis margin. Figure 2.8 shows the hyteresis margin between two base stations.
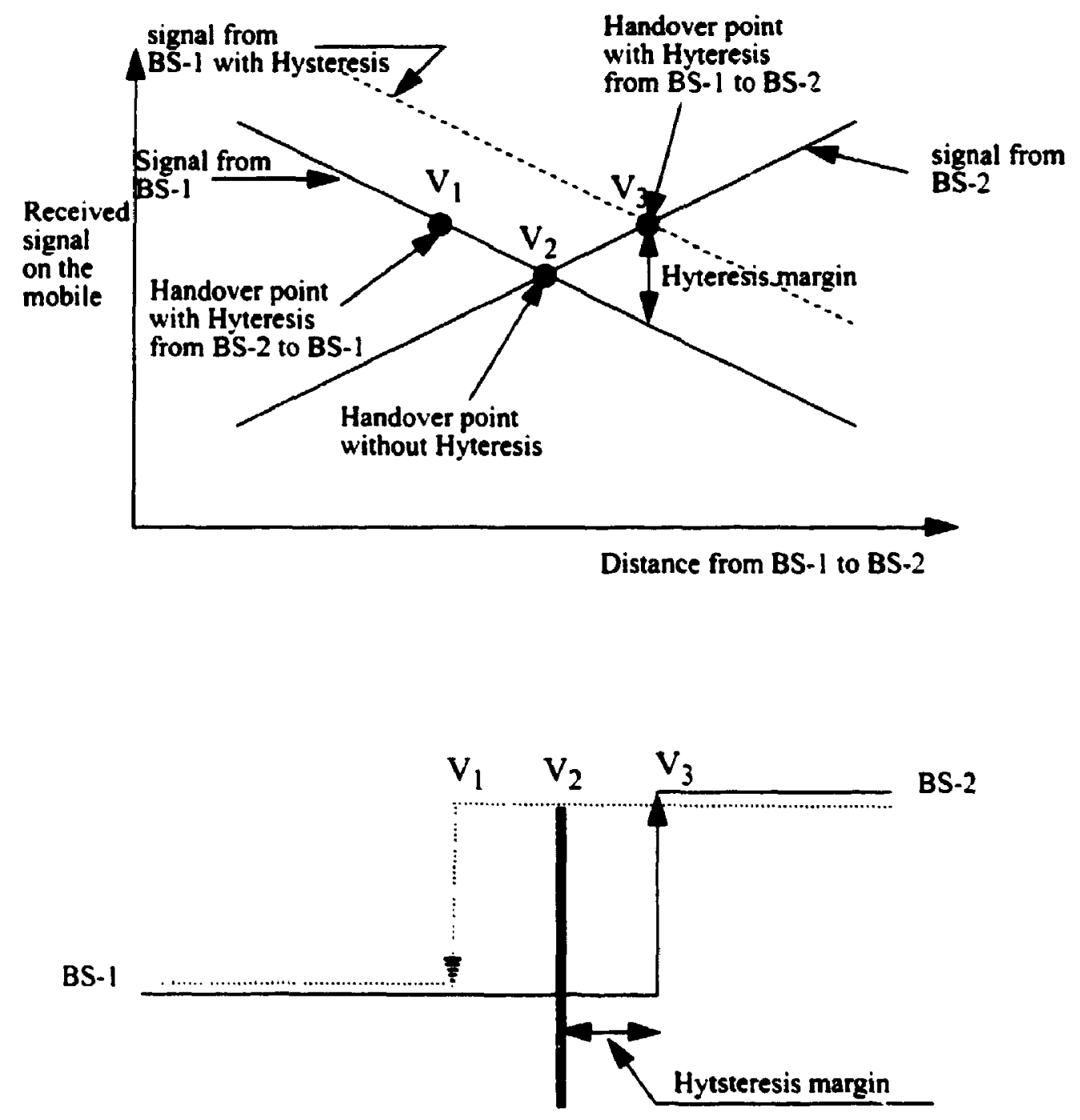

BS-2

Figure 2.8 Hysteresis Margin 
Due to the multipath fading and heavy shadowing. the received signal strength shows severe fluctuations causing a mobile to be handed over from one base station to another very frequently leading to an increase in the number of handovers. The number of handovers need to be minimized tecause a large number of handovers affect the quality of the call and may eventually lead to the loss of communication. In addition. the presence of large number of handovers indicate an increasing load to the system control due to the signalling and switching functions.

In order to reduce the processing load and maintain good communication quality, pattern recognition technique using fuzzy algorithm ${ }^{1}$ is studied in this thesis. This technique allows the classification of elements using a data analysis method which is known as clustering. Clustering analysis is a fuzzy notion in the sense that elements are classified based on the degree they belong to the clusters or their membership functions to the clusters. The advantage of fuzzy set representation in classification analysis is that isolated points as well as other types of uncertainties may be classified based on their membership functions. In the handover process, the uncertainty at the boundary region duc to the variation of received signal strength measurements leading to an increase in the number of handovers can be improved by evaluating the membership function of the signal strength using fuzzy algorithm. The obtained membership function will help decide whether the mobile should continue to be served by the old base station or be handed over to a new base station.

1. A detall review of pattern recognition technqque using fuzzy algorithm is presented in chapter 3 


\section{Chapter 3}

\section{Fuzzy Set and its Application in Handover Process}

The concept of fuzzy set was initially introduced by Lotfi A. Zadeh in 1965 [29]. Fuzzy set theory, a generalization of algebraic set theory, provides a convenient framework and mathematical tool in a wide variety of applications, particularly in the fields of pattern recognition, classification and information processing.

This chapter provides an overview of fuzzy set theory and its applications. The first part describes the basics of fuzzy set theory. This is followed by the description of fuzzy application in pattem recognition techniques. Finally, a brief explanation on how pattern recognition technique using fuzzy algorithm can be adopted in handover process is presented.

The details of the information provided in this chapter can be found in $[29,30,31,32,33$, $34,35]$.

\subsection{Basics of Fuzzy set}

This section describes several aspects that have been introduced in the framework of fuzzy set theory. It outlines the basic definition of fuzzy set and describes the algebraic operations, properties, relations and fuzzy measures.

\subsubsection{Definition and Operations}

The definition of a fuzzy set as given by L.A. Zadeh is: 
"A fuzzy set is a class of objects with a continuum of grades of membership".

The grade of membership or membership function constitutes a set of non negative real numbers ranging between zero and one, with one representing the highest membership function.

In order to understand the properties and operations of fuzzy set. the definition of fuzzy set using mathematical notation and terminology is given below.

A fuzzy set $A$, which belongs to a space of points $X=\{x\}$, is a class of events which is characterized by a membership function $\mu_{A}(x)$ which associates with each point in $\mathrm{X}$ a real number in the interval $[0,1]$, with the value $\mu_{A}(x)$ at $x$ representing the membership function of $x$ in $A$.

The support of a fuzzy set $A$, is the set of all $x \in X$ such that $\mu_{A}(x)$ is positive. A crossover point in $\mathrm{A}$ is an element in $\mathrm{X}$ whose membership function in $\mathrm{A}$ is 0.5 . The height of A is defined as the supremum of $\mu_{A}(x)$ (i.e $\operatorname{hgt}(A)=\sup _{x \in X}\left\{\mu_{A}(x) ;\right)$ ). A fuzzy set $\mathrm{A}$ is empty if and only if its membership function is zero (i.e $A=\varnothing \Leftrightarrow \mu_{A}(x)=0$ ). Two fuzzy set A and B are equal if and only if their membership functions are equal (i.e $\left.A=B \Leftrightarrow \mu_{A}(x)=\mu_{B}(x)\right)$. Fuzzy set $A$ is contained in fuzzy set $B$ if and only if the membership function of $A$ is less than or equal to that of $B$ (i.e $A \subset B \Leftrightarrow \mu_{A}(x) \leq \mu_{B}(x)$ ).

\section{Operations of Fuzzy Sets}

Membership functions play an important role in fuzzy sets and therefore the operations of fuzzy sets are defined in terms of the membership functions. The basic operations of fuzzy sets for all $x \in X$ are: 
denoted by $\mu_{C A}(x)$ and is defined by

$$
\mu_{C A}(x)=1-\mu_{A}(x)
$$

Union:

The membership function $\mu_{C}(x)$ of the union $C=A \cup B$ is defined by

$$
\mu_{C}(x)=\max \left\{\mu_{A}(x), \mu_{B}(x)\right\}
$$

Intersection: $\quad$ The membership function $\mu_{D}(x)$ of the intersection $D=A \cap B$ is defined by

$$
\mu_{D}(x)=\min \left\{\mu_{A}(x), \mu_{B}(x)\right\}
$$

\section{Algebraic Operations}

The algebraic operations of fuzzy sets are described below in terms of their membership functions.

The membership function of the cartesian product of fuzzy sets $A_{1}, A_{2} \ldots, A_{n}$ is defined as

$$
\mu_{\left(f_{1} \times \ldots \times A_{n}\right)}(x)=\min _{i}\left\{\mu_{A_{1}}\left(x_{i}\right) \mid x=\left(x_{1}, \ldots, x_{n}\right),\left(x_{i} \in X_{1}\right)\right\}
$$

The membership function of the $m t h$ power of a fuzzy set $A$ for all $x \in X$ is defined as 


$$
\mu_{f^{m}}(x)=\left[\mu_{1}(x)\right]^{m}
$$

The membership function of the algebraic sum (probabilistic sum) $C=A+B$ for all $x \in X$ is defined as

$$
\mu_{A-B}(x)=\mu_{A}(x)+\mu_{B}(x)-\left(\mu_{A}(x) \cdot \mu_{B}(x)\right)
$$

The membership function of the bounded sum $C=A \oplus B$ for aii $x \in X$ is defined as

$$
\mu_{(A \oplus B)}(x)=\min \left\{1,\left(\mu_{f}(x)+\mu_{B}(x)\right)\right\}
$$

The membership function of the bounded difference $C=A \Theta B$ for all $x \in X$ is defined as

$$
\mu_{(A \odot B)}(x)=\max \left\{0,\left(\left(\mu_{A}(x)+\mu_{B}(x)\right)-1\right) ;\right.
$$

The membership function of the algebraic product $C=A \cdot B$ for all $x \in \lambda$ is defined as

$$
\mu_{(A B)}(x)=\mu_{A}(x) \cdot \mu_{B}(x)
$$

Other operations of fuzzy sets are those used to represent the linguistic variables or hedges such as ven: highly, more or less. These operations include:

Concentration: $\quad$ Given a fuzzy set $A$, in a space of points $X$. the concentration of $A$ is given by 


$$
\operatorname{CoN}(A)=A^{2}
$$

Dilation:

The dilation of fuzzy set $\mathrm{A}$ is given by

$$
\operatorname{DIL}(A)=A^{05}
$$

The effects of these two operations on a fuzzy set are:

Applying the operation of concentration to fuzzy set A, results in a small reduction of the magnitude of the membership function $\mu_{4}(x)$ for points $\mathrm{x}$ which have high membership functions and a large reduction of $\mu_{A}(x)$ for points $x$ with low membership functions.

The operation of dilation has the opposite effect to that of concentration.

\section{Contrast Intensification:}

The operation of contrast intensification of fuzzy set $A$ in a space of points $\mathrm{X}$ is defined as

$$
\operatorname{INT}(A)=\left\{\begin{array}{c}
2 A^{2}, 0 \leq \mu_{A}(x) \leq 0.5 \\
2(\bar{A})^{2}, 0.5 \leq \mu_{A}(x) \leq 1
\end{array}\right.
$$

This operation has the effect of increasing the values of mernbership functions $\mu_{A}(x)$ which are greater than 0.5 and decreasing the values of $\mu_{A}(x)$ lower than 0.5 . 


\subsubsection{Fuzzy Relations}

Fuzzy relations are used to describe the interactions between elements of fuzzy sets. Examples of fuzzy relations are considerably larger than, ven close to. resembles, is relevant to.

Mathematically, a fuzzy relation is defined as:

If $X \times Y$ is a cartesian product of sets $\mathrm{X}$ and $\mathrm{Y}$, then a fuzzy relation $\mathrm{R}$ in $X \times Y$ is a fuzzy subset of $X \times Y$, where $\mathrm{R}$ is characterized by a membership function $\mu_{R}(x, y)$.

Example of a fuzzy relation may be " $\mathrm{x}$ is considerably larger than $\mathrm{y}$ ", where $x \in X$ and $y \in Y$. The membership function of this relation which represents a fuzzy set on $X \times Y$ may be defined as

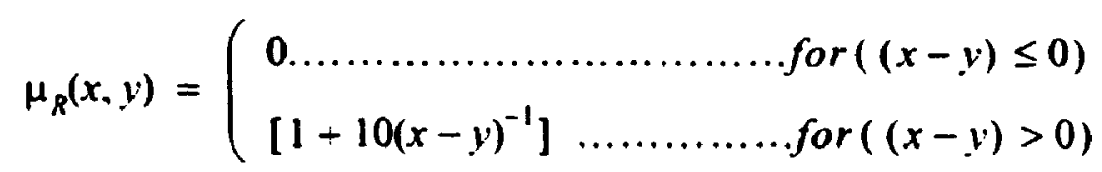

\subsubsection{Measure of Fuzziness}

This is used to indicate the degree of fuzziness of a set. The degree of fuzziness in a fuzzy set $A$, describes the doubt or uncertainty in making a decision regarding which elements belong and which do not belong to set $\mathrm{A}$.

The two measures of fuzziness are described below.

Index of fusziness:

The index of fuzziness of a set $\mathrm{A}, I(A)$ with $\mathrm{n}$ number of supporting points is defined as 


$$
I(A)=\left(\frac{2}{n^{k}}\right) d(A, C A)
$$

where the number 2 and constant $\mathrm{k}$ are used to ensure $I(A)$ lies between 0 and $1, \mathrm{~d}(\mathrm{~A}, \mathrm{CA})$ represents the distance between fuzzy set $A$ and its complement. The value of $k$ depends on the type of distance function used. For $k=1, d(A, C A)$ yields the hamming distance given by

$$
d(A, C A)=\sum_{i=1}^{n}\left|\mu_{A}\left(x_{i}\right)-\mu_{C A}\left(x_{1}\right)\right|
$$

For $k=0.5 . d(A, C A)$ yields the Euclidean distance given by

$$
d(A, C A)=\left(\sum_{1=1}^{n}\left(\mu_{A}\left(x_{1}\right)-\mu_{C A}\left(x_{1}\right)\right)^{2}\right)^{1 / 2}
$$

\section{Entropy:}

The entropy as a measure of fuzziness of fuzzy set $A$, with $\mathbf{n}$ supporting points is defined as

$$
d(A)=H(A)+H(C A) \text { for all } x \in X
$$

where

$$
H(A)=-K \sum_{i=1}^{n} \mu_{A}\left(x_{i}\right) \ln \left(\mu_{A}\left(x_{i}\right)\right)
$$




\subsection{Fuzzy Pattern Recognition}

Fuzzy set theory can be applied in a wide variety of fields such as biological and medical sciences, industrial control, social sciences and engineering. In this section application will be described by considering fuzzy pattem recognition which can be applied in the handover process.

The process of pattem recognition is viewed as the search for a structure in data. It involves developing theory and techniques and use them in making a decision to classify data in different groups. Principally, when a recognition algorithm is applied to an object, it gives the degree to which it belongs to a certain group. An important property in pattern recognition is to ensure the process is fuliy automated in order to be performed by the computer. There are two approaches to pattern recognition developed so far and these are supervised and unsupervised classification.

\subsubsection{Supervised Classification}

The supervised pattern recognition is described as the process whereby a set of objects with known classification is provided to the machine and the machine is then used to classify an unknown object from the previous obtained information. Examples of supervised classification are discussed below.

\subsubsection{Recognition by fuzzy decision tree}

The important aspect in fuzzy decision tree is the possibility of maintaining a large number of classes as well as minimizing the time for making final decision by using a series of small local decisions.

Mathematically, fuzzy decision tree is defined as the tree $T_{r}$ with root $r$ such that each nonleaf node $i$ has a corresponding $k$-tuple decision function $f_{i}$ from $X$ to $[0,1]^{h}$ and $k$ ordered 
sons, where $\mathrm{X}$ is the input e.g a digitized picture or voice spectograph, the k-tuple represents the decision values $v\left(x_{i}\right)$ of the outgoing branches $\left(x, x_{i}\right), i=1, \ldots, k$ and $x_{i}$ is the ith son of node $x$. Each branch in the tree is associated with a value in the interval $[0,1]$ and each leaf correspond to a pattern class. Figure 3.1 shows an example of a fuzzy decision tree.

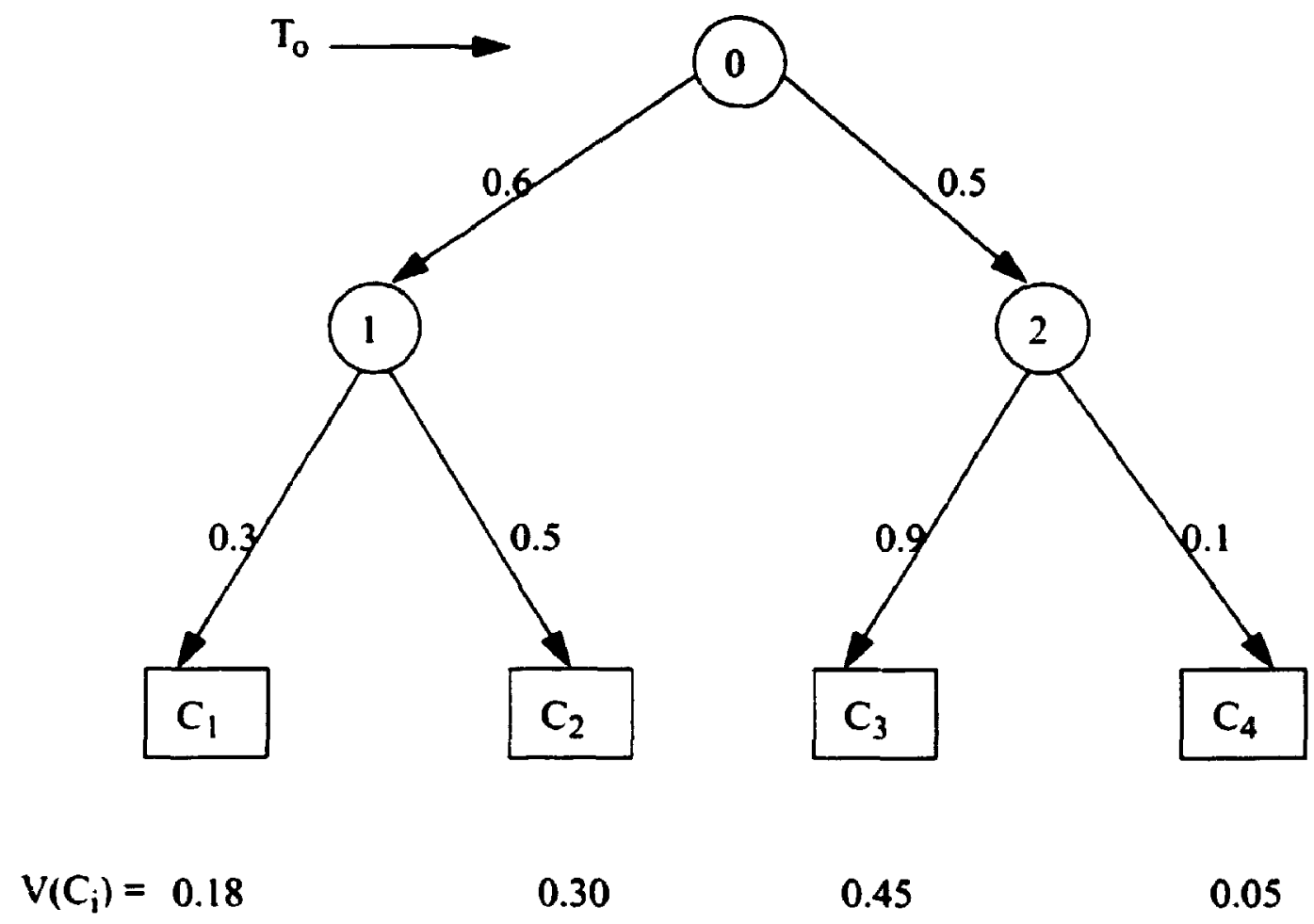

Figure 3.1 Fuzzy decision tree

The value $V\left(C_{i}\right)$ in figure 3.1 represents the decision value of the decision path which is the product of the decisisn values of the branches composing the path and $C_{i}$ represents the class.

Fuzzy decision tree has been used in curve fitting and handwritten numerical recognitions. 


\subsubsection{Recognition by welghted distance}

This methods is used for classification of small number of data samples in which statistical independence cannot be assumed.

The weighted distance is calculated and used to estimate the membership function corresponding to different classes. The membership function $\mu_{i}(X)$ associated with pattern $X$ to the ith class is defined by

$$
\mu_{i}(X)=\left[1+\left\{\left(d\left(X, C_{i}\right)\right) / E\right\}^{F_{i}}\right]^{-1}
$$

where $E$ and $F_{e}$ are constants which controls the amount of fuzziness, $d\left(X, C_{j}\right)$ is the minimum weighted euclidean distance from $X$ to all expected values in class $C_{i}$ and is given by

$$
d\left(X, C_{i}\right)=\min \left|X-C_{i}\right| \mid
$$

Once the membership function has been evaluated, the unknown pattern $\mathrm{X}$ is assigned to the class to which it has the highest value of the membership function.

\subsubsection{Recognition by Similarity Vectors}

This method is also used for small number of data samples. The evaluation is achieved by first evaluating the membershin functions $\mu_{n}$ for all samples in a pattern $X$, and the membership functions $\mu_{n}$ of all prototypes in a class using equation 3.18. The similarity vector $\mathrm{S}$ for pattern $\mathrm{X}$. with respect to mth prototype in the ith class is Liven by

$$
S^{m}(X)=\left[S_{11}^{m}, S_{2 i}^{m}, \ldots, S_{N_{i}}^{m}\right]
$$


and the degree of similarity between nth component of $X$ and the $m$ th prototype of $C_{i}$ is defined as

$$
S_{n t}^{m}=\left[1+W\left|1-\frac{\mu_{n}}{\mu_{n i}}\right|\right]^{-2 \beta}
$$

where $W$ is a positive constant which depend on the properties of the class and $\beta$ is an arbitrary positive integer. The values of the degrees of similarity obtained from equation 3.21 are averaged through all possible values of $\mathrm{m}$ to obtain the components $S_{n i}$ where $n=1, \ldots, N$. The unknown pattern $X$ is assigned to the class to which it shows maximum similarity determined by the component $S_{n i}$ i.e $\mathrm{X}$ is assigned to kth class if

$$
S_{k}(X)=\max _{j}\left(\left|S_{j}(X)\right|\right)
$$

\subsubsection{Unsupervised Classification}

In this type of pattern recognition, the classification is done by using a data analysis method called clustering. Cluster analysis is the process of sorting data into the natural groups in which the members of the same group show higher similarity and there is a very low similarity to the menibers of different groups. There are different algorithms which have been developed for cluster analysis and examples of such algorithms are

\subsubsection{Clustering by Fuzzy Partition}

A fuzzy partition is defined as the group of fuzzy sets $F_{1}, F_{2}, \ldots, F_{m}$ on $X$ such that for all $x \in X$. 


$$
\sum_{i=1}^{m} \mu_{F}(x)=1
$$

The main advantage of clustering by fuzzy partition is that it allows classification of data points which are isolated from clusters and also clarify the uncertainties. For a finite data set $X$, and a positive real valued similarity function $\delta$, whose domain is $X^{2}$ such that

$$
\begin{gathered}
\delta(x, x)=0 \text { for all } x \in X \\
\delta(x, y)=\delta(y, x) \text { for all } x, y \in X .
\end{gathered}
$$

a fuzzy partition $\left(F_{1}, F_{2}, \ldots, F_{m}\right)$ is the one that elements in data set $X$ which are close together in the sense of similarity function $\delta$ will have similar classification and dissimilar elements will have different classification. The classification of an element $\mathrm{x}$ is the vector $C(x)=\left[\mu_{F_{1}}(x), \ldots, \mu_{F_{m}}(x)\right]$.

\subsubsection{Fuzzy ISODATA}

This method is used in the cluster analysis where it is required to establish cluster centers as the representative elements of the cluster. Fuzzy ISODATA (Iterative Self Organizing Data Analysis Technique A) algorithm assumes that the data to be clustered is linearly operable and requires the specification of parameters such as number and centres of initial clusters and minimum number of points in a cluster. The description of the algorithm is illustrated in the following steps:

Step 1. Choose initial centres $v_{1}$, of nonfuzzy partition $F_{1}$ where $i=1, \ldots, m$

Step 2. Compute the membership functions $\mu_{F_{i}}(x)$ using 


$$
\mu_{F}(x)=\left\{\sum_{j}\left\{\frac{\left|x-v_{1}\right|^{2}}{\left\|x-v_{\jmath}\right\|^{2}}\right\}^{\frac{1}{(11-1)}}\right\}^{-1}
$$

$$
\text { where } \mathrm{i}=1, \ldots, \mathrm{m} \text {; and } \mathrm{j}=1, \ldots, \mathrm{m} \text {. }
$$

Step 3. Update the centres $v$, with

$$
v_{1}=\frac{\sum_{x \in X}\left[\left(\mu_{F}(x)\right)^{n} x\right]}{\sum_{x \in X}\left[\mu_{F i}(x)\right]^{n}}
$$

Step 4. Repeat step 2 and 3 until the convergence is obtained i.e $\max _{i}\left|\mu_{F_{1}}(t+1)-\mu_{F_{1}}(t)\right|<\varepsilon$ where $t$ is the iteration number and $\varepsilon$ is the specified threshold.

ISODATA algorithm has been applied in the process of feature selection for binary data and biological classification.

\subsubsection{Fuzzy Algorithm}

This algorithm is used in similar cases as the fuzzy ISODATA but it has the advantage that it indicates the presence or absence of compact well separated clusters in set $X$. Fuzzy algorithm technique is described in the following five steps.

Step 1. Choose initial partitions $U_{i}(x)$ which are considered as hard partitions (i.e the membership function is 0 or 1 ).

Step 2. Calculate the weighted mean vectors $V_{i}$ using the formula given below 


$$
V_{i}=\frac{\sum_{t \in X}\left(U_{i}(x)\right)^{2} \times x}{\sum_{x \in X^{2}} U_{i}^{2}(x)}:(1 \leq i \leq k)
$$

Step 3. Construct new partition $U^{*}(x)$ according to the following formula

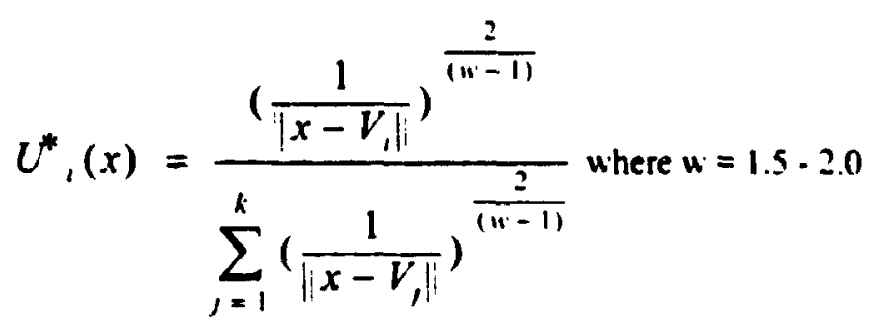

Step 4. Compute new weighted mean vector $V^{*}$, corresponding to $U^{*},(x)$ using equation (3.28) and compute the corresponding max norm defect $\delta$.

$$
\delta=\max \left|V_{1}-V^{*}\right|
$$

Step 5. If $\delta<e$ where e represents the specified threshold, then the calculation of membership function ends and $U^{*}{ }_{1}(x)$ is the membership function. Otherwise. put $V_{1}=V^{*}$, and go to step 3 . The procedure is repeated until the condition is satisfied.

This algorithm has been applied in experiments for partitioning different clusters and it was found to be more effective as compared to ISODATA algorithm.

\subsubsection{Fuzzy Algorithm Application to Handover Process}

In order to evaluate the membership function of the received signal strength measure- 
ments, a pattern recognition technique using unsupervised classification of fuzzy algorithm is proposed in this thesis. Unsupervised classification provides a better solution to evaluate the membership function of the received signal strength measurements than supervised classification. This is due to the fact that evaluation using supervised classification will require a set of signal strength measurements with known classification which is difficult to obtain due to unpredictable vanation of signal strength.

Fuzzy algorithm was selected in favor of other unsupervised classification algorithm such as Clustering by Fuzzy Partition and Fuzzy ISODATA because it does not require prior specification of cluster parameters such as cluster centres. In fuzzy algorithm. the signal strength measurements are first assigned membership function using hard parition and use them in the algorithm to evaluate the desired membership function. The algorithm allows the measurements to belong in more than one cluster (which in this case will mean to belong in more than one base station) with a certain degree of membership.

In using fuzzy algorithm described in section 3.2.2.3, average signal strength measurements received by the mobile represent the data set $\mathrm{X}$ with unknown classification to be assigned the membership function. The membership function $U_{i}(x)$ indicates the grade of membership of the signal strength $\mathrm{x}$ at a point to the base station $i$ where $1<i \leq k$ and $\mathrm{k}$ is the number of base stations. The obtained membership function will determine whether the mobile will continue to be served by the old base station or it should be handed over to the new base station. This is achieved by performing handover when the membership of the signal strength at the serving base station shows lower grade of membership. 


\section{Chapter 4}

\section{Performance Analysis and Simulation Results}

In this chapter, analysis of handover process and the results of several simulation experiments are presented to show the performance of fuzzy algorithm based handover. The first section describes the problem formulation including propagation characteristics in the mobile environment, models and parameters used in the handover process. It also describes the performance measure used in this evaluation. Section 2 presents simulation results with signal strength measurements using existing (conventional) algorithm and fuzzy algorithm. The simulation experiments were performed in Rayleigh fading environment with several shadowing parameters. Finally, section 3 presents the results when signal strength and CIR measurements are combined using fuzzy technique.

\subsection{Experimental Analysis of Handover Process}

The analysis of handover process is done by considering two decision parameters which are signal strength and CIR measurements. In the following sub-sections, evaluation of signal strength and CIR measurements is described including the propagation characteristics and the parameter used in the handover process. In addition, the analysis using fuzzy technique which combines signal strength and CIR measurements is described. Finally, a description of the performance measure used in the simulation of handover process is presented. 


\subsubsection{Analysis using Signal Strength Measurements}

In order to examine the performance of handover process using fuzzy algorithm, the handover problem is formulated by considering two hexagonal cells with base stations positioned at the centre of each cell as shown in figure 4.1. Each $c$ :ll is assumed to have a radius of $1 \mathrm{~km}$. The mobile of interest is assumed to be in cell $C_{1}$ and is travelling from cell $C_{1}$ to the dirertion of the cell $C_{2}$. As the mobile moves through handover region indicated in figure 4.1, it measures the signal strength from each of the two base stations.

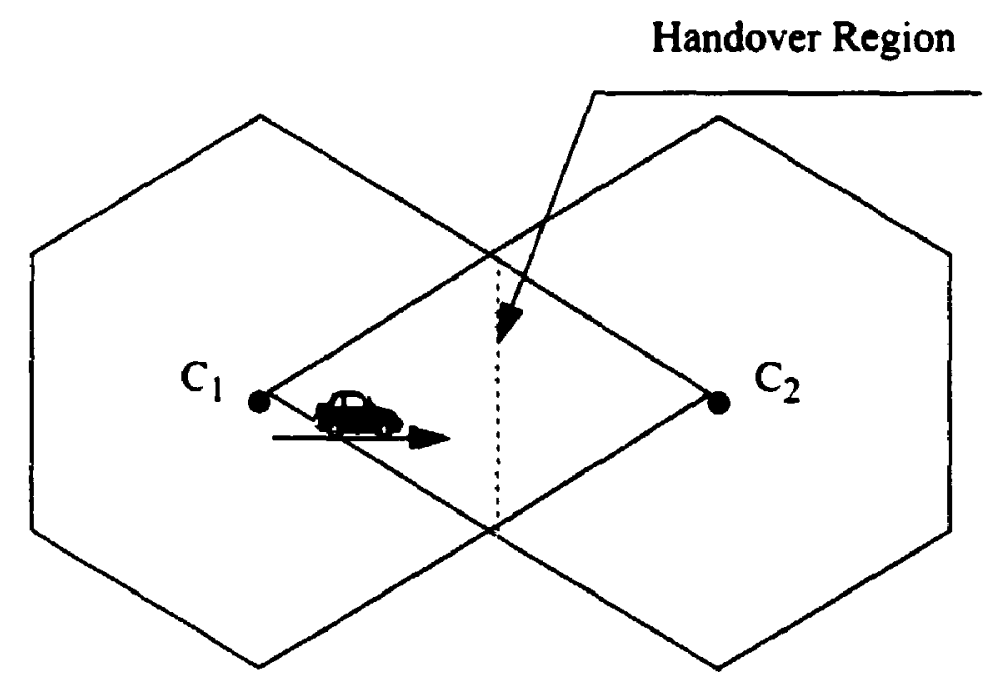

Figure 4.1 Handover model

The measurements of the received signal strengih at the mobile are obtained by using modified propagation model described by Hata and Nagatsu [17]. The model describes that, a land mobile radio propagation is characterized by three components. First there is instantaneous variations which are Rayleigh distributed. The second component is the narrow area median due to shadowing and is lognormally distributed. Finally, there is long 
term median (path loss) of the signal strength which is proportional to the (distance) " between the mobile and the base station. $\alpha$. the distance related attenuation factor. is a function of base station antenna height and environmental characterization.

The long term median is evaluated using empirical formula provided by Hata [39] given below.

$$
\begin{aligned}
F_{\mathrm{Hata}}(d B \mu \mathrm{V} / m)= & 108.45-10 \log \left(\lambda^{2} / 4 \pi\right)-26.15 \log \left(f_{b}\right)+13.82 \log \left(h_{h}\right)+ \\
& \left(6.55 \log \left(h_{h}\right)-44.9\right) \log R+10 \log P+2.2
\end{aligned}
$$

where $F=$ is the long term median of the signal strength

$$
\begin{aligned}
& \lambda=\text { wavelength of the carrier frequency } \\
& f_{c}=\text { carrier frequency in } \mathrm{MHz} \\
& h_{b}=\text { base station antenna height in meters } \\
& R=\text { mobile distance from the base station in } \mathrm{km} \\
& P=\text { transmitted power in Watts }
\end{aligned}
$$

The following parameters were used for the evaluation of the long term median:

$f_{c}=900 \mathrm{MHz}, h_{b}=30 \mathrm{~m}, P=1 \mathrm{~W}$.

By substituting the values of $f_{c}, h_{b}$ and $P$, equation 4.1 is re juced to a simplified form as indicated in equation 4.2 . 


$$
F(d B \mu V / m)=A-B \log (R)
$$

where $A=-52.55$

$$
\mathrm{B}=\left(\begin{array}{l}
20 \ldots \ldots \text { for }(R<1 \mathrm{~km}) \\
35 \ldots \ldots \ldots \text { for }(R \geq 1 \mathrm{~km})
\end{array}\right.
$$

The observed long term median as a function of distance is shown figure 4.2. It shows that the signal strength $\mathrm{FCl}$ from cell $\mathrm{C}_{1}$ decreases as the distance between the mobile and the base station increases. At the same instant, the mobile is moving towards the direction of cell $C_{2}$ and reducing the distance between the mobile and the base station of cell $C_{2}$. Thus, the signal FC2 is observed to increase as the distance between the mobile and the base station of cell $C_{2}$ decreases.

The Rayleigh distributed instantaneous variations are generated by random phase modulation as described in [37]. In generating the Rayleigh fading signal, it is assumed that the carrier frequency is $900 \mathrm{MHz}$ and the mobile is travelling with an average speed of $50 \mathrm{~km}$ ' h.

The shadowing is statistically modelled as lognormally disiributed. 


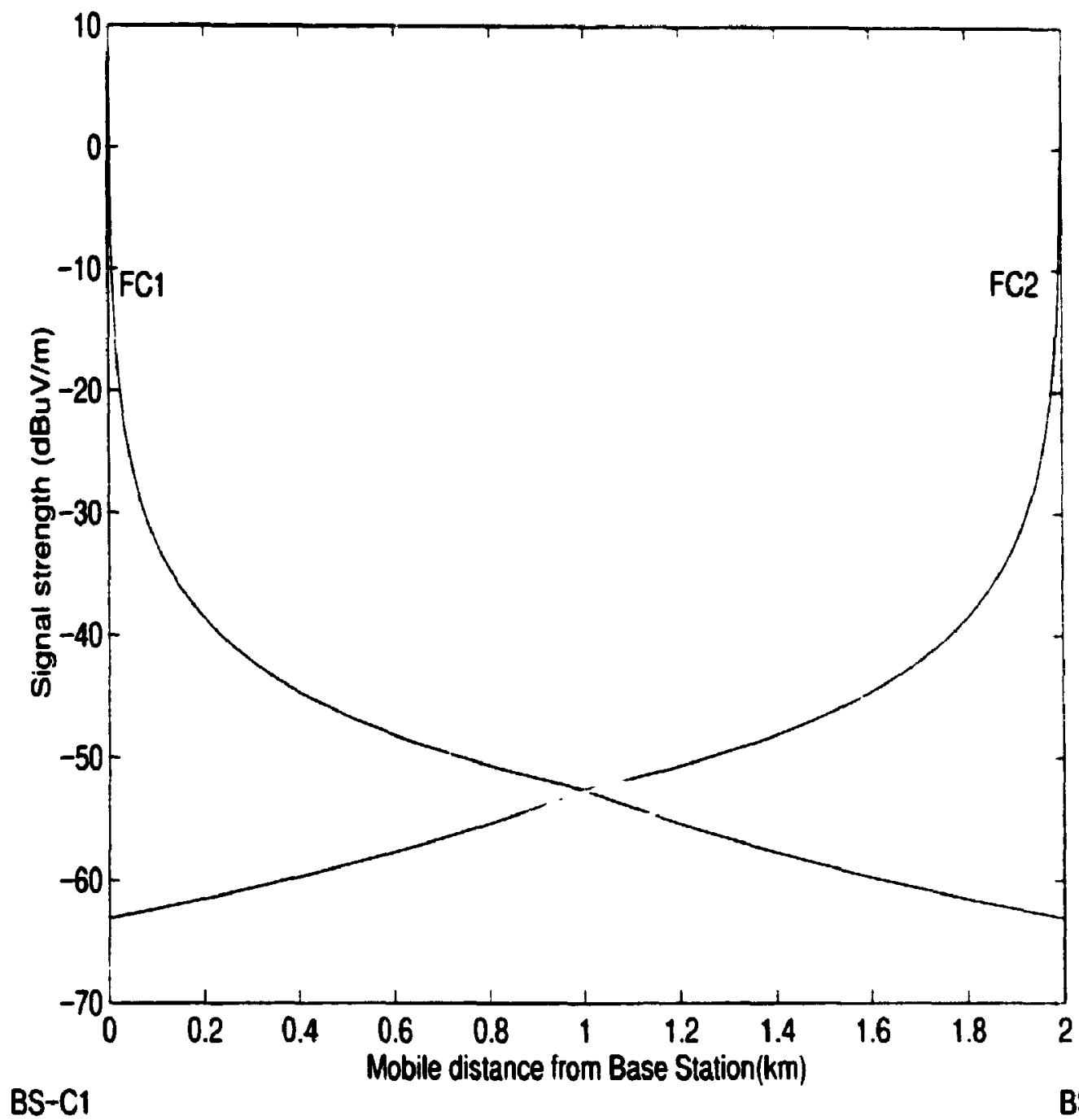

BS-C2

Figure 4.2 Long term median of the received signal strength

It is assumed that the measured power $\mathrm{L}$ is given by

$$
L=10^{X / 10}
$$

where

$L$ is lognormally distributed

$X$ is in $\mathrm{dB}$ and is normally distributed 
A normally distributed random variable $X$ is generated using the mean $m_{X}$ and the standard deviations $\sigma_{X}$. The mean $m_{X}$ is defined as

$$
m_{\lambda}=10 \log \left(F-a \sigma_{X}^{2}\right)
$$

where

$$
\begin{aligned}
& F=\text { long term median derived from the empirical formula provided by Hata } \\
& a=\text { constant equal to } \log e(\ln 10)^{2} / 200 \text { or } 0.0115 \\
& \sigma_{X}=\text { Shadowing parameter (standard deviation of Gaussian process in } \mathrm{dB} \text { ) }
\end{aligned}
$$

The shadowing which is lognormally distributed is therefore obtained by converting $\mathbf{X}$ into linear scale using equation 4.3 .

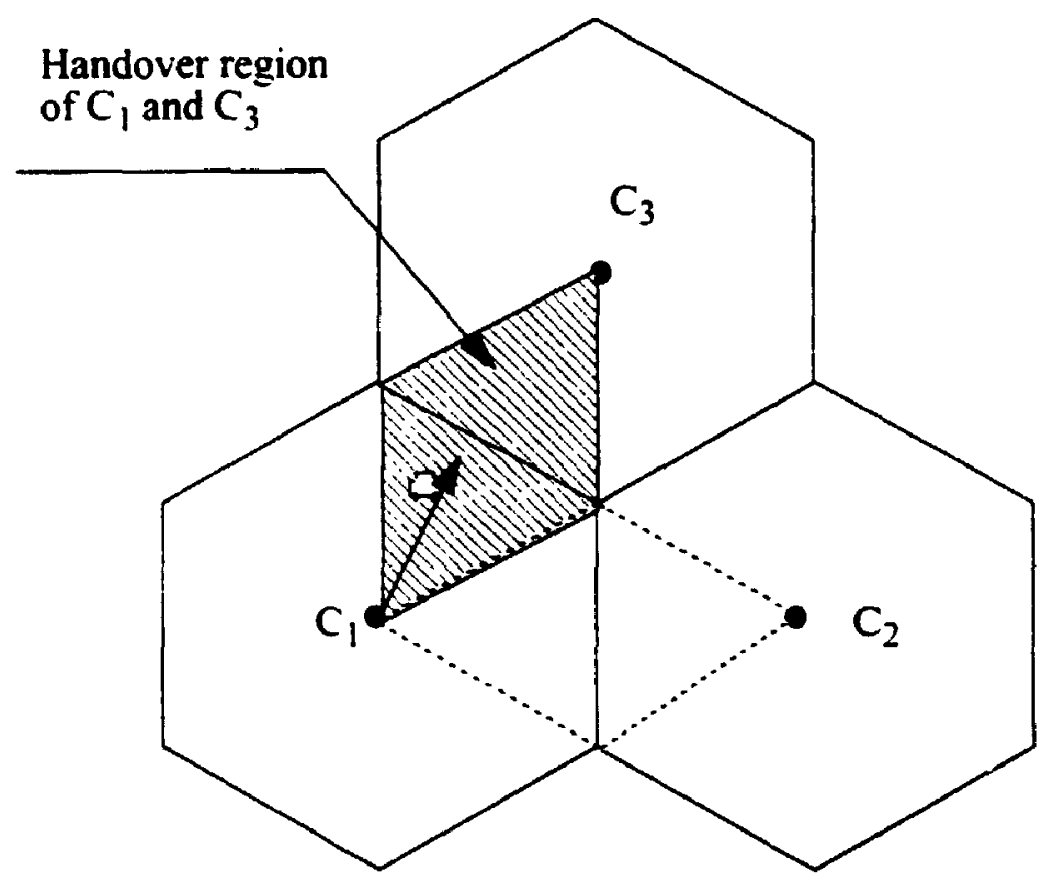

Figure 4.3 A mobile outside handover region of cell $C_{1}$ and cell $C_{2}$ 
For a mobile travelling outside handover region of cell $C_{1}$ and cell $C_{2}$ as shown in figure 4.3, a similar procedure described above can be used. In this case. handover can occur between cell $C_{1}$ and cell $C_{3}$ and the handover region is as shown in figure 4.3 .

\subsubsection{Analysis using CIR Measurements}

CIR measurements are obtained by considering a cellular system with cluster size of three as shown in figure 4.4, with base stations located at the centres of the cells. A mobile is located at a distance $r$ from the desired base station (serving BS) and a distance $r_{i}$ from the base station of the interfering cell.

In cellular hexagonal system. the distance $r_{i}$ is given by

$$
r_{1}^{2}=9 R^{2}+r^{2}+6 R r \cos \left(\theta+m \frac{\pi}{3}-\frac{\pi}{2}\right)
$$

where $\mathrm{R}=$ cell size,

$$
\mathbf{m}=\text { the number of active interference. }
$$

The average received signal power by the mobile at a distance $r$ from the desired base station is given by

$$
S=\frac{C}{r^{\alpha}}
$$

where $C$ is a constant and $\alpha$ represent the propagation parameter ranging between 2 and 5 .

The average power of interference signal received by the mobile is given by

$$
I_{t}=\sum_{m=1}^{M} \frac{C}{r_{1}^{2}}
$$

where $M=$ the number of base station contributing to the interference. 


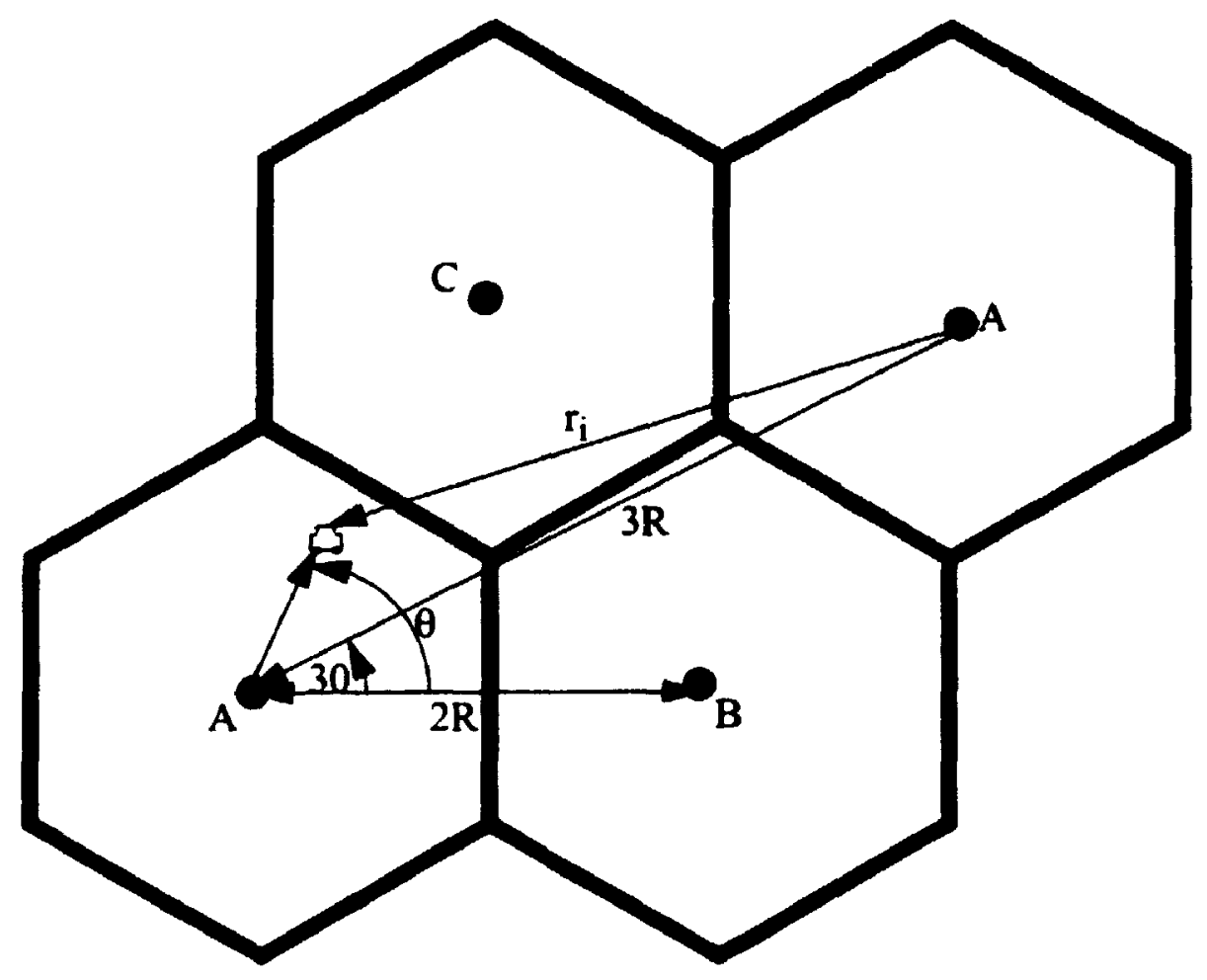

Figure 4.4 A mobile in cellular system of cluster size three

$$
I_{1}=C \sum_{m=1}^{n} E\left[\frac{1}{\left(9 R^{2}+r^{2}+6 R r \cos \left(\theta-m \frac{\pi}{3}-\frac{\pi}{2}\right)\right)^{\alpha / 2}}\right]
$$

where $E[$.$] represents expectation on \theta$.

It is suggested by computer simulation that the above equation is empirically equivalent to [38] 


$$
I_{l}=\frac{M C}{\left(9-0.5 \alpha r^{2}\right)^{\alpha 2}}
$$

The signal to interference ratio can be calculated according to:

$$
\frac{S}{I_{i}}=\frac{\left(9-0.5 \alpha r^{2}\right)^{\alpha 2}}{M r^{\alpha}}
$$

and therefore

$$
S I R(d B)=5 \alpha \log \left(9-0.5 \alpha r^{2}\right)-10 \alpha \log (r)-10 \log (M) .
$$

In this analysis it is assumed that $M=6$ and $\alpha=2$

The variation of signal to interference ratio as a functiou of distance is shown in figure 4.5. It is observed that the signal to interference ratio decreases as the distance increases, indicating that the interference becomes higher as the mobile moves away from the serving $3 S$ to the boundary of the cell.

\subsubsection{Multiple Criteria using Signal Strength and CIR}

In the systems where multiple decision parameters are used in the handover control process, measurements of each parameter are used to determine if a handover should be performed. When more than one parameter indicate the requirement for handover at the same instant, handover is based on the priority given to the one of the parameter.

Fuzzy technique provides a convenient way of forming handover logic using multiple parameters. This can be achieved by the evaluation of their membership functions and combining them using fuzzy algebraic operations. In this thesis, the membership functions of the signal strength and CIR are evaluated and combined using probabilistic sum opera- 
tion and the decision for handover was based on the combined membership function.

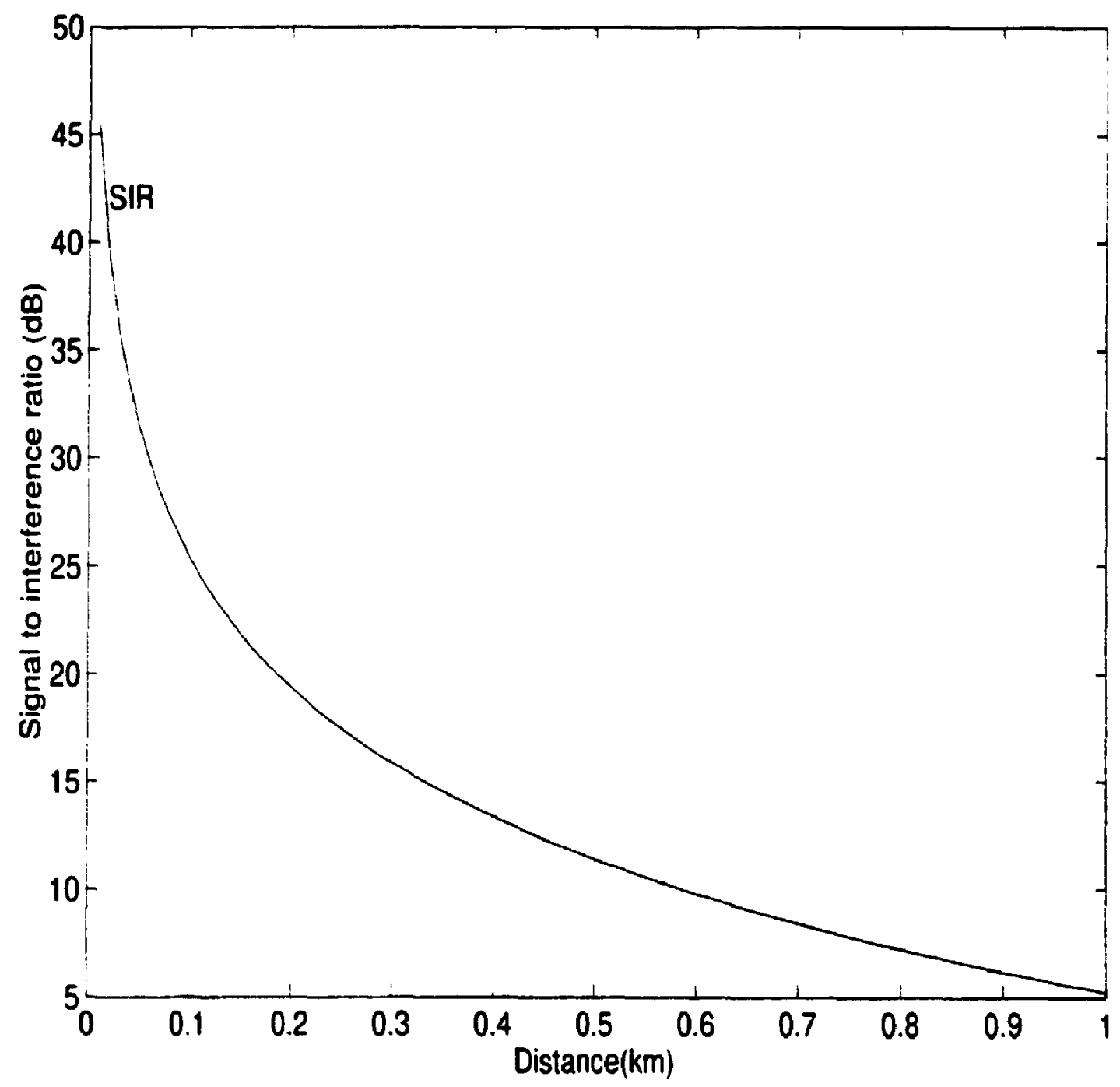

Figure 4.5 SIR versus distance 


\subsubsection{Performance Measure}

The performance was assessed by examining the average number of handovers which occur when signal strength and CIR measurements vary as the mobile travels through the handover region. First. handover distribution which indicate the average number of handovers over the travelled distance between the two base stations is examined. The simulation was performed for different averaging distance in Rayleigh fading environment with several shadowing parameters. This is followed by the evaluation of total number of handovers which indicate the average number of handovers for each averaging distance and shadowing parameter. Simulations were also performed to examine the average number of handovers which occur over a short distance interval and long distance interval. In all of the above cases. the comparison was made between conventional algorithm and fuzzy algorithm.

\subsection{Performance with signal strength measurements}

The path loss, Rayleigh fading and shadowing were obtained as described in section 4.1.1. The measurements for both Rayleigh fading and shadowing were averaged over a certain distance interval and the resulting mean signal strength were used in the handover decision. For conventional handover algorithm, it was assumed that the handover is performed from the currently used base station to another with higher averaged signal strength. The results obtained using conventional algorithm are compared with those using proposed fuzzy algorithm. In using fuzzy algorithm described in chapter 3 , the average received signal strength represents the pattern $X$ whose membership functions $U_{1}(X)$ define the degree of signal strength $\mathrm{X}$ on the base station $\mathrm{i}$. The decision for handover using fuzzy algorithm is based on the membership functions.

In the case of conventional algorithm, it was also assumed that handover occurs from one 
base station to another, when the signal strength of the new base station exceeds that of the serving base station by a hysteresis margin $(H)$. The results using this algorithm are compared with those using fuzzy algorithm for different shadowing parameters and are presented in section 4.2.2.

\subsubsection{Handover Distribution}

Figure 4.6 shows the distribution of handover using conventional algorithm for averaging distance $d_{a v e}=5 \mathrm{~m}, 10 \mathrm{~m}$ and $15 \mathrm{~m}$ in Rayleigh fading environment. The results indicate that the average number of handover is reduced when the averaging distance is increased from $5 \mathrm{~m}$ to $15 \mathrm{~m}$ and they are concentrated over a relatively short distance. The results of handover distribution when using fuzzy algorithm are shown in figure 4.7. It is observed that compared to conventional algorithm, the average number of handovers is significantly reduced. For example, for $5 \mathrm{~m}$ averaging distance, the average number of handovers dropped from 27.89 for conventional algorithm to 10.2 i.e a reduction of $63 \%$ is observed when fuzzy algorithm is used. A reduction in handover distribution is also observed for larger values of averaging distance.

A similar trend is observed when those handover algorithms are investigated in shadowing environment. Figure 4.8 shows the distribution of handovers using conventional algorithm for shadowing parameter (standard deviation) $S=9 \mathrm{~dB}$. It is observed that the handovers take place over a wider distance as compared to those in pure Rayleigh fading environment. In addition, the handovers are widely spread for averaging distance of $5 \mathrm{~m}$ and the spreading is slightly reduced for averaging distance of $10 \mathrm{~m}$ and $15 \mathrm{~m}$ The average number of handovers is reduced when fuzzy algorithm is used as shown in figure 4.9. However, the handovers are still spread over larger area because shadowing causes greater mean signal strength fluctuations outside the narrow area of handovers. 
In both of the above cases (figures 4.6. 4.7. 4.8 and 4.9), the results indicate fuzzy algorithm as well as averaging distance has significant impact on the reduction of the distribution of handovers.

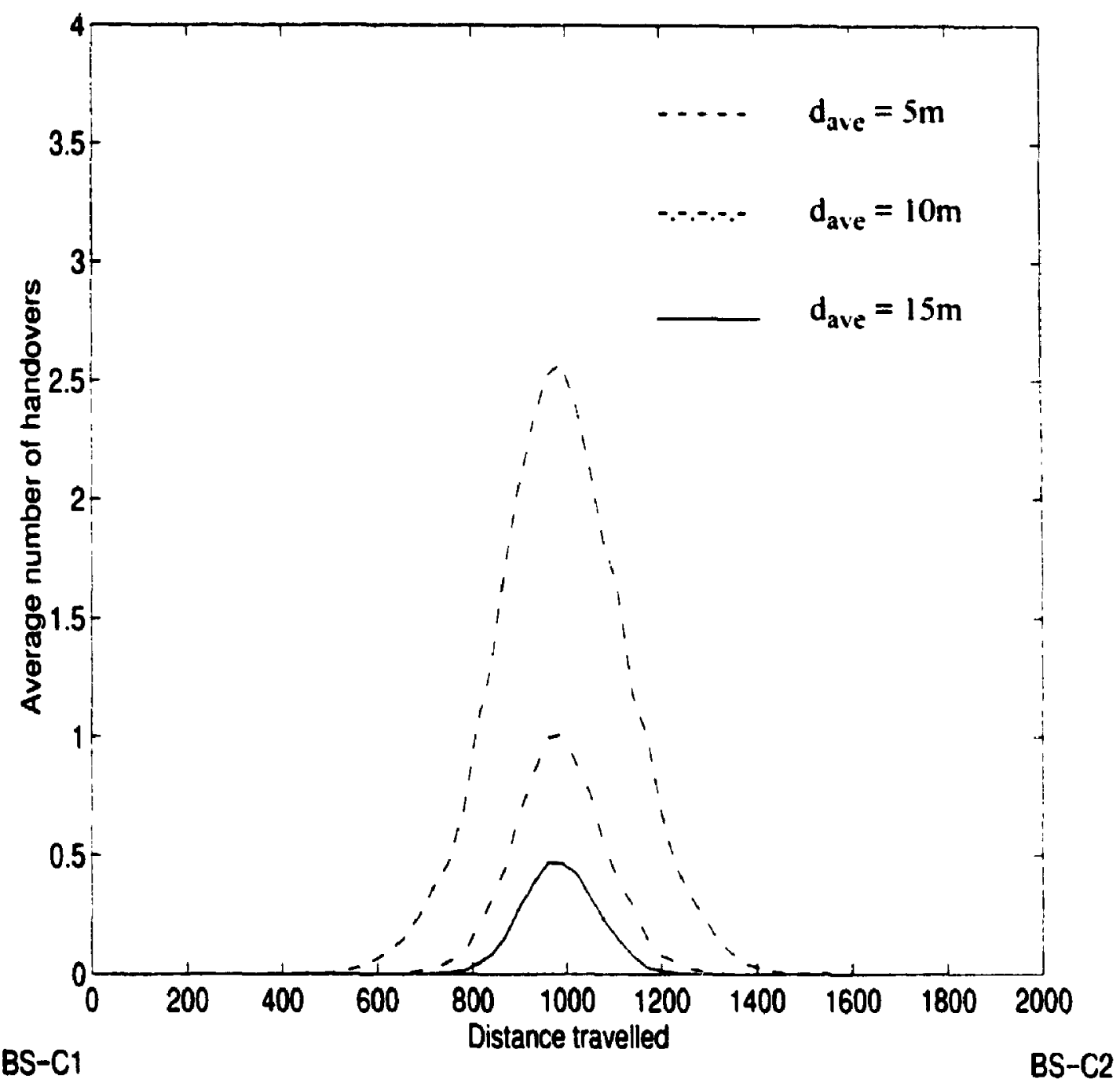

Figure 4.6 Handover distribution with Rayleigh fading using conventional algorithm 


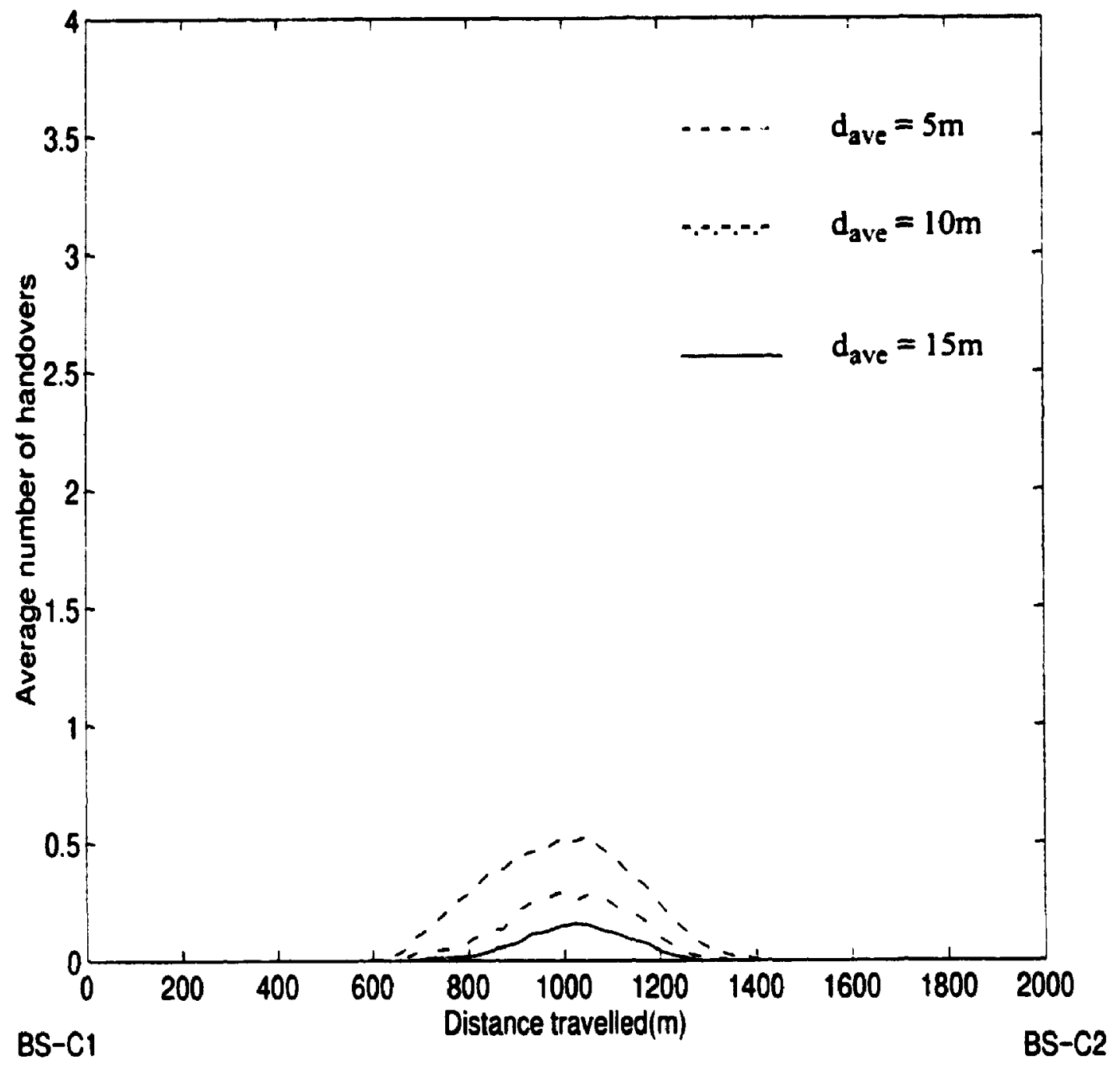

Figure 4.7 Handover distribution with Rayleigh fading using fuzzy algorithm 


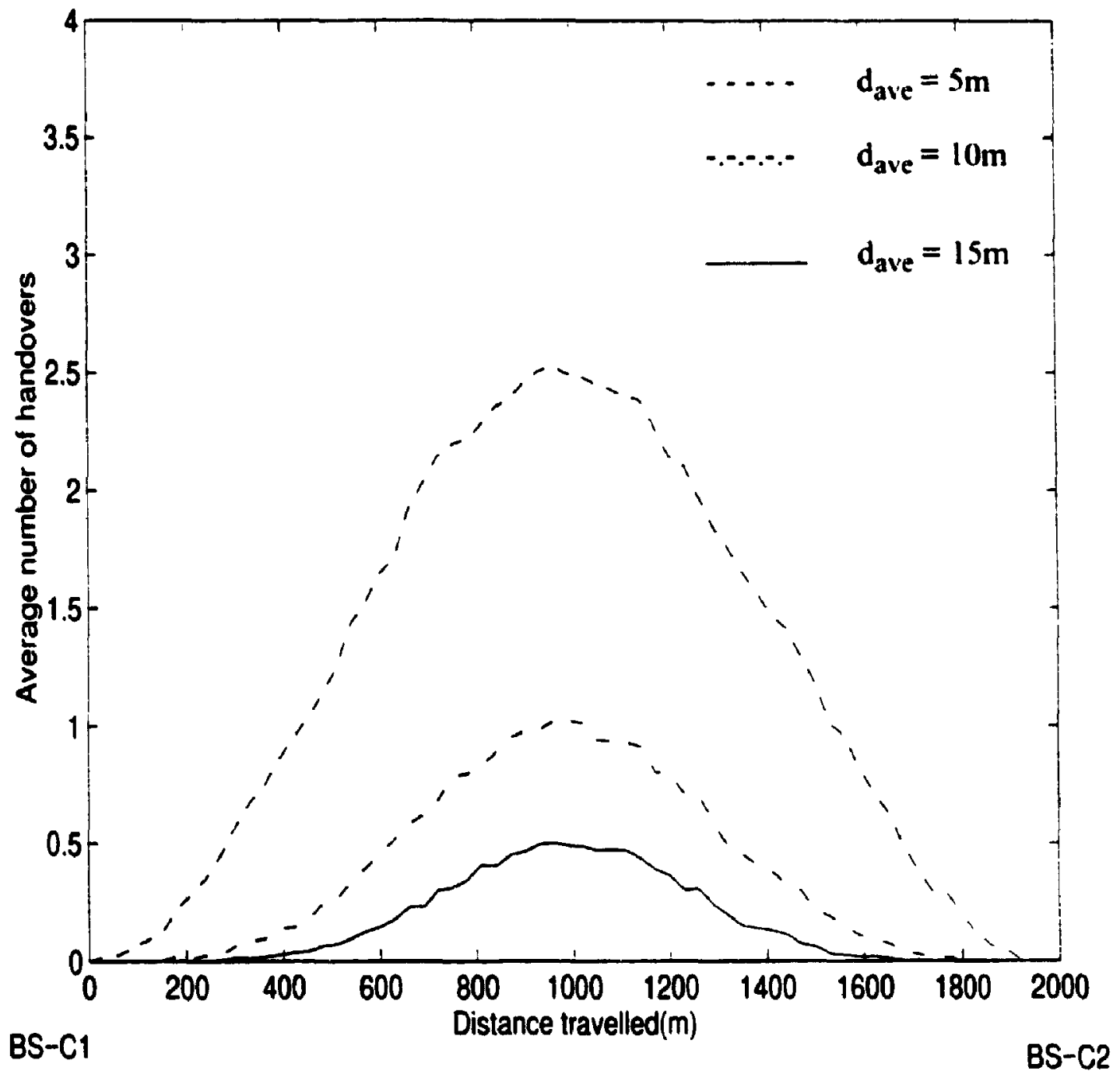

Figure 4.8 Handover distribution with shadowing $S=9 \mathrm{~dB}$ using conventional algorithm 


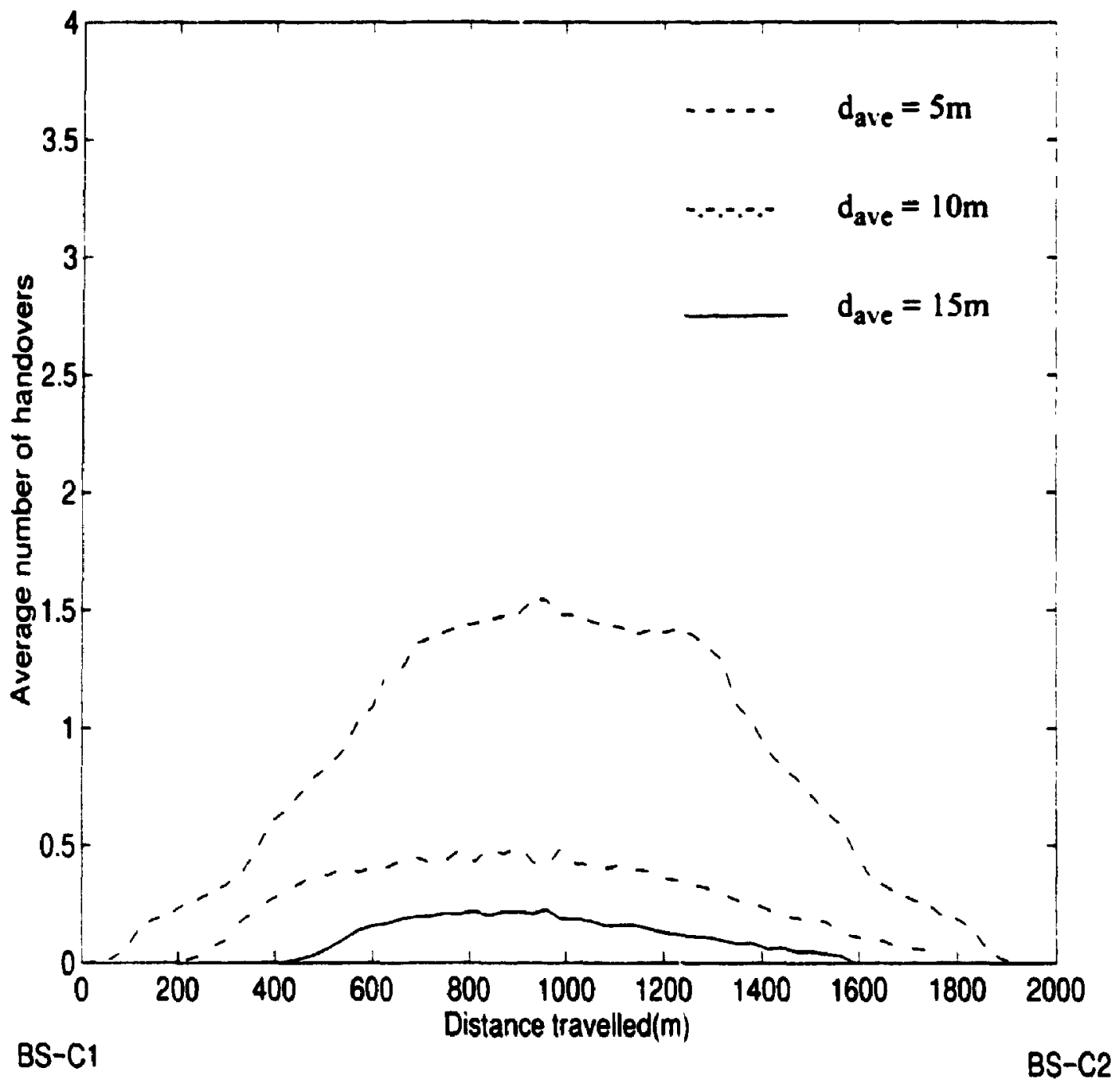

Figure 4.9 Handover distribution with shadowing $S=9 d B$ using fuzzy algorithm 
Figures 4.10 and 4.11 show the effe-t 0 iadowing on the handover distribution. The simulation was performed for averaging dir $\cdot n \cdot e d_{\text {ave }}=10 \mathrm{~m}$. The results in each figure ind1cate handover distribution for shadowing parameters $S=6.9$ and $12 \mathrm{~dB}$ and their effect on the spread of handovers.

The results using conventional algorithm shown in figure 4.10 indicate that a large number of handovers is concentrated at the centre i.e $1 \mathrm{~km}$ distance from the first cell (cell $\mathrm{C}_{1}$ ) which represents the boundary of the two cells. The average number of handovers is seen to be maximum at the same point for different shadowing parameters indicating a critical area for handovers. The concentration of many handovers at one area may result in the loss of significant number of calls due to the time limitation.

Figure 4.11 shows the results using fuzzy algorithm. It is observed that the average number of handovers is reduced when compared to thonse in the case of conventional algorithm. For example, for shadowing parameter $S=6 \mathrm{~dB}$. average number handovers drop from 17.1 to 8.9 which is a reduction of approximately 48 percent. The figure also indicates the boundary area, around $1 \mathrm{~km}$ distance is well dispersed and the average number of handovers varies with shadowing parameters. This indicates that fuzzy algorithm besides reducing number of handovers, also helps in avoiding the risk of handover failure and eventually loss of the call.

Figures 4.10 and 4.11 also show that increasing shadowing parameter has the effert of causing a wider spread of handovers 


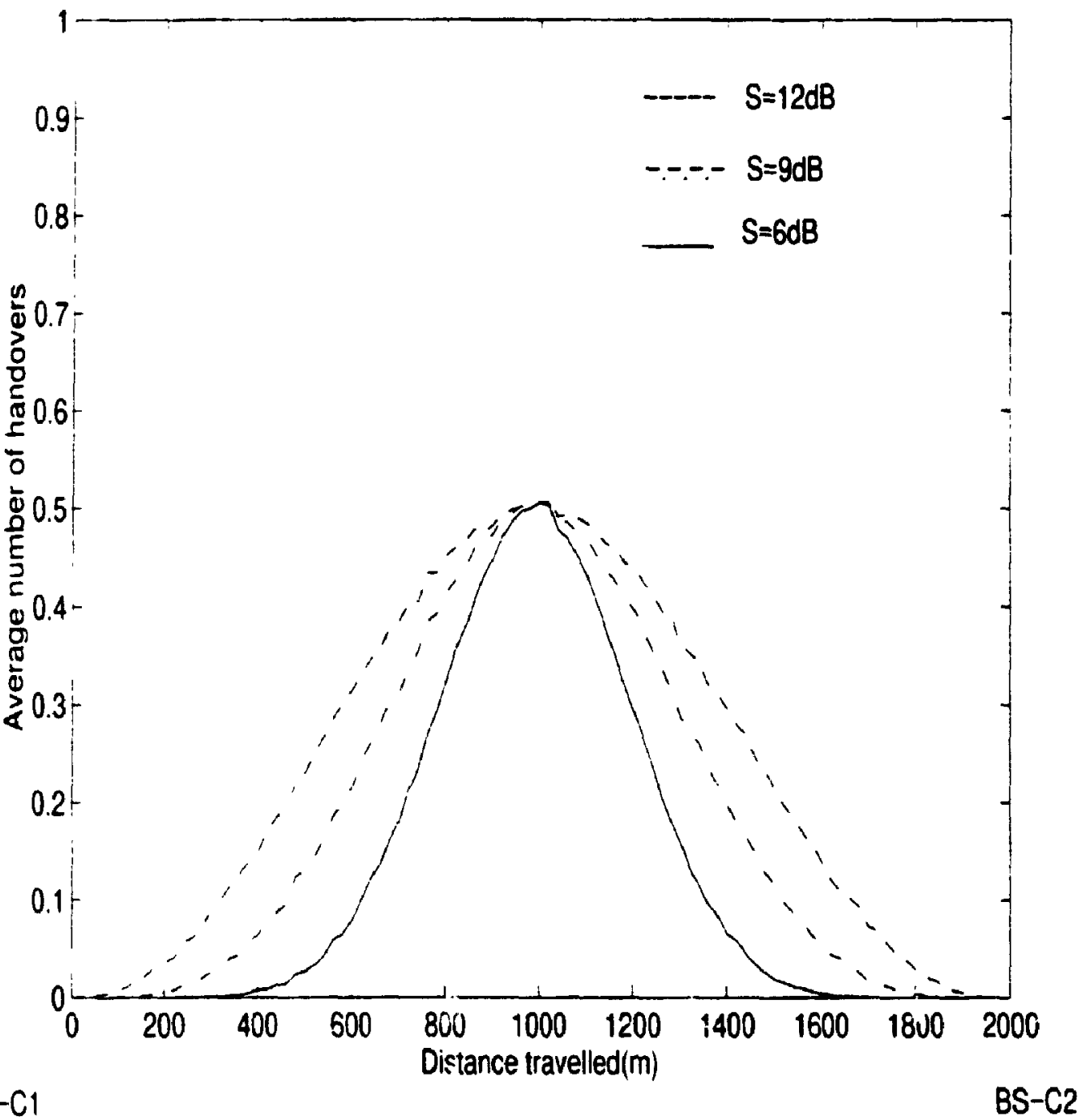

Figure 4.10 Handover distribution for different shadowing parameters using conventional algorithm 


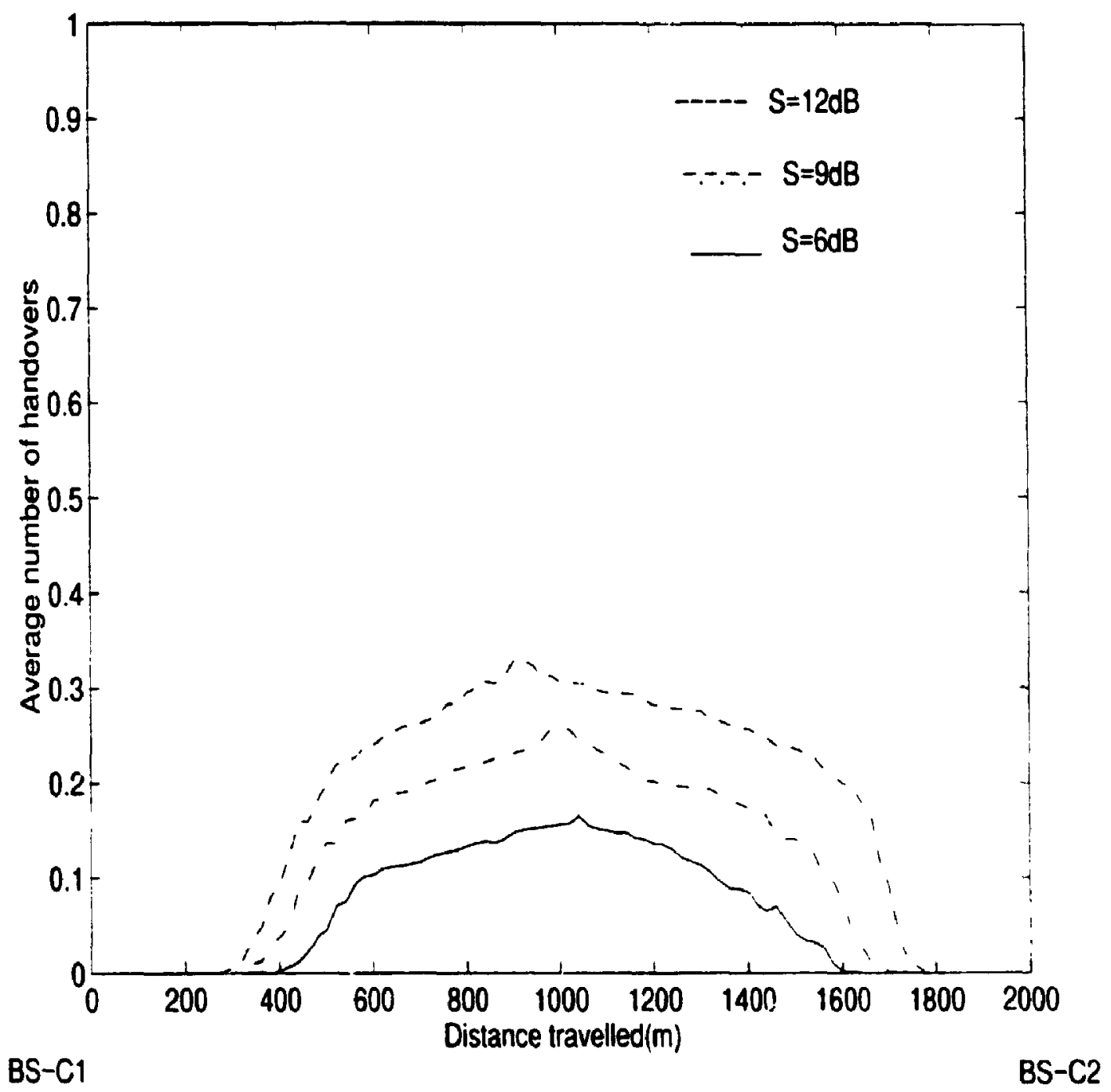

Figure 4.11 Handover distribution for different shadowing parameters using fuzzy algorithm 


\subsubsection{Total Number of Handovers}

Figure 4.12 shows the total number of handovers obtained with Rayleigh fading for different averaging distances. The results show fewer number of handovers when fuzzy algorithm was implemented as compared to conventional algorithm. The improvement is observed to be more significant when the averaging distance is less than $10 \mathrm{~m}$.

Figure $4.13,4.14$ and 4.15 show the total number of handovers with shadowing parameters $S=6,9,12 \mathrm{~dB}$ for different averaging distances. In all cases, the performance using tuzzy algorithm indicates fewer number of handovers. In figure 4.13, the decrease in the number of handovers when using fuzzy algorithm as compared to when conventional algorithm is used is greater for averaging distance less than $10 \mathrm{~m}$. However, figure 4.14 4.15 and show the improvement gets smaller as the shadowing parameter $S$ increases.

The effect of shadowing on the number of handovers is also indicated in figure 4.16, 4.17 and 4.18 for averaging distance $d_{a v e}=5,10$ and $15 \mathrm{~m}$. In these figures, fuzzy algorithm also indicates fewer number of handovers as compared to conventional algorithm. A significant improvement is observed for averaging distance of $5 \mathrm{~m}$ while the improvement is observed to be lower when the averaging distance is $15 \mathrm{~m}$.

The above results show total number of handovers are smaller in Rayleigh fading environment and increase with shadowing parameter. In addition. the improvement when fuzzy algorithm is used is observed to be smaller for higher values of shadowing parameter.

Fis'ire 4.19, 4.20 and 4.21 show the total number of handovers obtained with different shadowing parameters for averaging distance $d_{\text {ave }}=5,10$ and $15 \mathrm{~m}$. The results indicate fewer number of handovers when fuzzy algorithm is used as compared to conventional algorithm with hysteresis margin $\mathrm{H}=0,3$ and $5 \mathrm{~dB}$. 


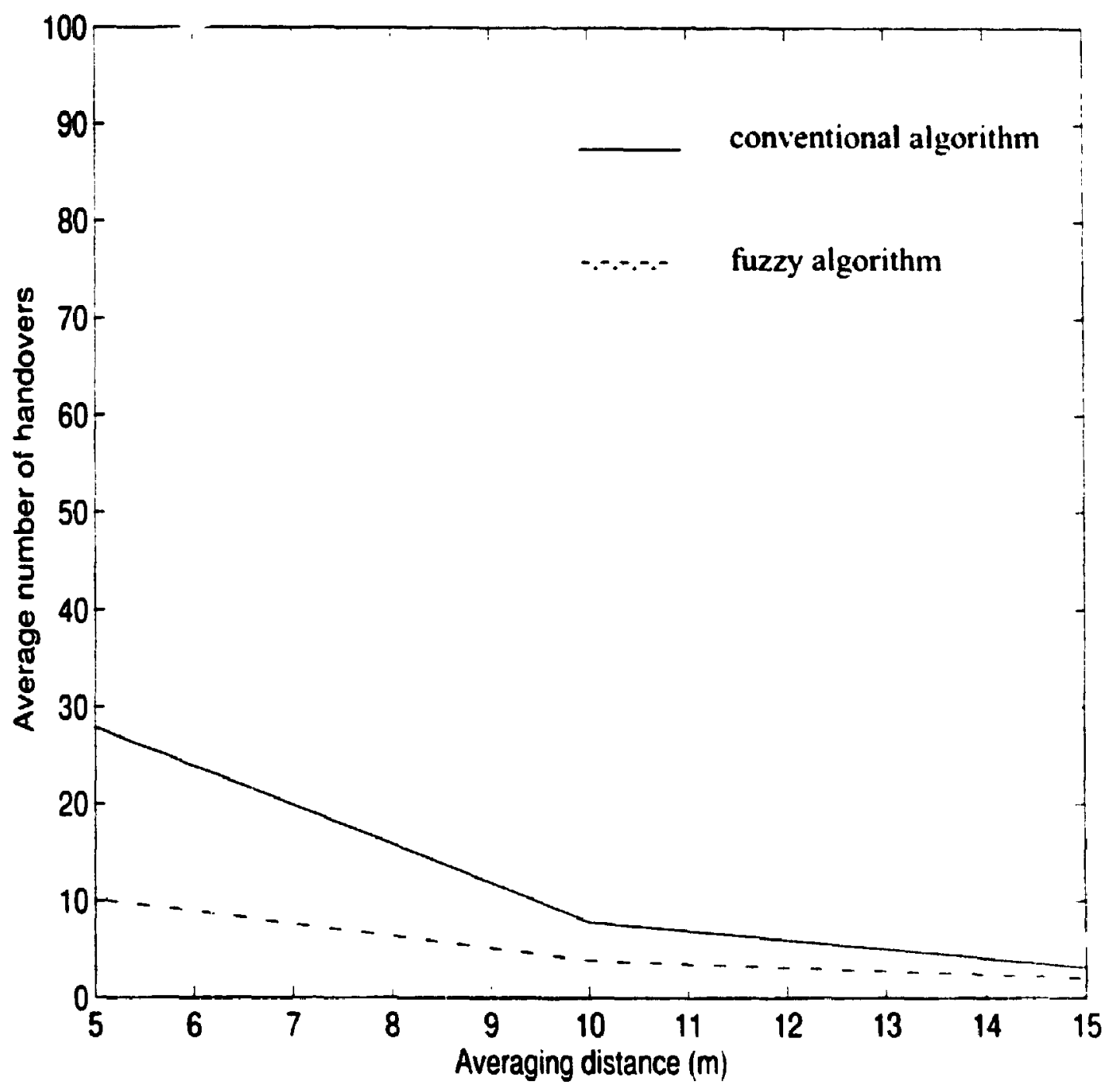

Figure 4.12 Total number of handovers with Rayleigh fading 


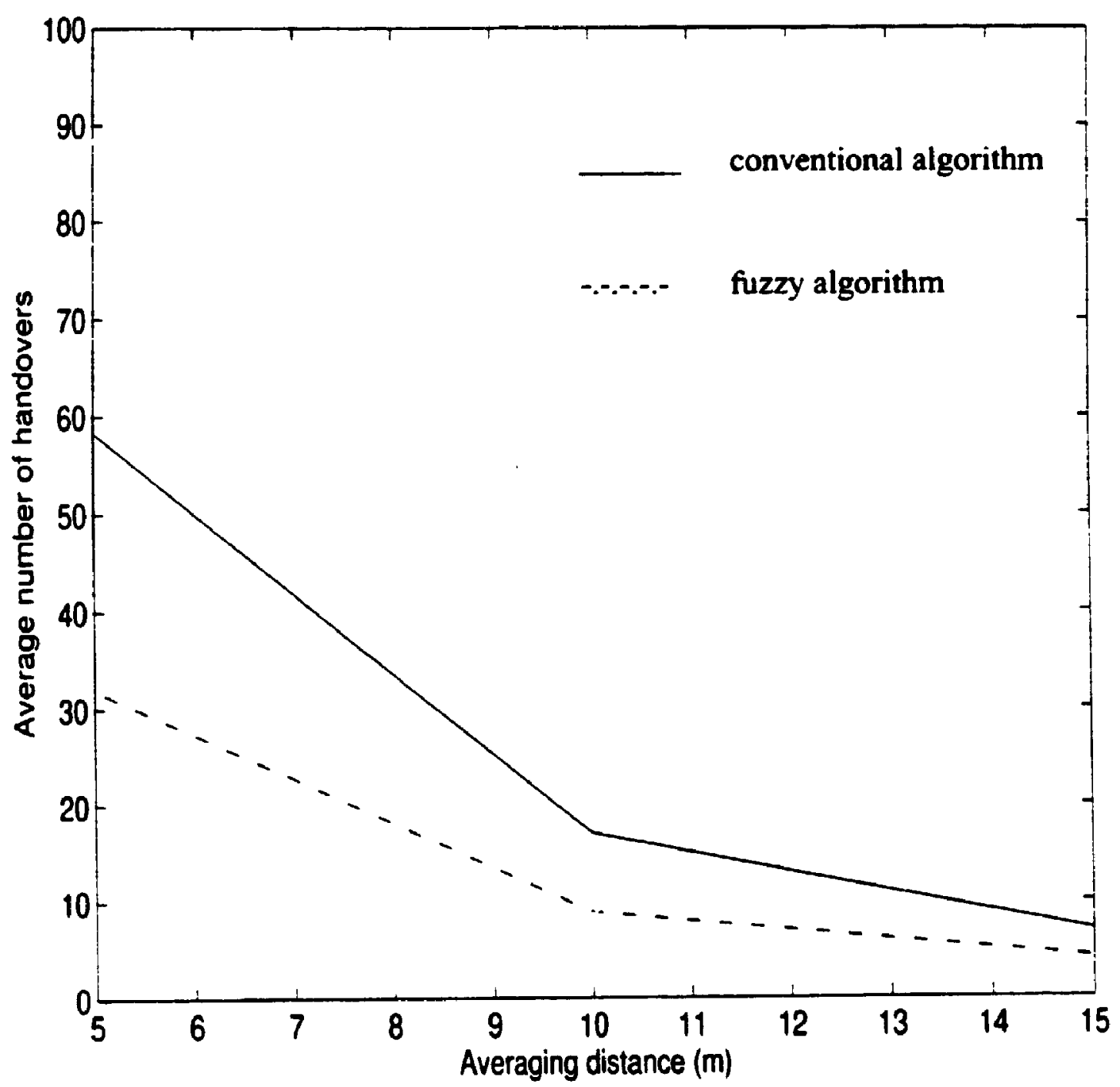

Figure 4.13 Total number of handovers with shadowing parameter $S=6 \mathrm{~dB}$ 


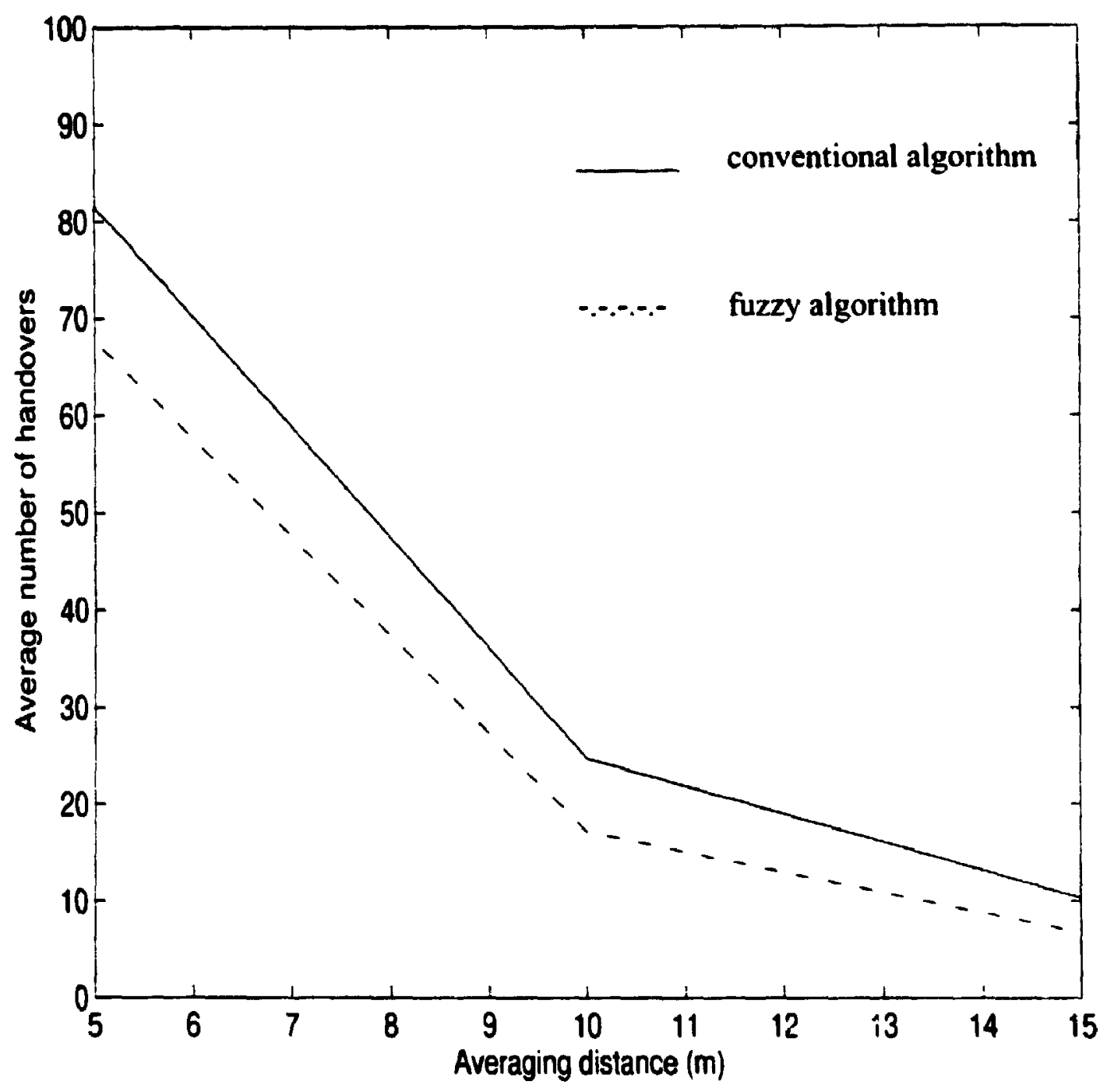

Figure 4.14 Total number of handovers with shadowing parameter $S=9 \mathrm{~dB}$ 


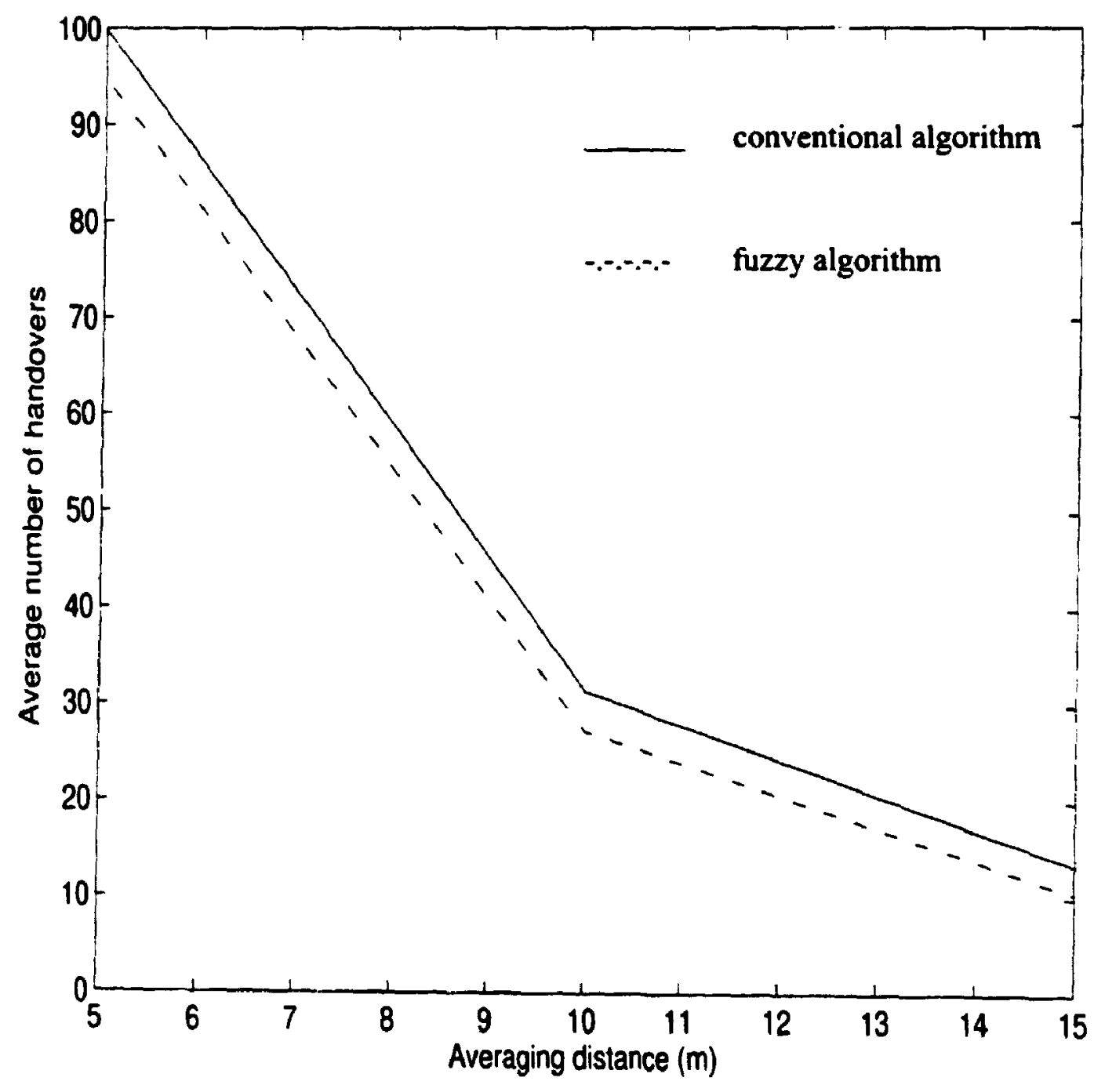

Figure 4.15 Total number of handovers with shadowing parameter $S=12 \mathrm{~dB}$ 


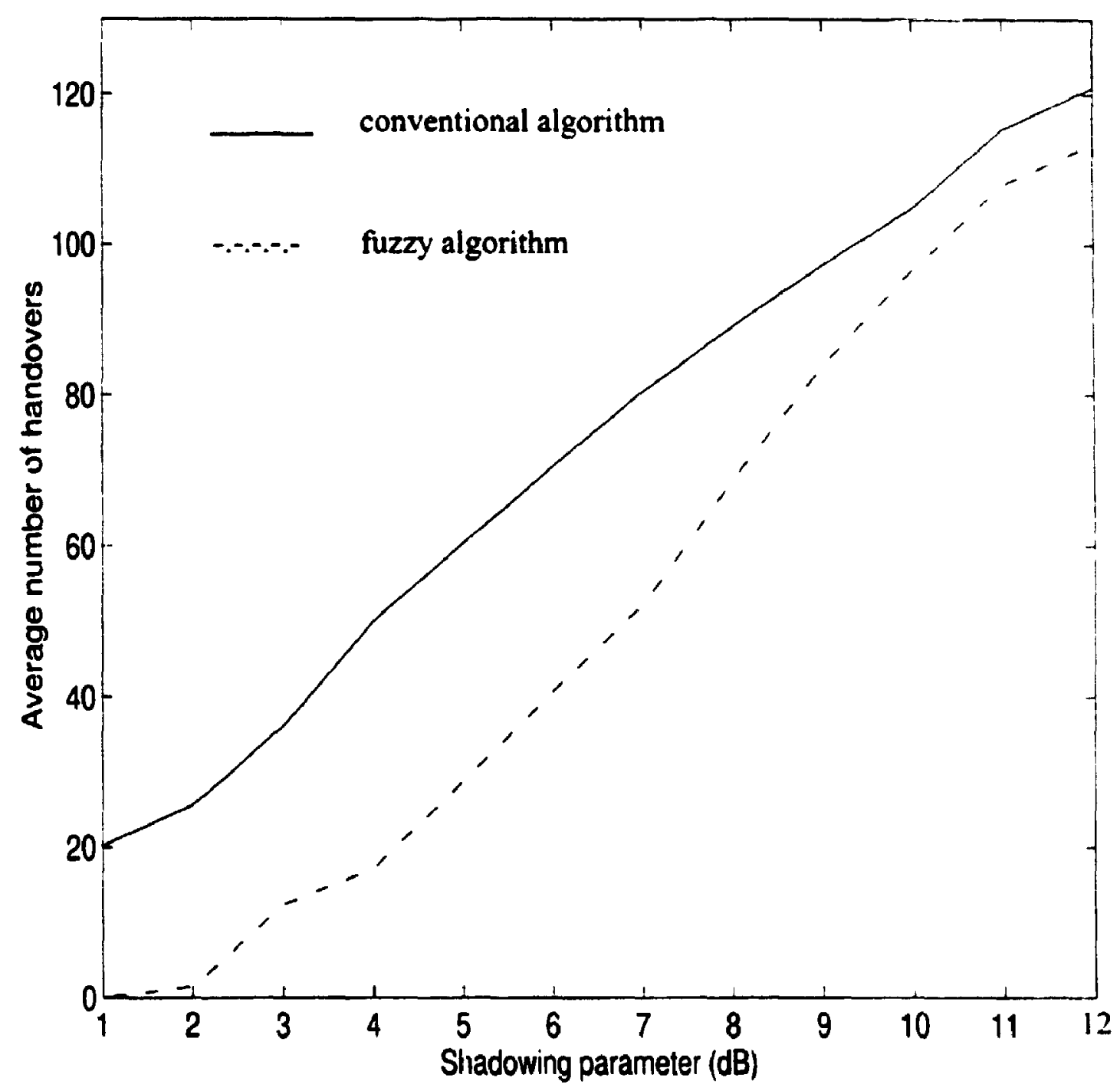

Figure 4.16 Total number of handovers for averaging distance $d_{a y e}=5 \mathrm{~m}$ 


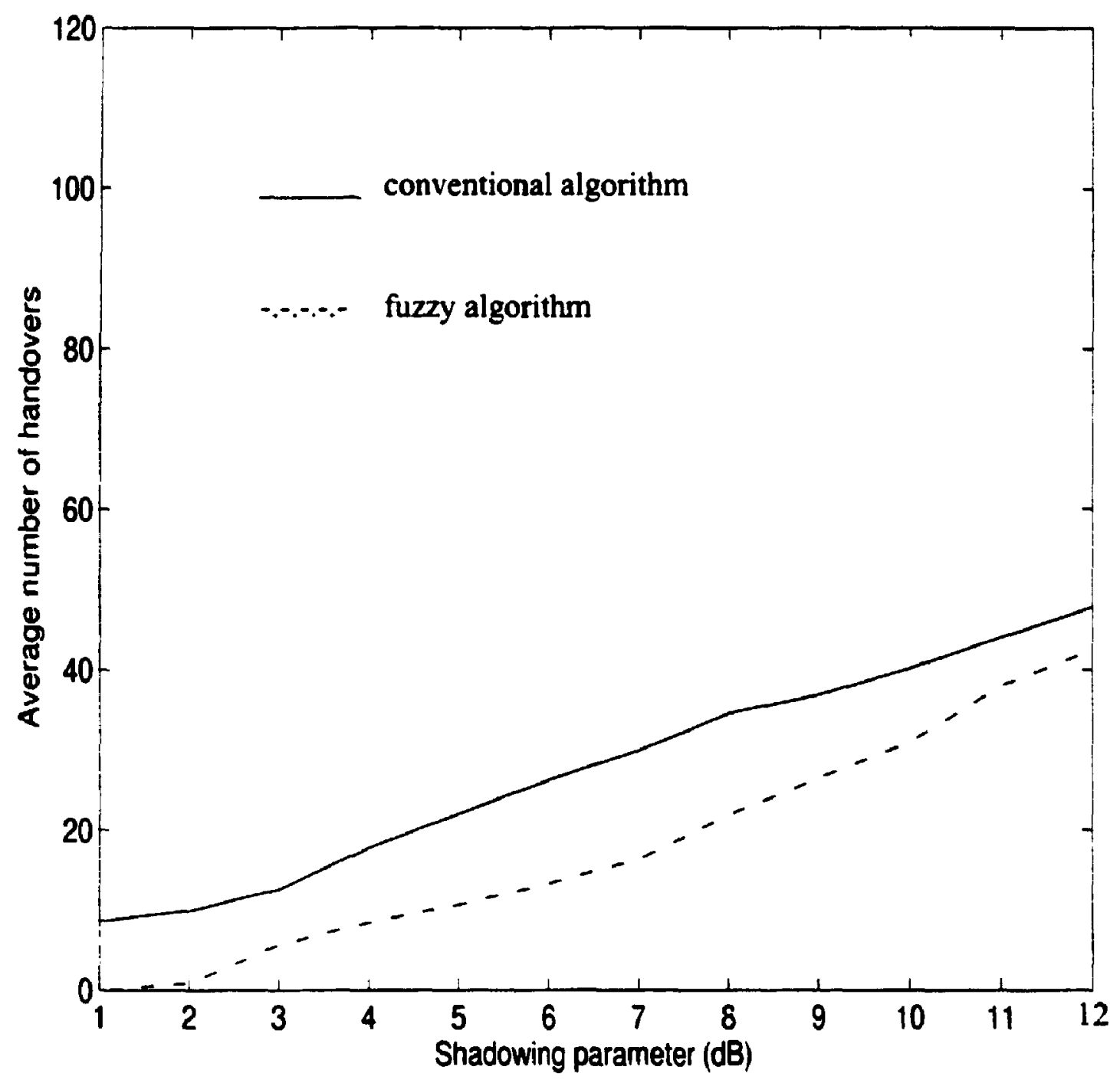

Figure 4.17 Total number of handovers for averaging distance $d_{a v e}=10 \mathrm{~m}$ 


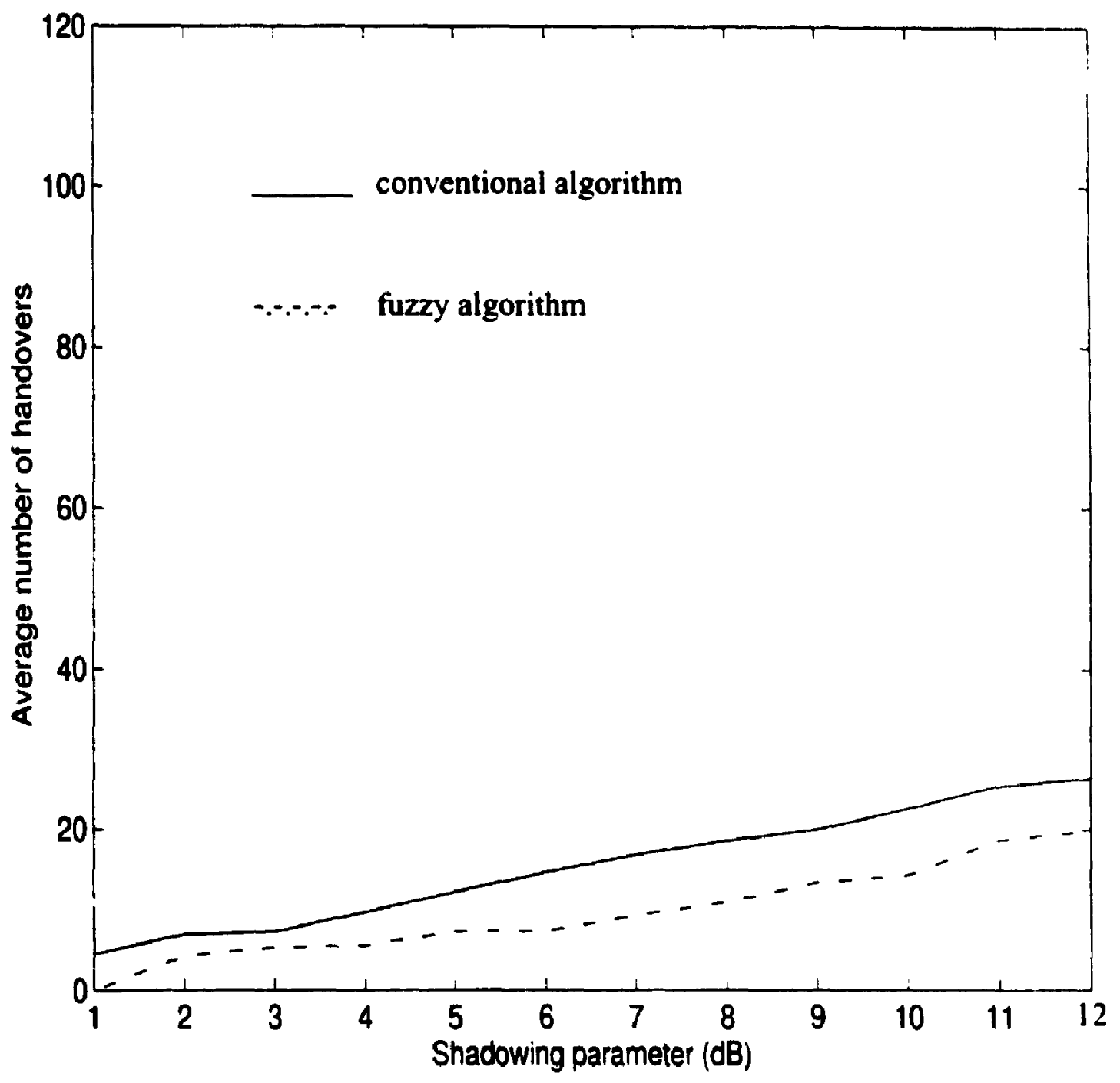

Figure 4.18 Total number of handovers for averaging distance $d_{a v e}=15 \mathrm{~m}$ 


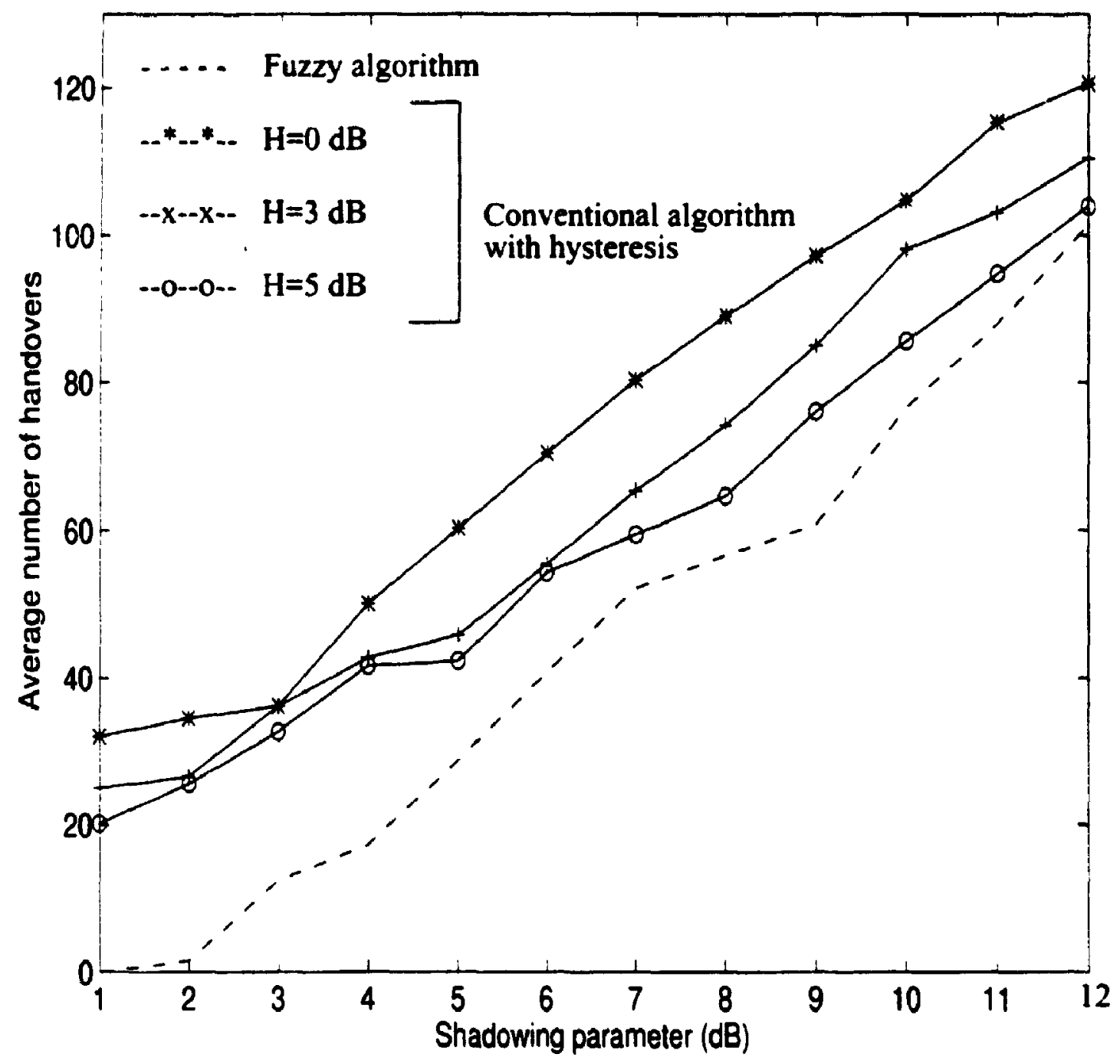

Figure 4.19 Total number of handovers for averaging distance $d_{a v e}=5 m$ with hysteresis 


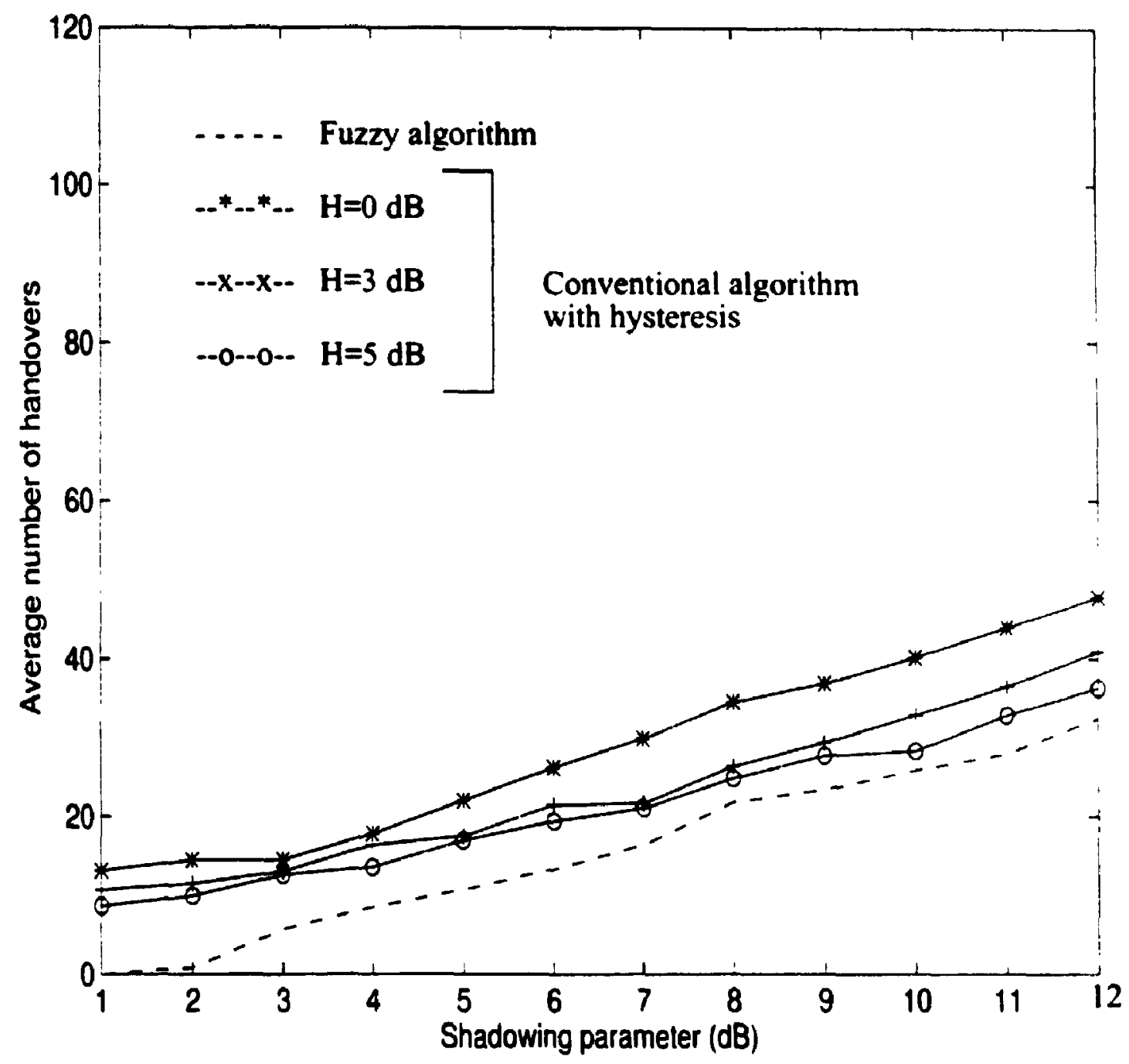

Figure 4.20 Total number of handovers for averaging distance $d_{a v e}=10 \mathrm{~m}$ with hysteresis 


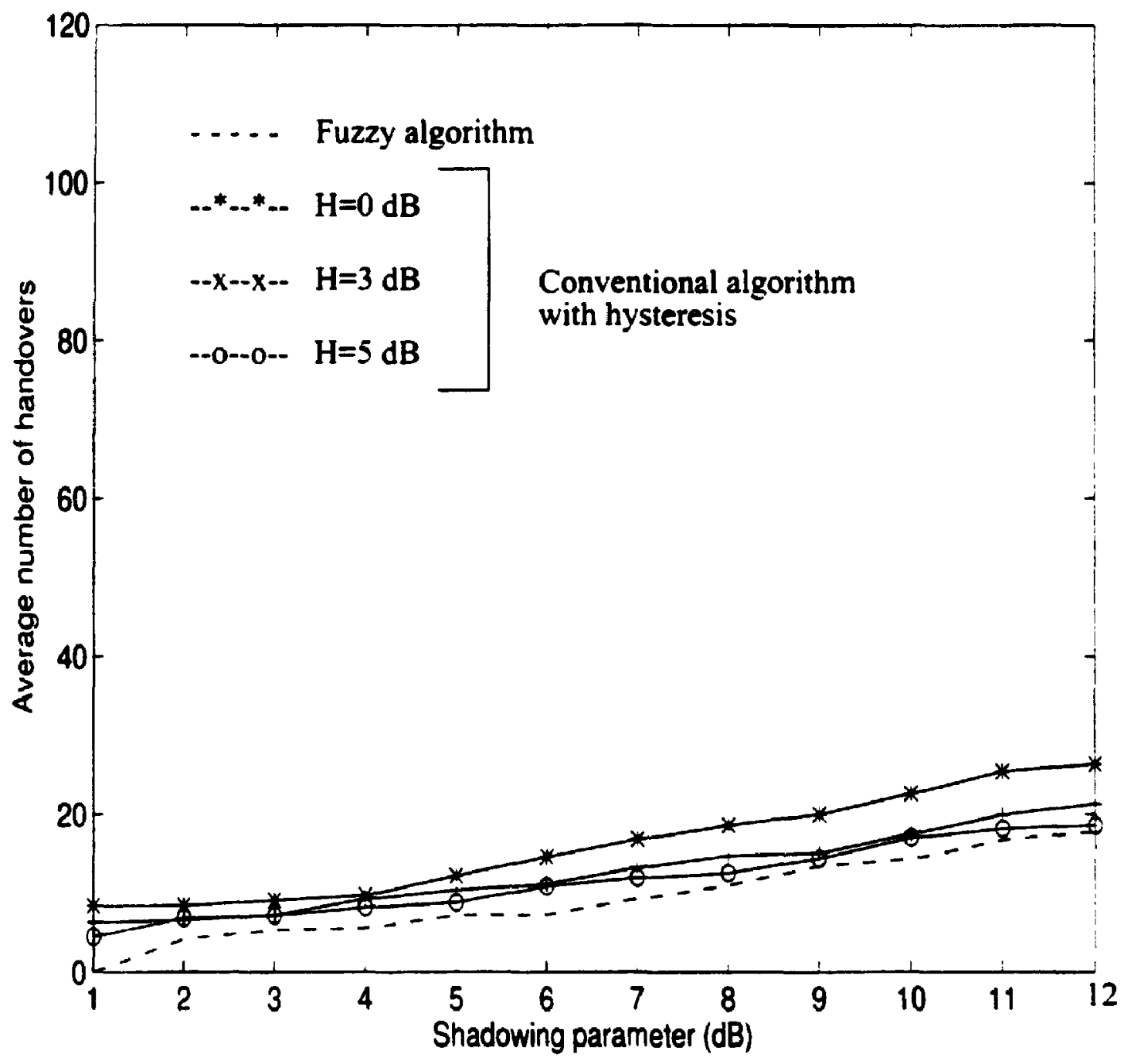

Figure 4.21 Total number of handovers for averaging distance $d_{a v e}=15 m$ with hysteresis 
Total number of handovers for different averaging distance in Rayleigh fading environment are shown in table 4.1. Table 4.2, 4.3 and 4.4 show the total number of handovers with shadowing parameters of 6,9 and $12 \mathrm{~dB}$ respectively. It is observed that there is a significant increase in the number of handovers with shadowing. Moreover. averaging over shorter distances. for example $5 \mathrm{~m}$, results in very large number of hando: ers The percentage increase of handovers over Rayleigh sâding for conventional and fuzzy algorithm for averaging distance of $5 \mathrm{~m}$ are shown in table 4.5 . It should be noted. however. that the total number of handovers using fuzzy logic is always lower. For example. the number of handovers for averaging distance $5 \mathrm{~m}$ with Rayleigh fading observed in table 4.1 are 27.891 and 10.205 using conventional and fuzzy algorithm respectively. The number of handovers increases to 58.280 using conventional algoritnm and 31.877 when using fuzzy algorithm for shadowing parameter of $6 \mathrm{~dB}$. Therefore, even though the percentage increment using fuzzy algorithm is higher as shown in table 4.5. the overall number of handovers is relatively small compared to conventional algorithm.

\begin{tabular}{|l|l|l|}
\hline Averaging distance $(\mathrm{m})$ & \multicolumn{1}{|c|}{$\begin{array}{c}\text { Average number of } \\
\text { handovers using } \\
\text { conventional algorithm }\end{array}$} & $\begin{array}{c}\text { Average number of } \\
\text { handovers using } \\
\text { fuzzy algorithm }\end{array}$ \\
\hline \hline 5 & 27.8910 & 10.2050 \\
\hline 10 & 7.8500 & 3.8980 \\
\hline 15 & 3.1570 & 2.0190 \\
\hline
\end{tabular}

Table 4.1: Comparison of the number of handovers with Rayleigh fading 


\begin{tabular}{|l|l|l|}
\hline Averaging distance $(\mathrm{m})$ & \multicolumn{1}{|c|}{$\begin{array}{c}\text { Average number of } \\
\text { handovers using } \\
\text { conventional algorithm }\end{array}$} & $\begin{array}{c}\text { Average number of } \\
\text { handovers using } \\
\text { Fuzzy Algorithm }\end{array}$ \\
\hline \hline 5 & 58.2800 & 31.8770 \\
\hline 10 & 17.1070 & 8.9370 \\
\hline 15 & 7.0260 & 4.1980 \\
\hline
\end{tabular}

Table 4.2: Comparison of the number of handovers with shadowing parameter $S=6 \mathrm{~dB}$

\begin{tabular}{|l|l|l|}
\hline Averaging distance $(\mathrm{m})$ & \multicolumn{1}{|c|}{$\begin{array}{c}\text { A rerage number of } \\
\text { handovers using } \\
\text { conventional algorithm }\end{array}$} & $\begin{array}{c}\text { Average number of } \\
\text { handovers using } \\
\text { fuzzy algorithm }\end{array}$ \\
\hline \hline 5 & 81.5310 & 67.7100 \\
\hline 10 & 24.7340 & 17.1230 \\
\hline 15 & 10.3650 & 6.7590 \\
\hline
\end{tabular}

Table 4.3: Comparison of the number of handovers with shadowing parameter $S=9 \mathrm{~dB}$ 


\begin{tabular}{|l|l|l|}
\hline Averaging distance $(\mathrm{m})$ & \multicolumn{1}{|c|}{$\begin{array}{c}\text { Average number of } \\
\text { handovers using } \\
\text { conventional algorithm }\end{array}$} & $\begin{array}{c}\text { Average number of } \\
\text { handovers using } \\
\text { fuzzy algorithm }\end{array}$ \\
\hline \hline 5 & 99.7780 & 94.7490 \\
\hline 10 & 31.4530 & 27.2260 \\
\hline 15 & 13.3660 & 10.5070 \\
\hline
\end{tabular}

Table 4.4: Comparison of the number of handovers with shadowing parameter $S=12 \mathrm{~dB}$

\begin{tabular}{|l|l|l|}
\hline Shadowing parameter $(\mathrm{dB})$ & \multicolumn{1}{|c|}{$\begin{array}{c}\text { Increment using } \\
\text { conventional algorithm } \\
(\times 100 \%)\end{array}$} & $\begin{array}{c}\text { Increment using } \\
\text { fuzzy algorithm } \\
(\times 100 \%)\end{array}$ \\
\hline \hline 6 & 2.09 & 3.12 \\
\hline 9 & 2.92 & 6.63 \\
\hline 12 & 3.58 & 9.28 \\
\hline
\end{tabular}

Table 4.5: Percentage increase of the number of handovers over Rayleigh fading 


\subsubsection{Evaluation of short term handovers}

Further investigations into quality of handover reveal that most of the handovers, especially around the boundary of the two cells, occ:ur within a short distance interval from the occurrence of the previous handover.

Figure 4.22 shows bar graph of the number of handovers in a Rayleigh fading channel when using conventional algorithm for different intervals. The results indicate that many handovers occur in the interval shorter than ten meters and fewer handovers last for large intervals. When compared with the results using fuzzy algorithm shown in figure 4.23 it is also observed that most of the handovers are in the interval less than $10 \mathrm{~m}$. However. the total number handovers is smaller compared to the results with conventional algorithm.

Figures $4.24,4.26$ and 4.28 show the total number of handovers for different intervals with shadowing parameters $S=6,9$ and $12 \mathrm{~dB}$ using conventional algorithm. The results alsu indicate that many handovers are concentrated in the intervals of less than $10 \mathrm{~m}$. The results using fuzzy algorithm are shown in figures $4.25,4.27$ and 4.29 in which the number of handovers is smaller compared to conventional algorithm. 


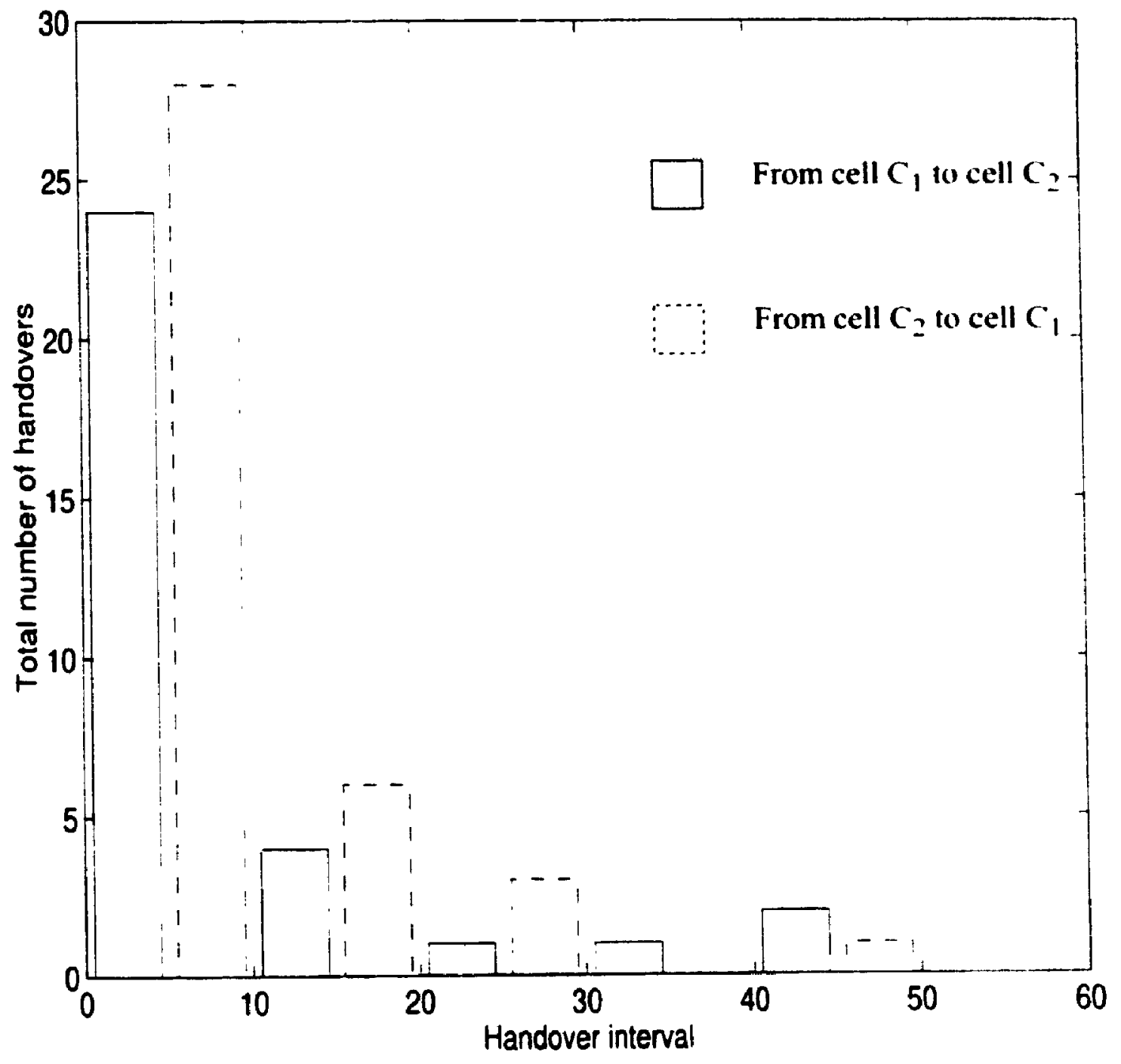

Figure 4.22 Handovers for different intervals with Rayleigh fading using conventional algorithm 


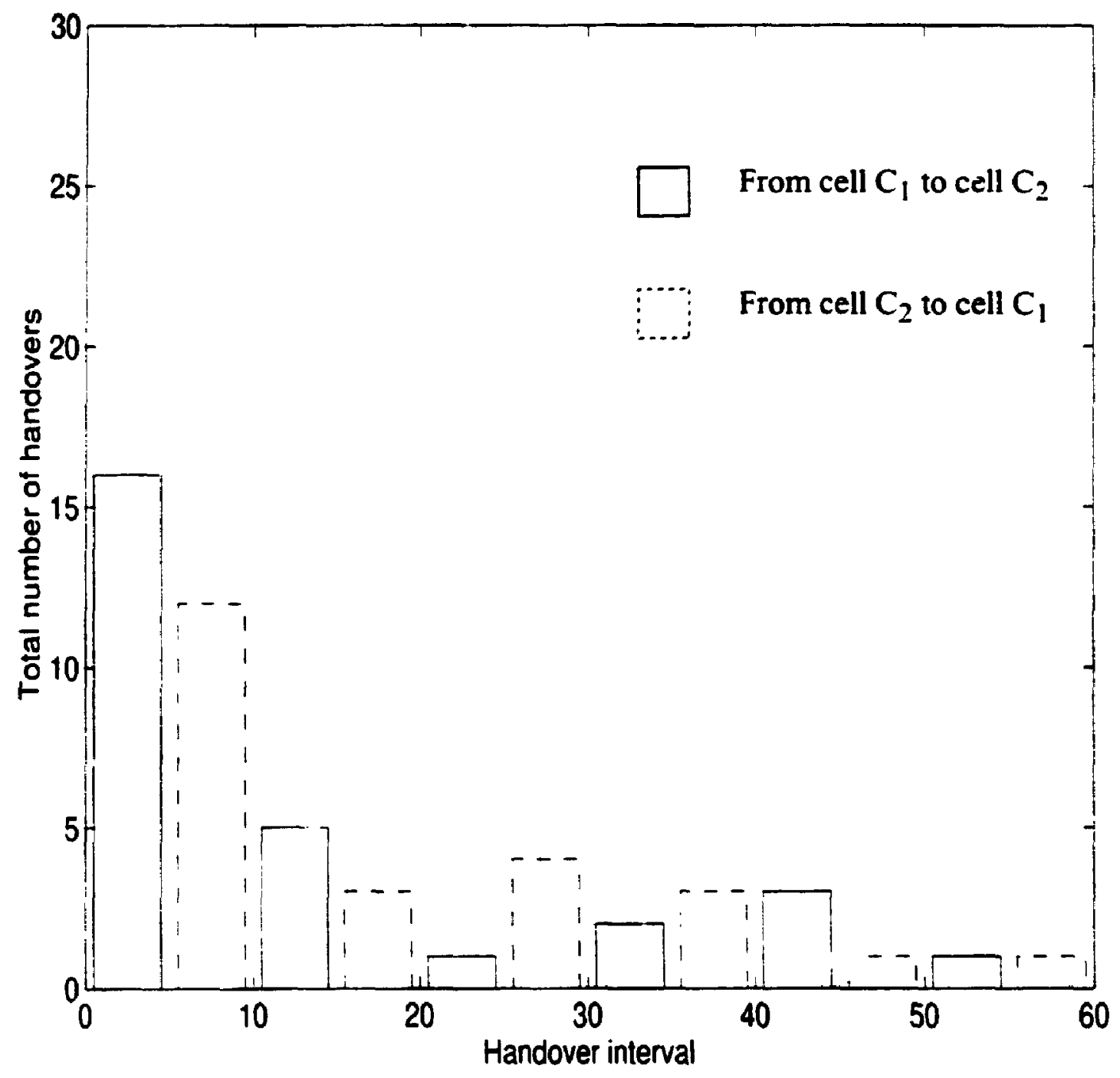

Figure 4.23 Handovers for different intervals with Rayleigh fading using fuzzy algorithm 


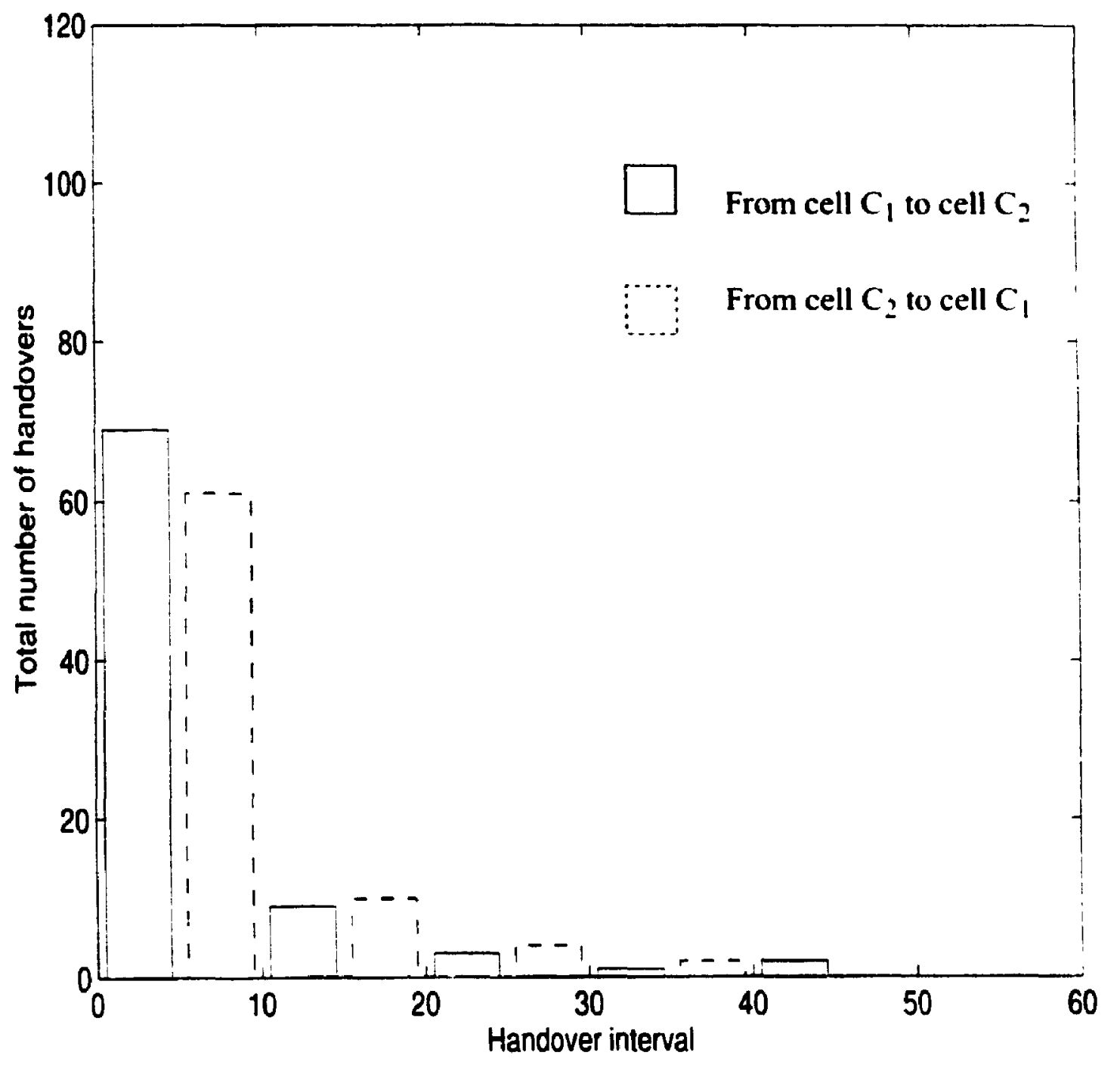

Figure 4.24 Handovers for different intervals using conventional algorithm with shadowing parameter $S=6 \mathrm{~dB}$ 


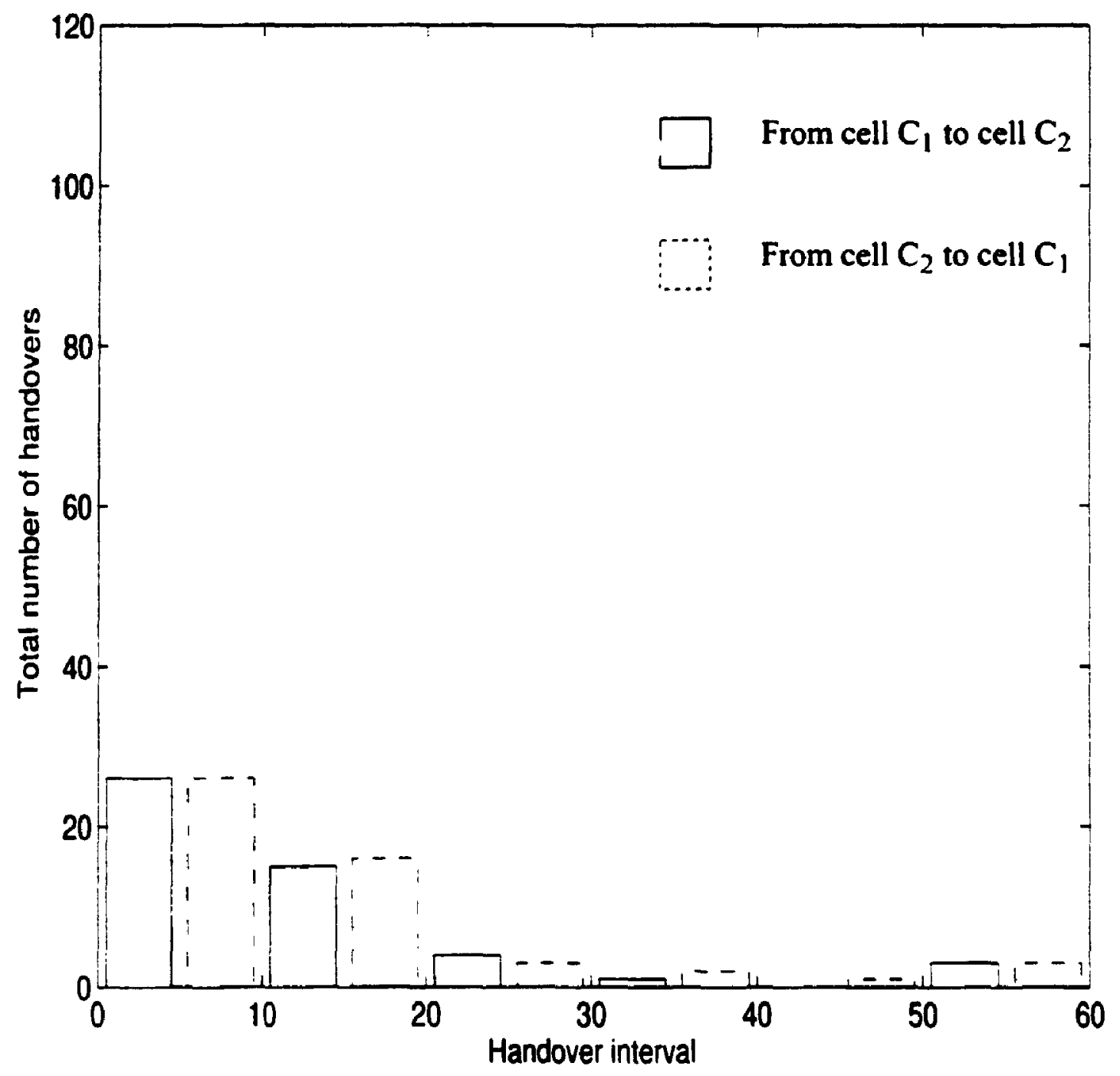

Figure 4.25 Handovers for different intervals using fuzzy algorithm with shadowing parameter $S=6 \mathrm{~dB}$ 


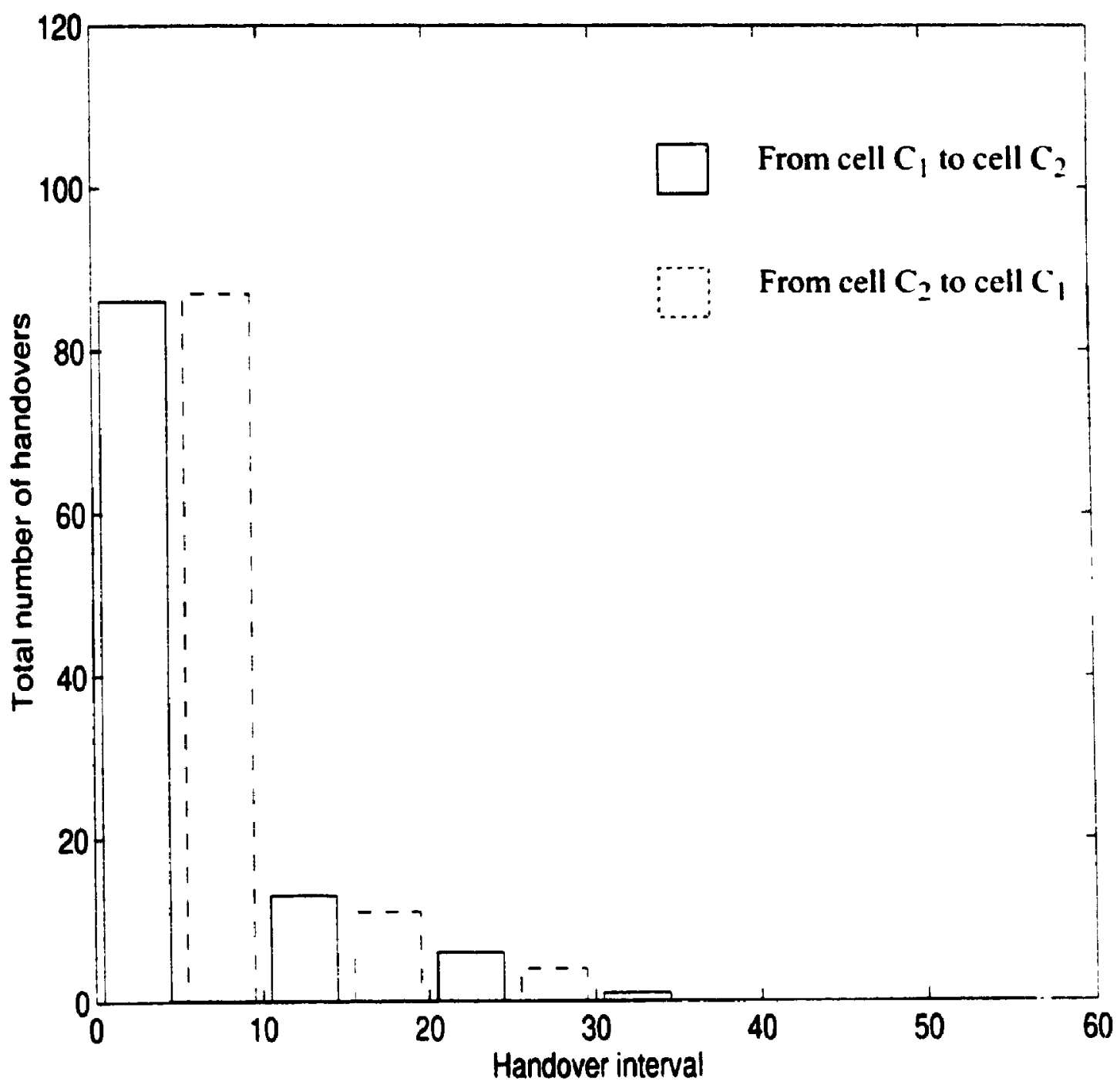

Figure 4.26 Handovers for different intervals using conventional algorithm with shadowing parameter $\mathrm{S}=9 \mathrm{~dB}$ 


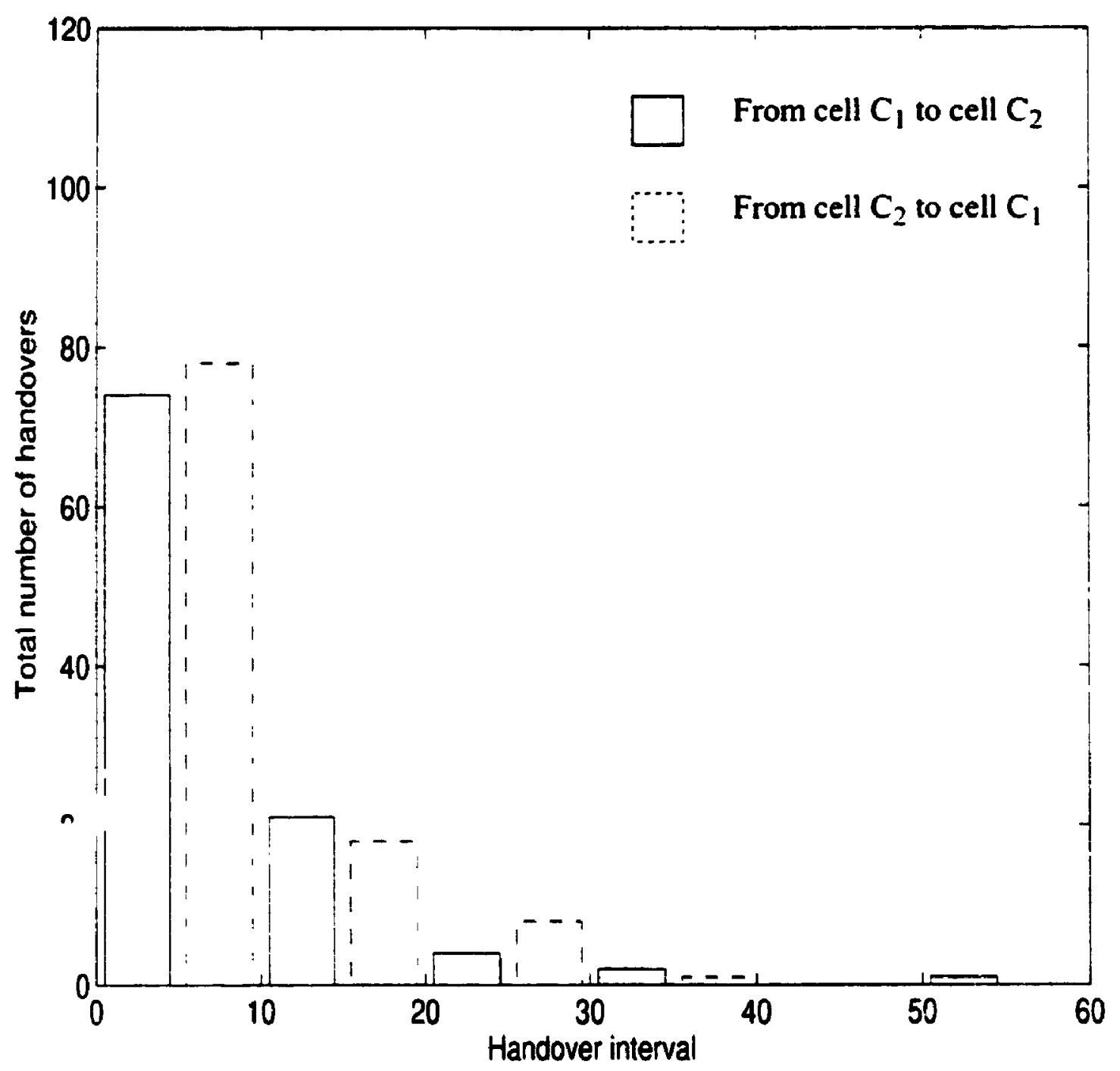

Figure 4.27 Handovers for different intervals using fuzzy algorithm with shadowing parameter $\mathrm{S}=9 \mathrm{~dB}$ 


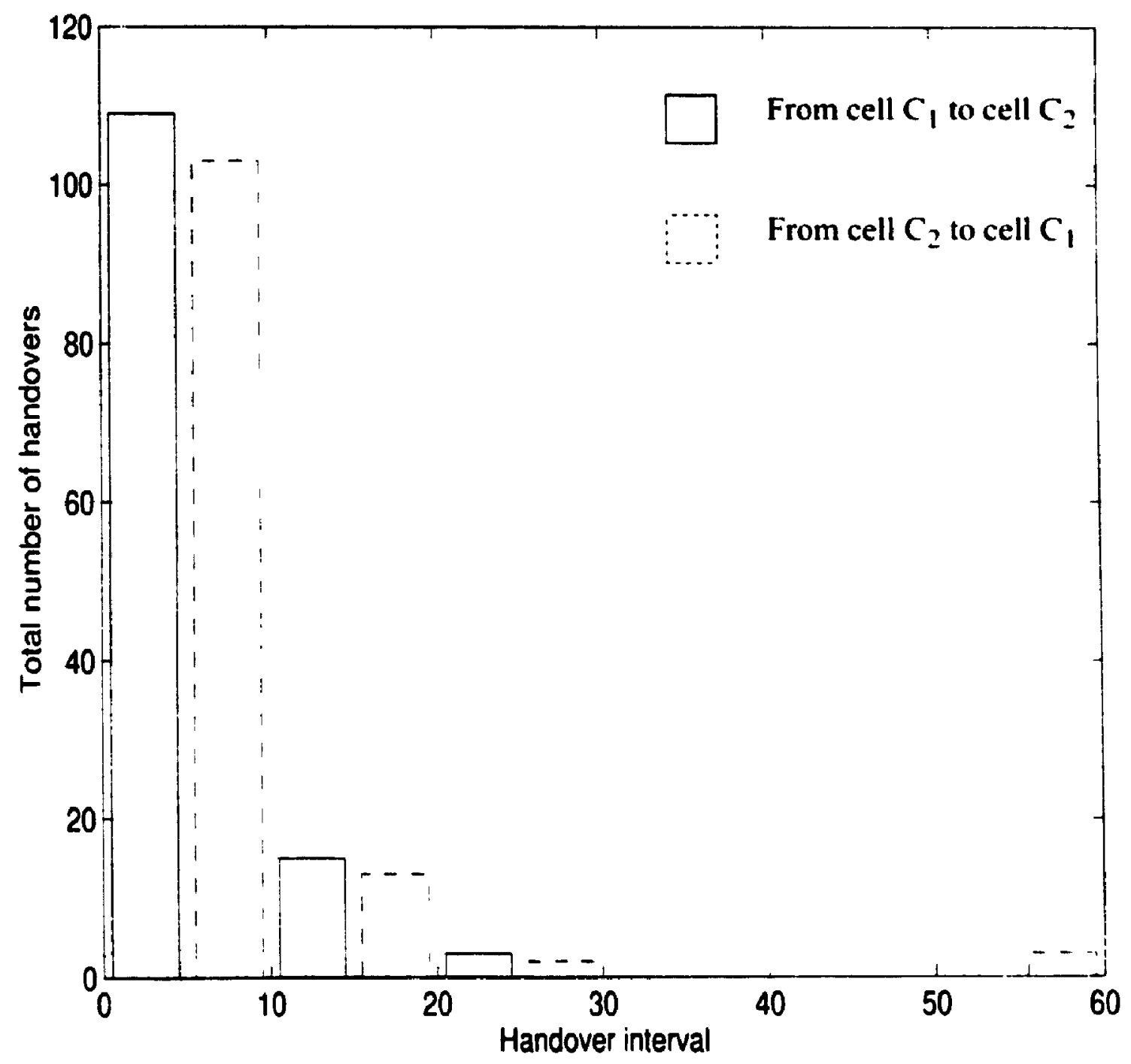

Figure 4.28 Handovers for different intervals using conventional algorithm with shadowing parameter $S=12 d B$ 


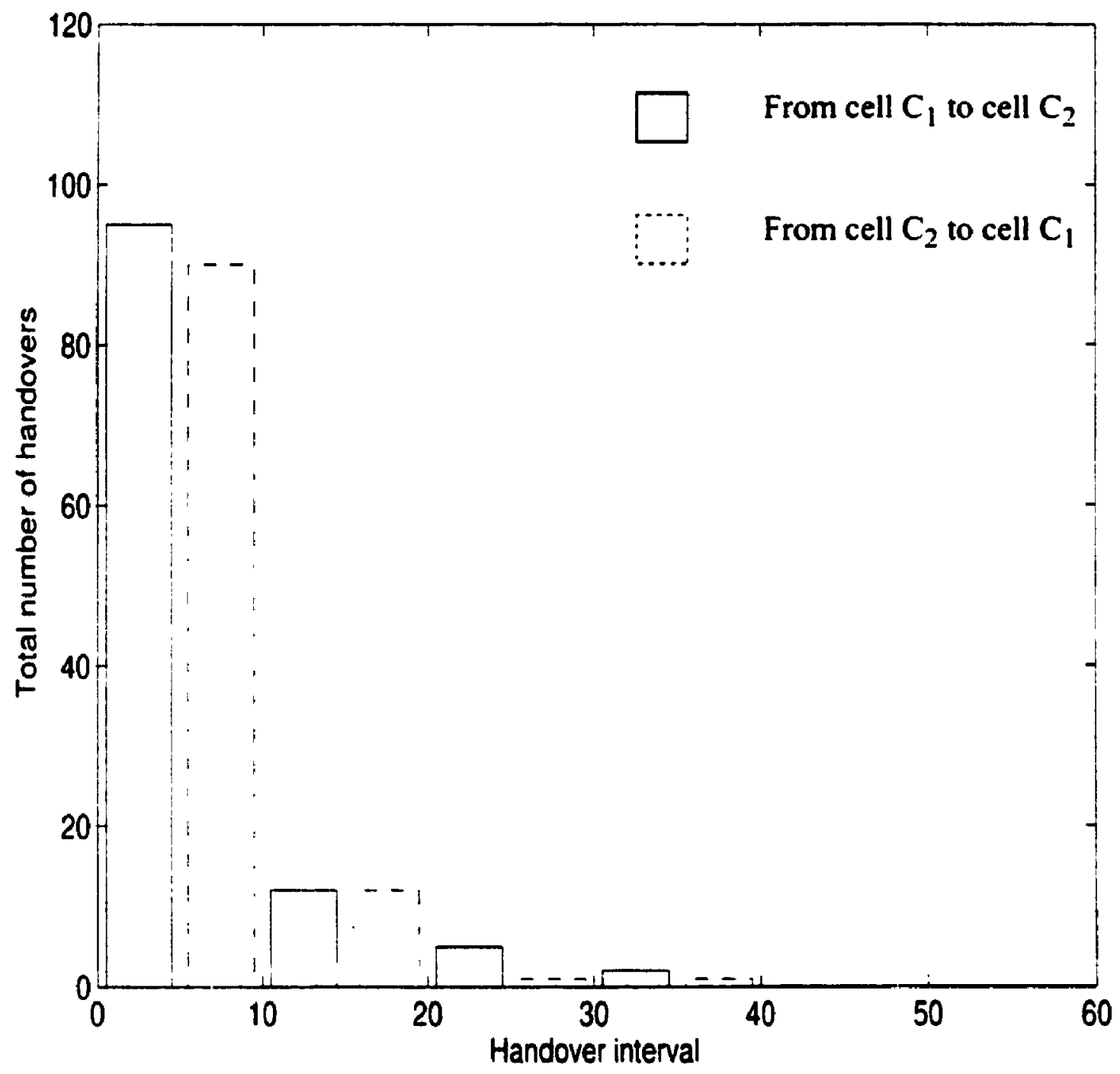

Figure 4.29 Handovers for different intervals using fuzzy algorithm with shadowing parameter $S=12 \mathrm{~dB}$ 
To illustrate the distribution of handovers in the intervals. handovers which occur in the interval of less than $10 \mathrm{~m}$ are referred to as short term handovers. Handovers which occur in the other intervals greater than $10 \mathrm{~m}$ are considered as long term handovers.

Figure 4.30 (a) shows the distribution of short term handovers using conventional algorithm in a Rayleigh fading environment. The results indicate a significantly large number of handovers at the boundary of two cells which is around $1 \mathrm{~km}$ distance from cell $C_{1}$. Figure 4.30 (b) shows the distribution of long term handovers using conventional algorithm in a Rayleigh fading environment. The results indicate the number of handovers is very small around the boundary of two cells.

Figure 4.31 shows the short term and long term handovers using fuzzy algorithm in a Rayleigh fading environment. The number of short term handovers is observed to be smaller compared to figure 4.30 (a) when conventional algorithm is used. The results also indicate the number of handovers is small in both short term and long term intervals.

Figures $4.32,4.33,4.34,4.35,4.36$ and 4.37 show the distribution of long term and short term handovers in a shadowing environment. The results show that a large number of short term handovers is observed to be spread around the boundary of two cells when using conventional algorithm. The spreading is found to be significant for shadowing parameter of 9 and $12 \mathrm{~dB}$. The results using fuzzy algorithm indicate less number of short term handovers for shadowing parameter $S=6 \mathrm{~dB}$. However, for shadowing parameter $S=9$ and $12 \mathrm{db}$ a large number of short term handovers is observed. This indicate fuzzy algorithm is more susceptible to higher shadowing parameters. 
Furthermore, these bar graphs show that with fuzzy algorithm, the long term handovers can occur anywhere in the cell and are not concentrated in the boundary region. It can also be observed that when using conventional algorithm as shown in figures $4.32,4.34$ and 4.36, long term handovers are fewer around the boundary region and show a significant peak over a certain distance from the boundary. The location of the peak where maximum number of handovers is observed is seen to be moving further from the boundary region when the shadowing parameter is increased. This is attributed to the effect of narrow area median due to shadowing where the mean of the signal is shifted and becomes very low at certain points causing a number of handovers to occur. In the case when fuzzy algorithm is used as shown in figures $4.33,4.35$ and 4.37 , the handovers are found to be evenly distributed because fuzzy algorithm remove the effect of the mean of the signal. 


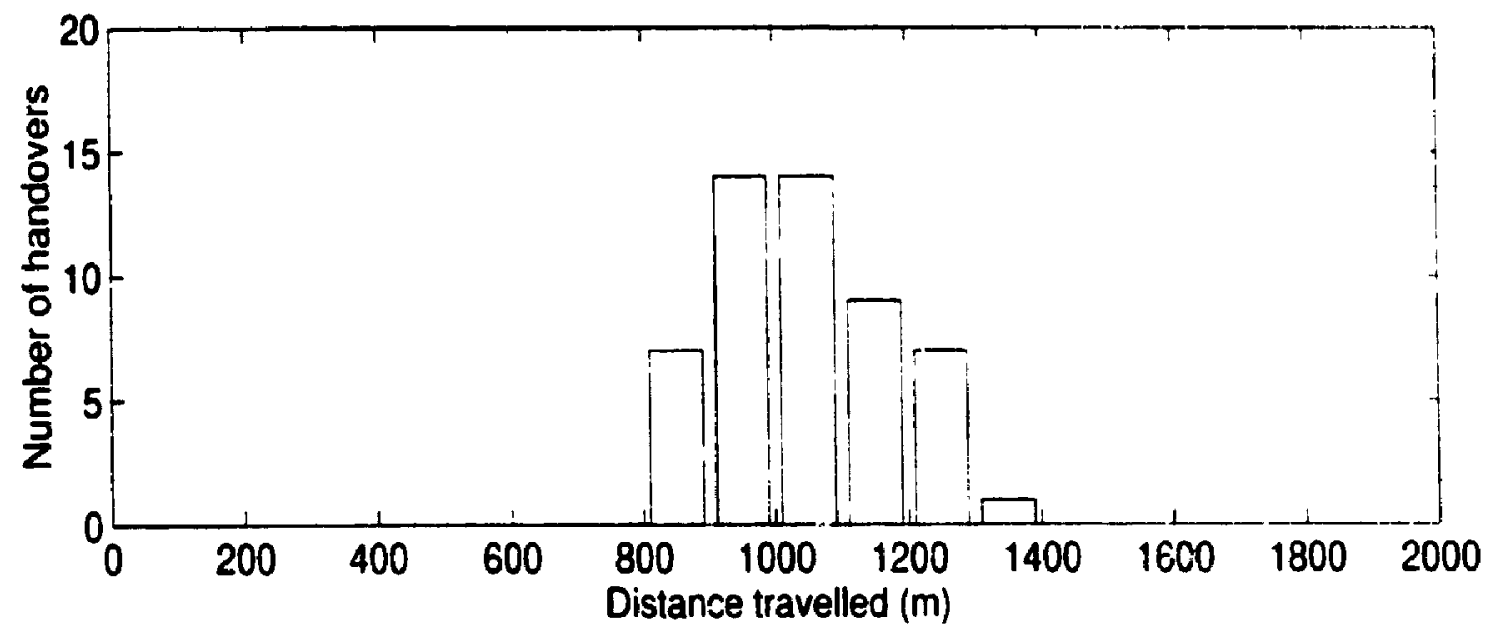

(a)

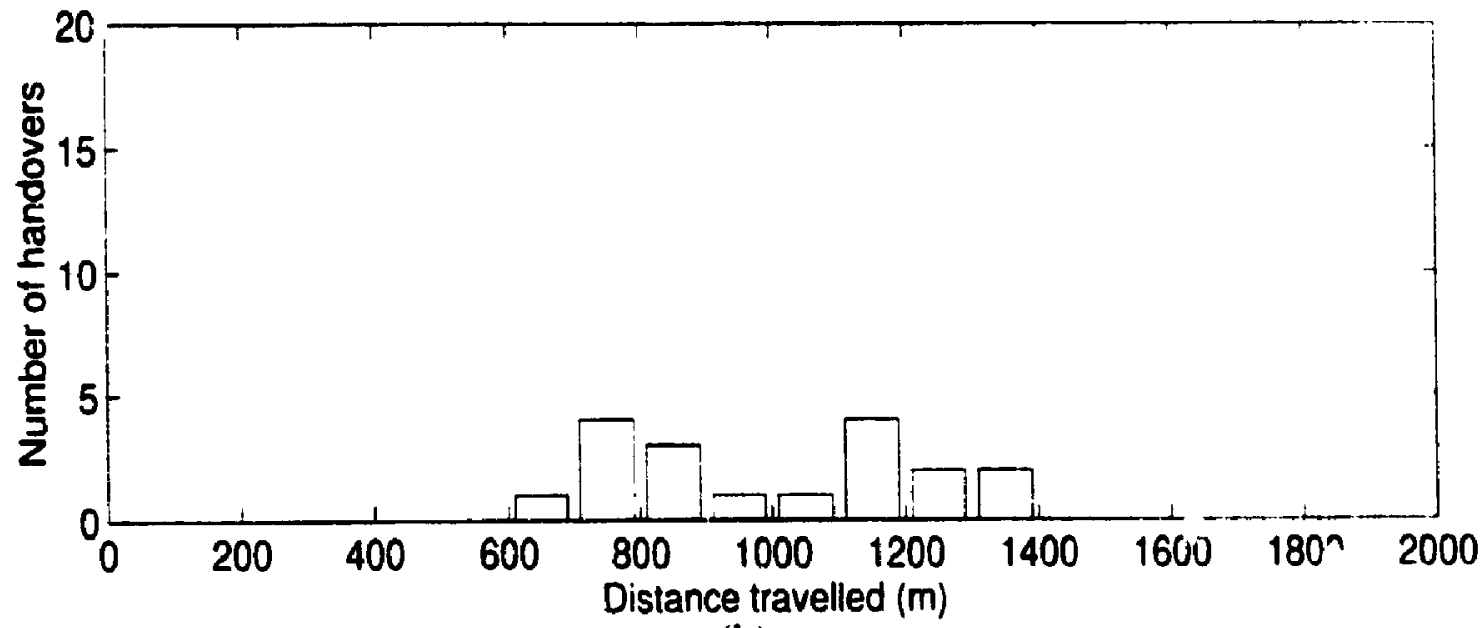

(b)

Figure 4.30 (a) Short term (b) long term handovers with Rayleigh fading using conventional algorithm 

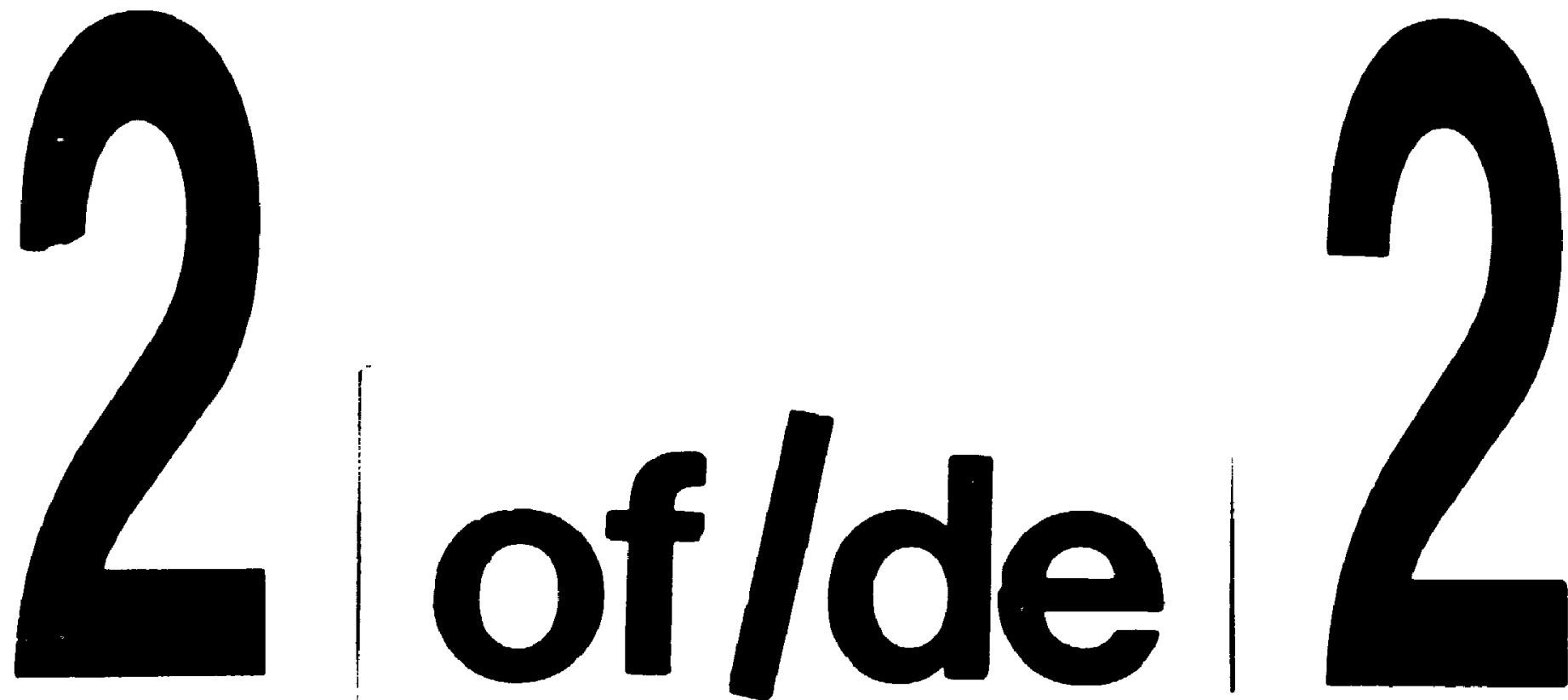

PM. $13 \frac{1}{2} " x 4^{\prime \prime}$ PHOTOGRAPHIC MICAOCOPY TARGET NES 1010a ANSIIISO "2 EQUIVALENT

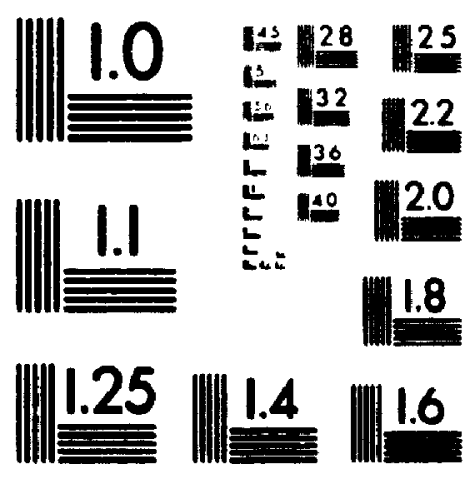

PRECISION"M RESOLUTION TARGETS 


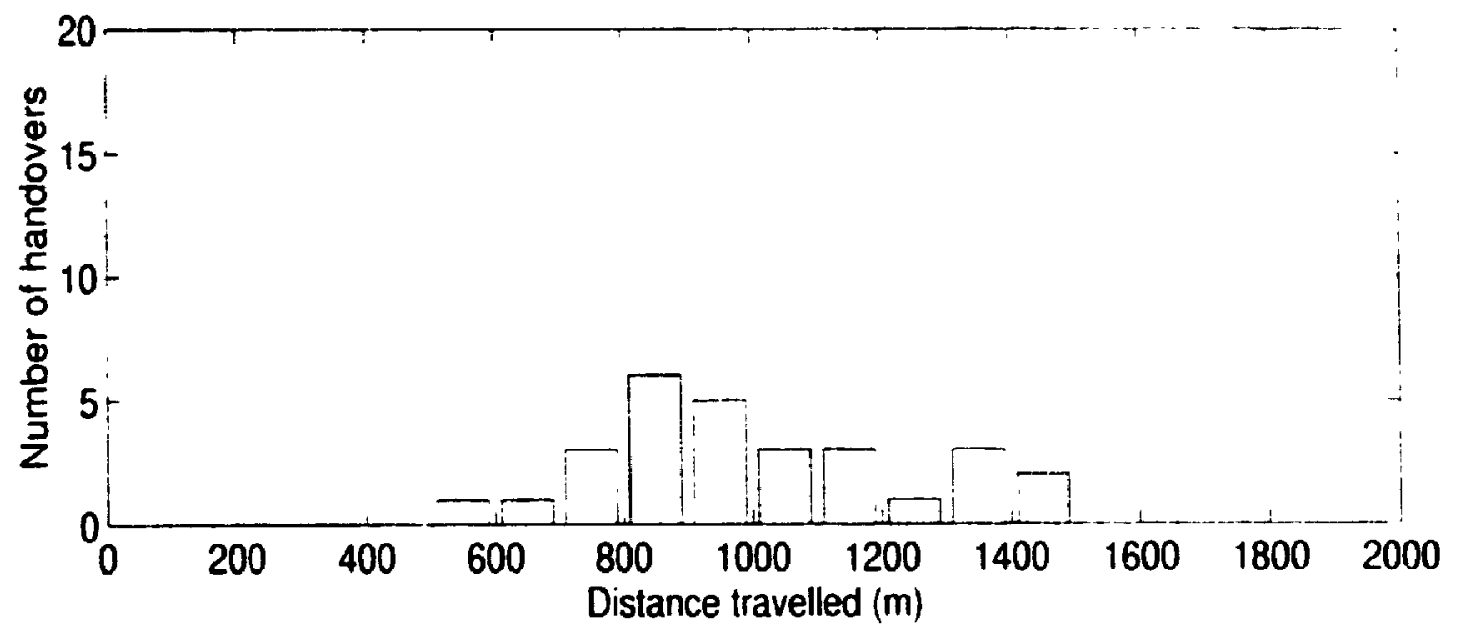

(a)

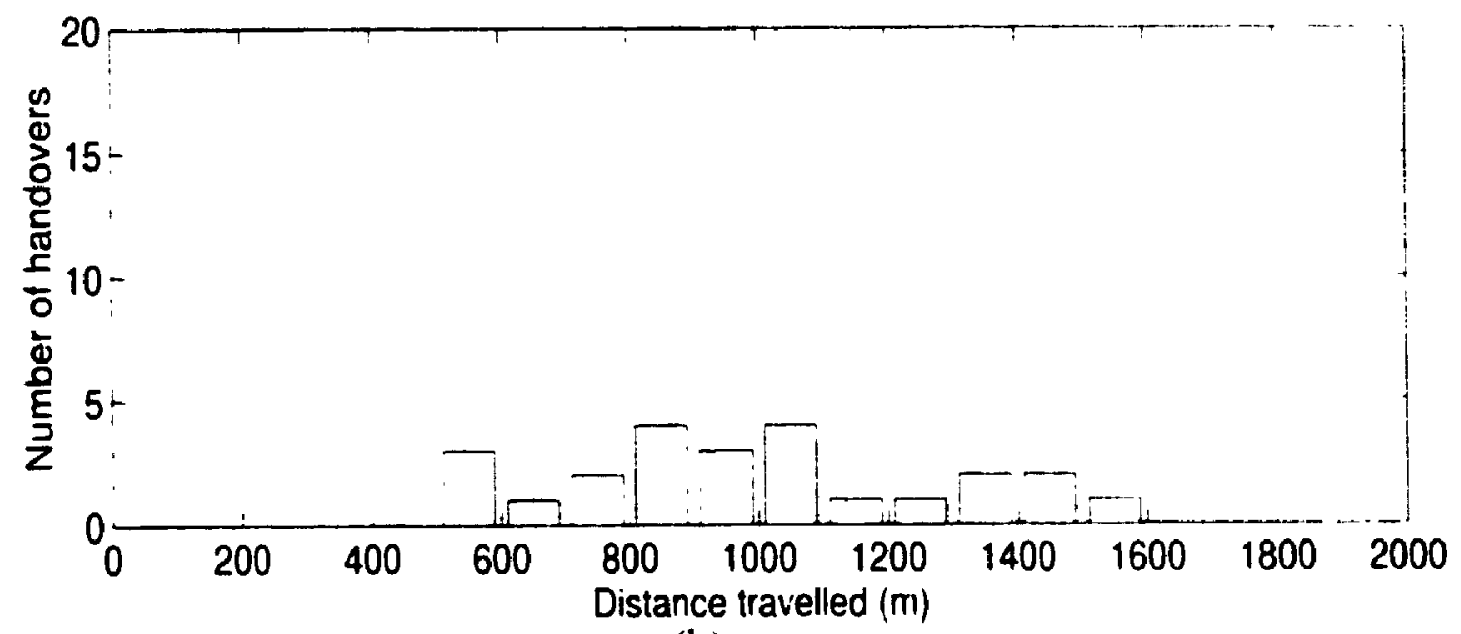

(b)

Figure 4.31 (a) Shon term (b) long term handovers with Rayleigh fading using fuzzy algorithm 


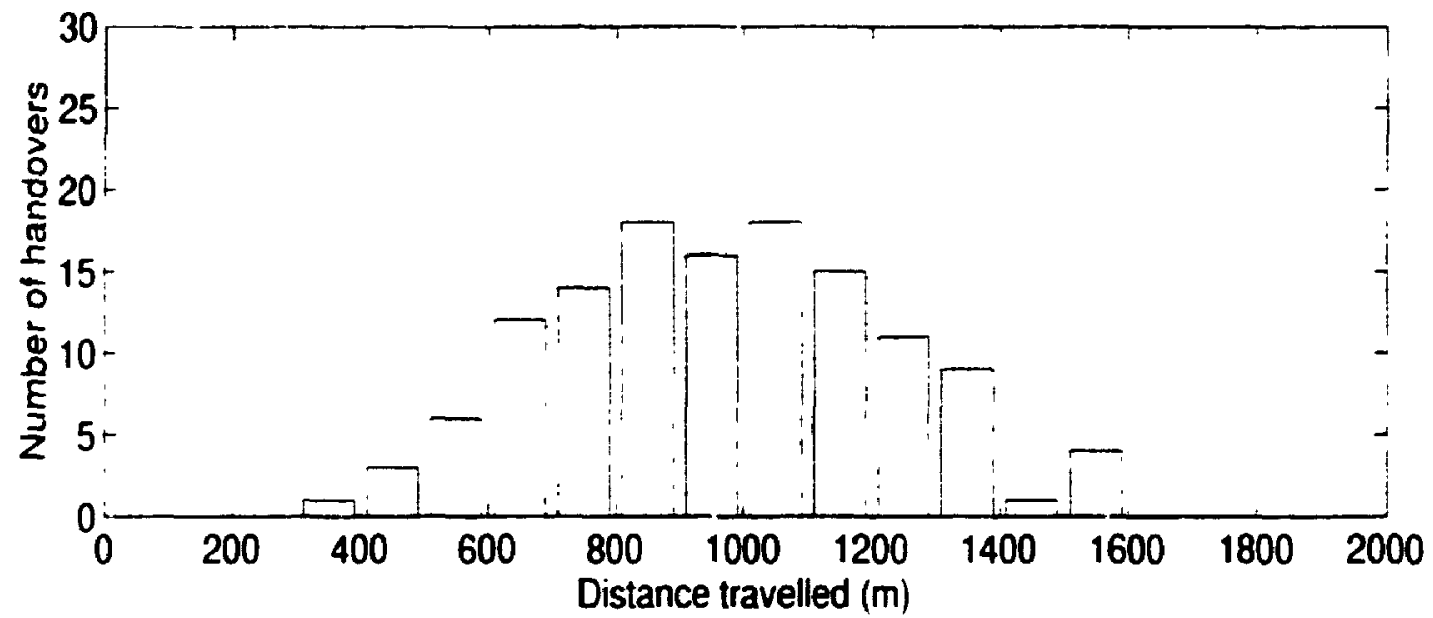

(a)

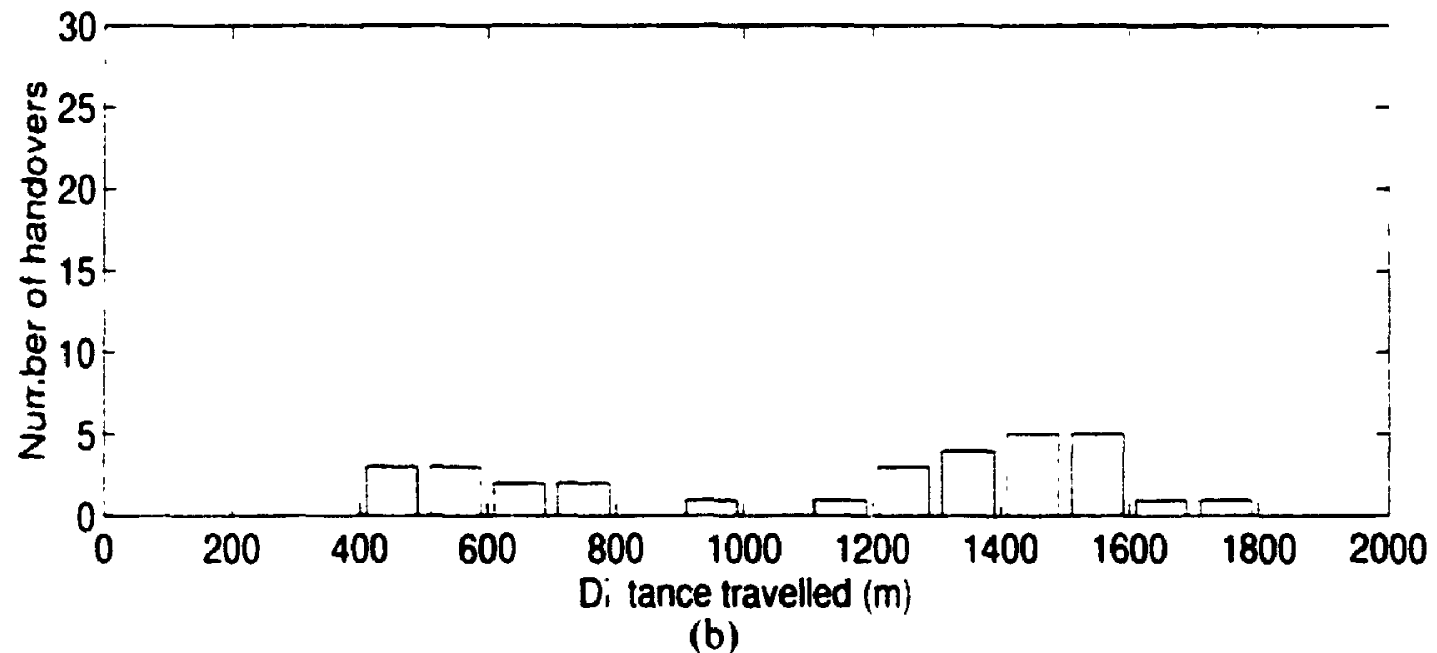

Figure 4.32 (a) Shon term (b) long term handovers using conventional algorlthm for shadowing parameter $S=6 \mathrm{~dB}$ 


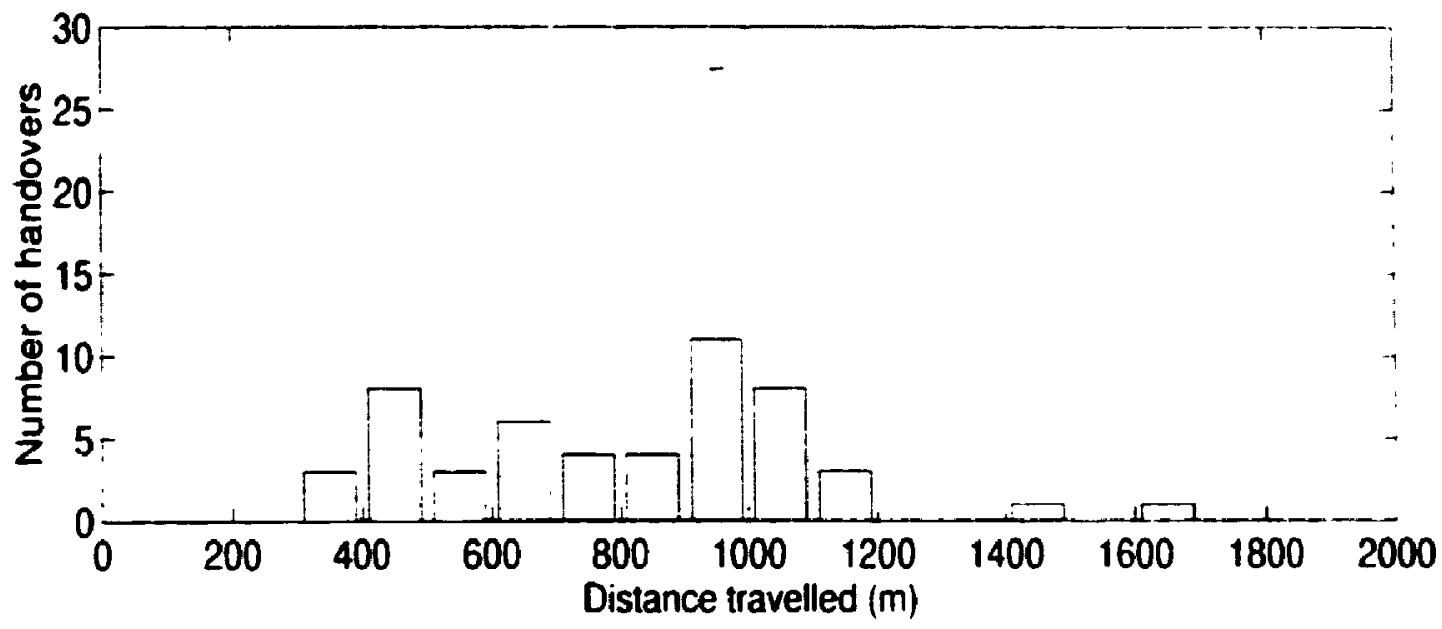

(a)

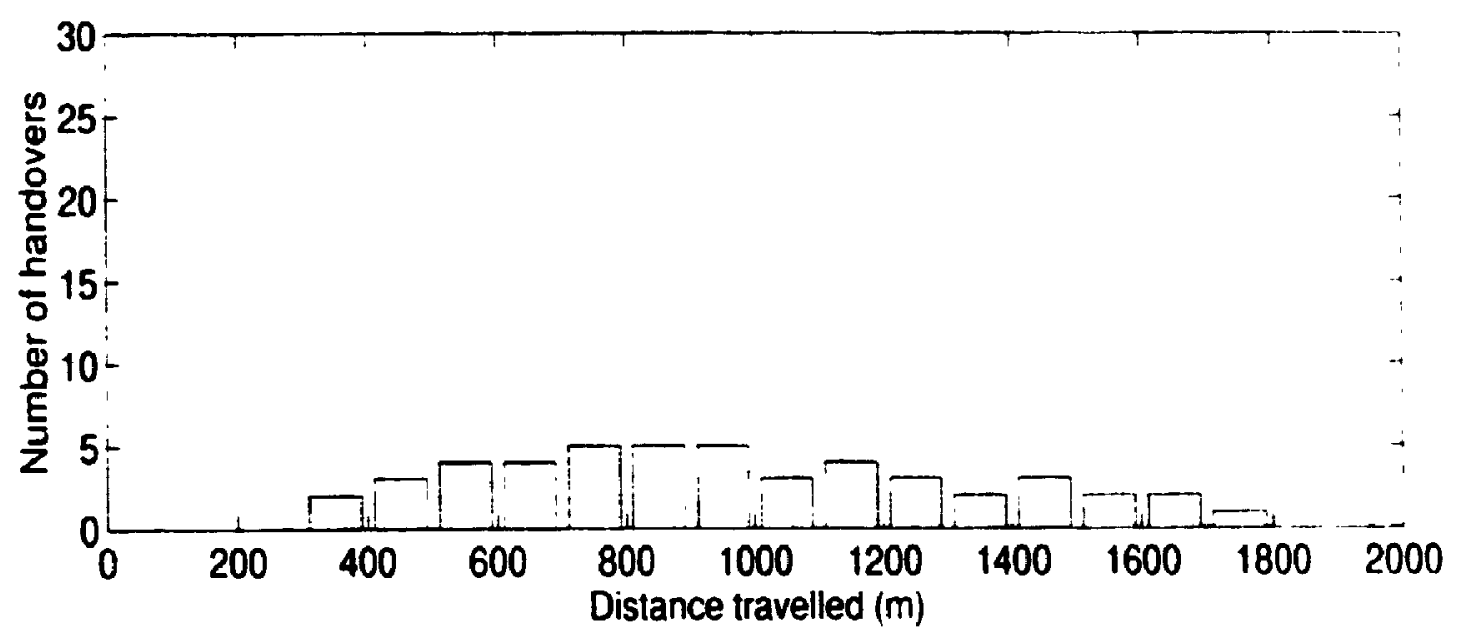

(b)

Figure 4.33 (a) Short term (b) long term handovers using fuzzy algorithm for shadowing parameter $S=6 \mathrm{~dB}$ 


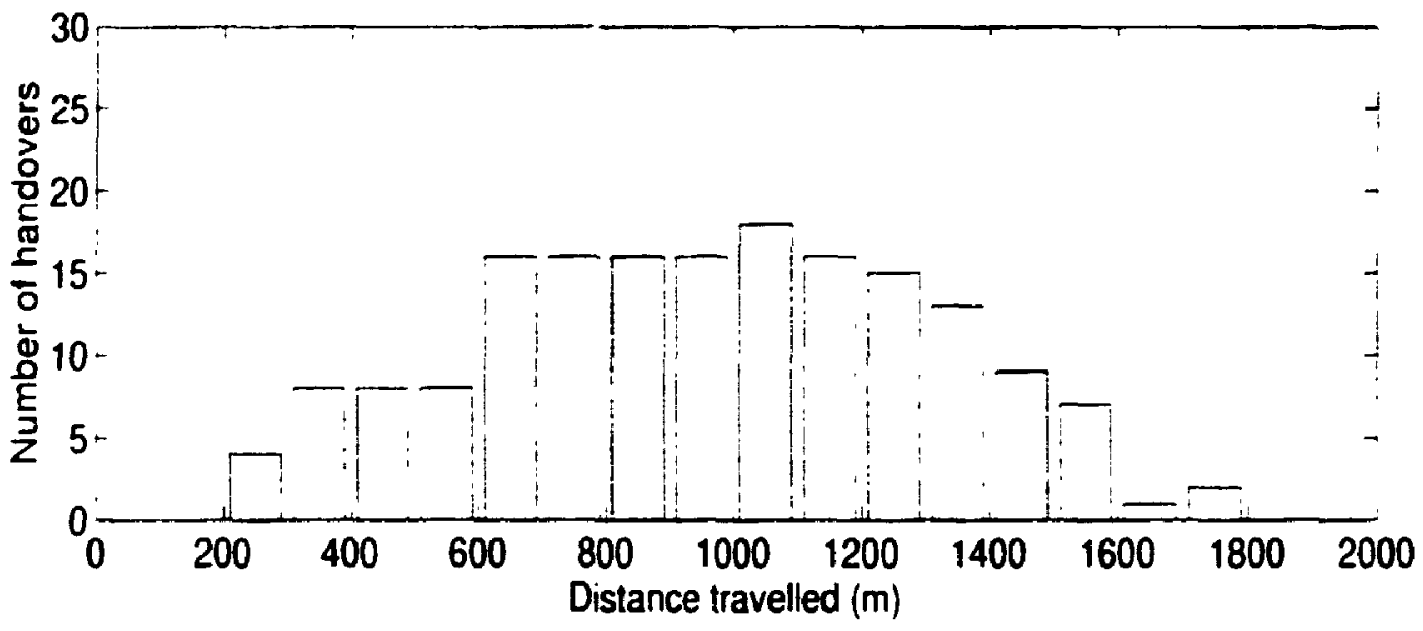

(a)

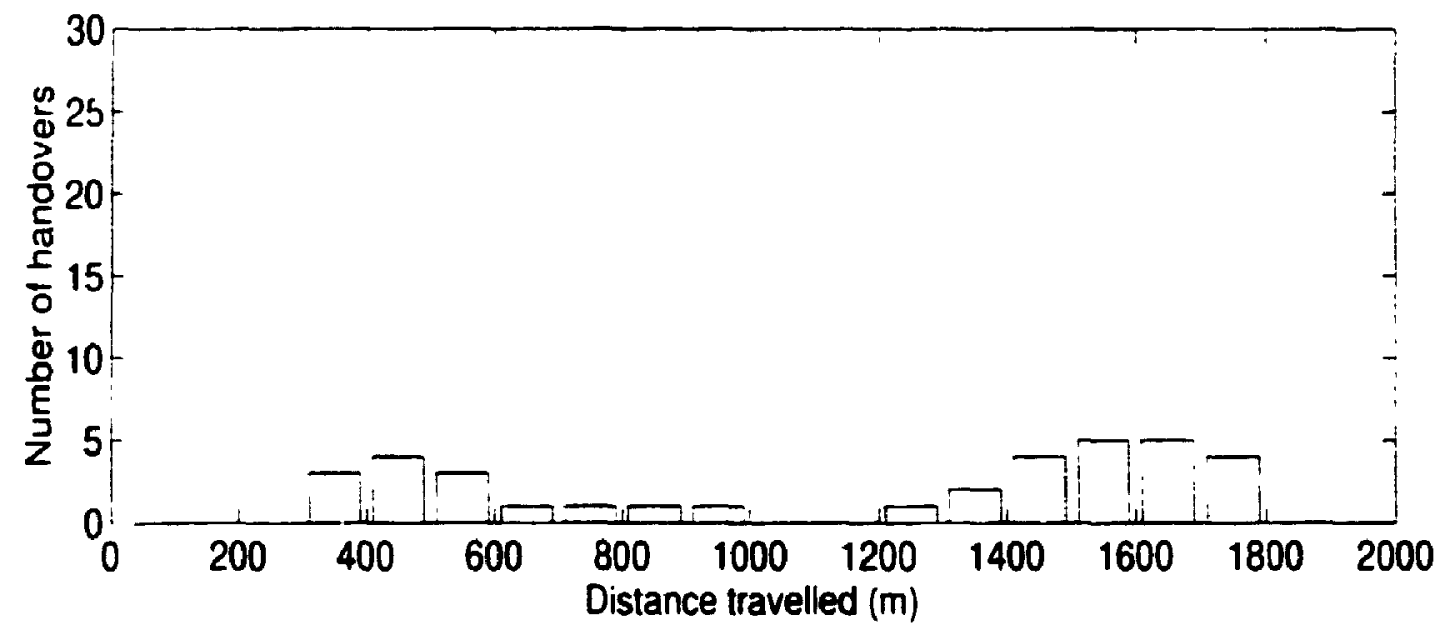

(b)

Figure 4.34 (a) Short term (b) long term handovers using conventional algorithm for shadowing parameter $S=9 d B$ 


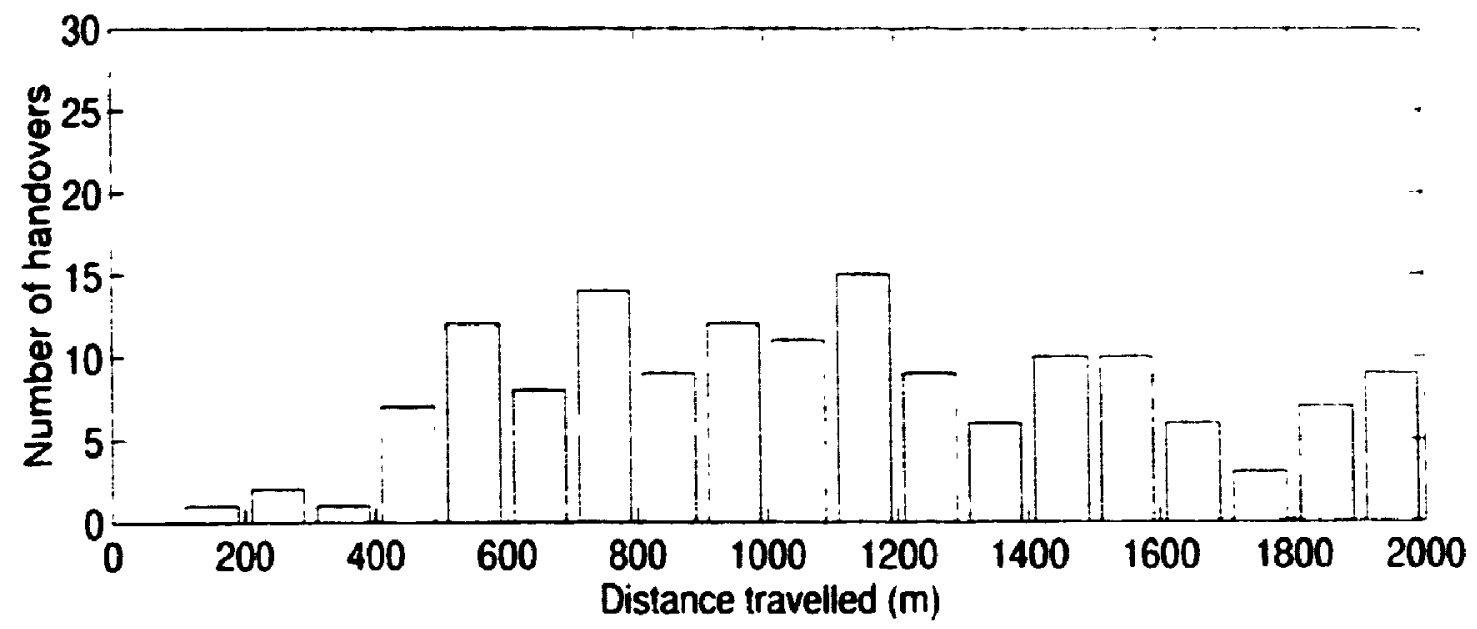

(a)

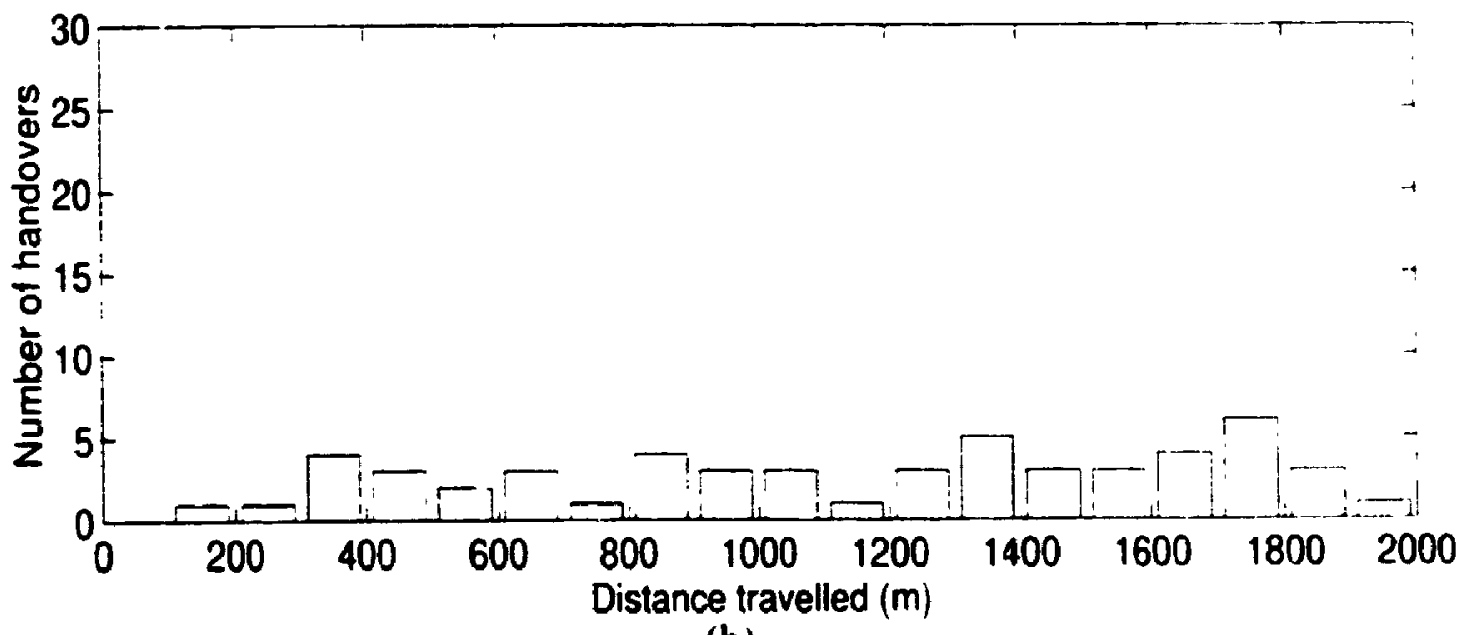

(b)

Figure 4.35 (a) Short term (b) long term handovers using fuzzy algorithm for shadowing parameter $\mathbf{S}=\mathbf{9 d B}$ 


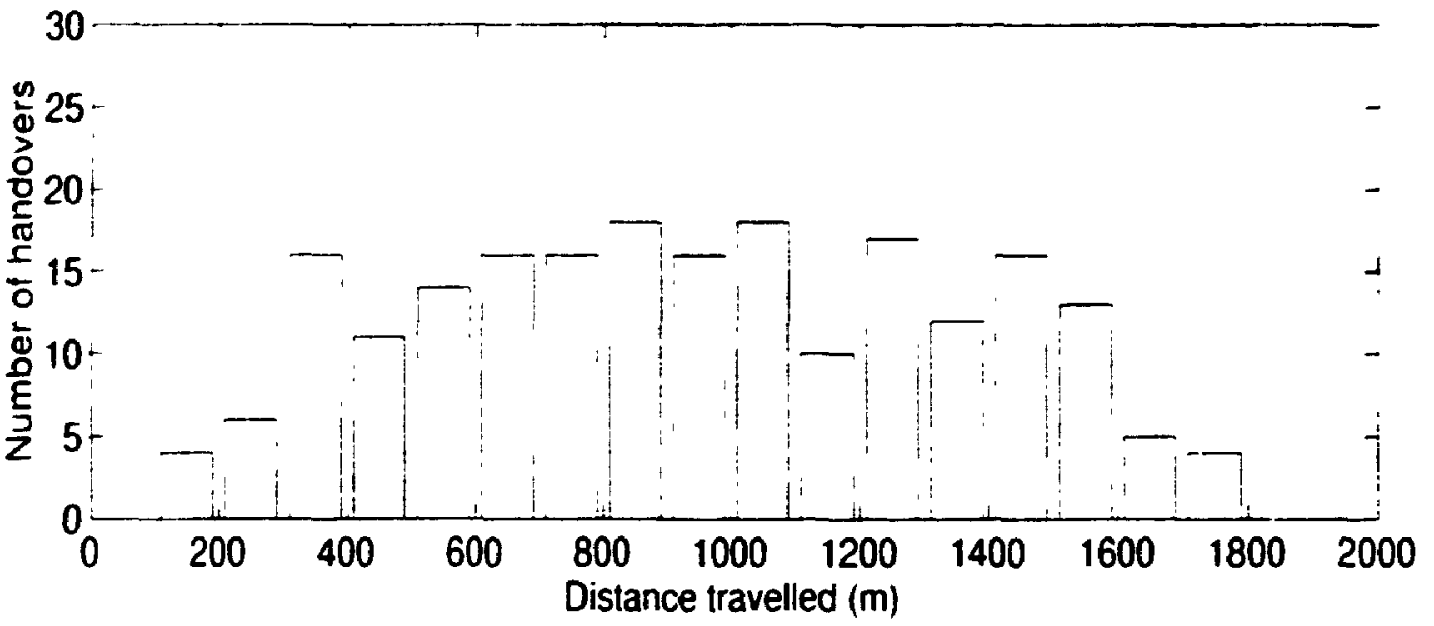

(a)

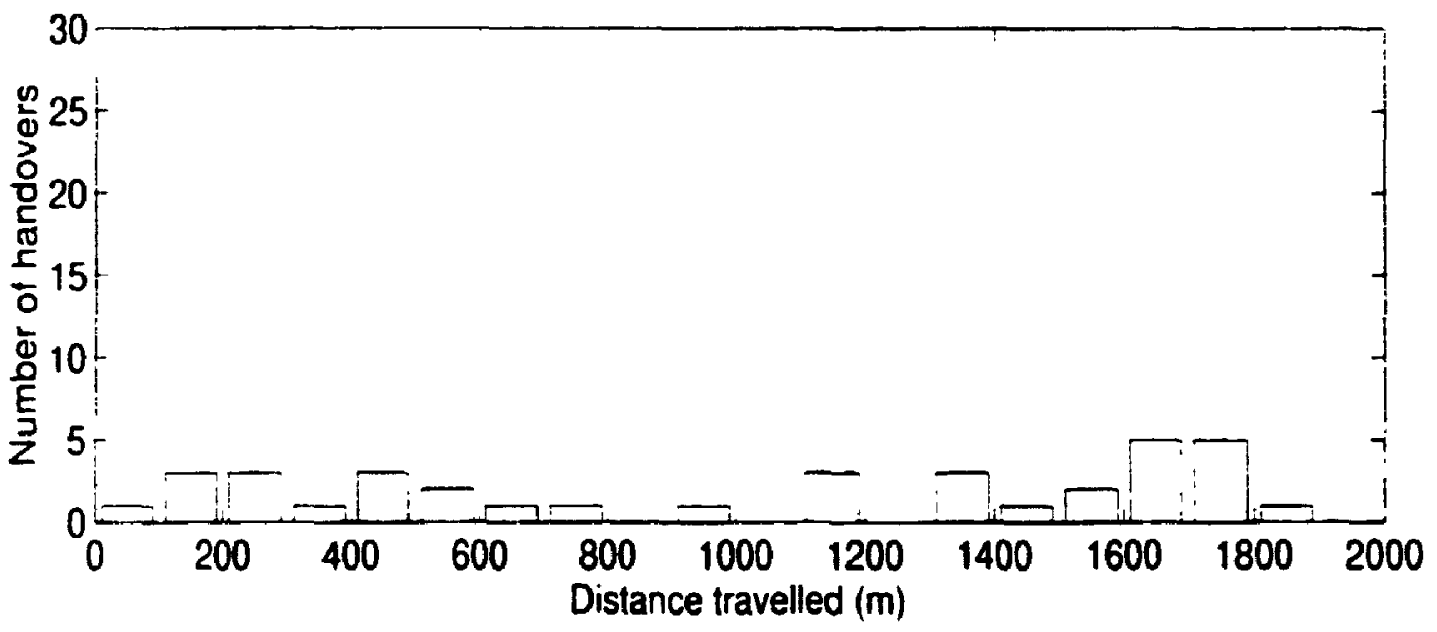

(b)

Figure 4.36 (a) Short term (b) long term handovers using conventional algorithm for shadowing parameter $S=12 \mathrm{~dB}$ 


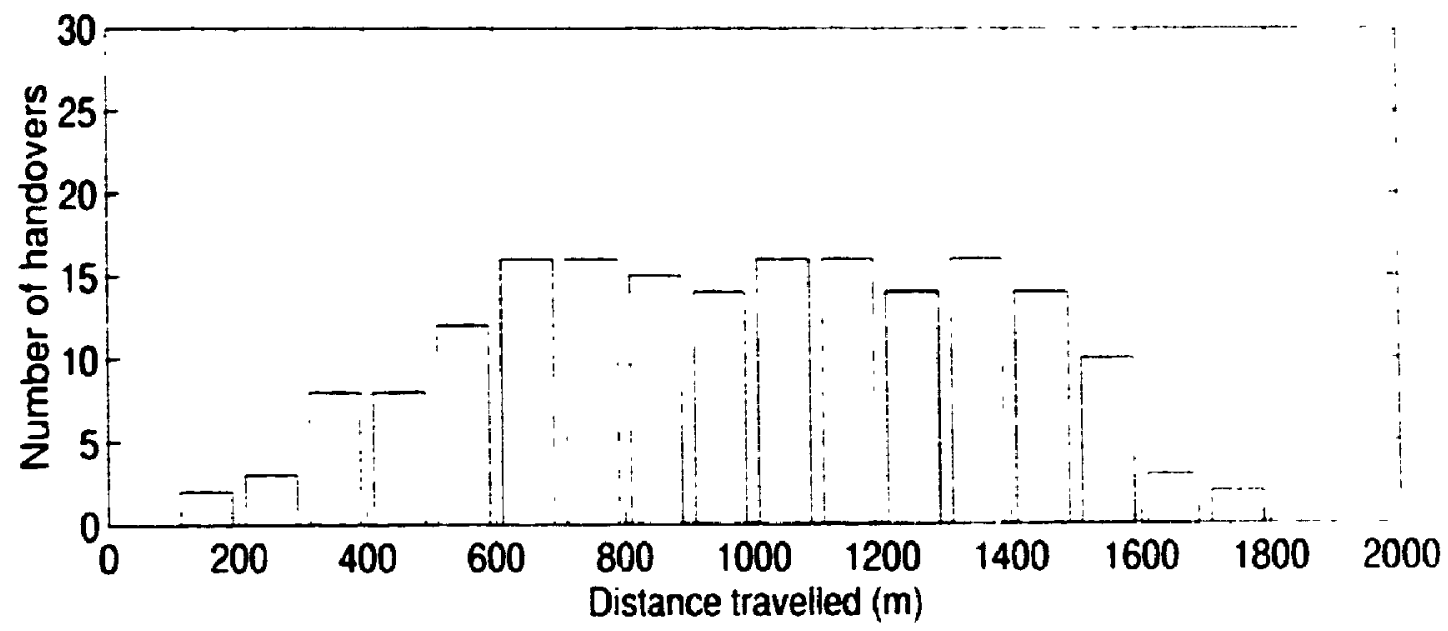

(a)

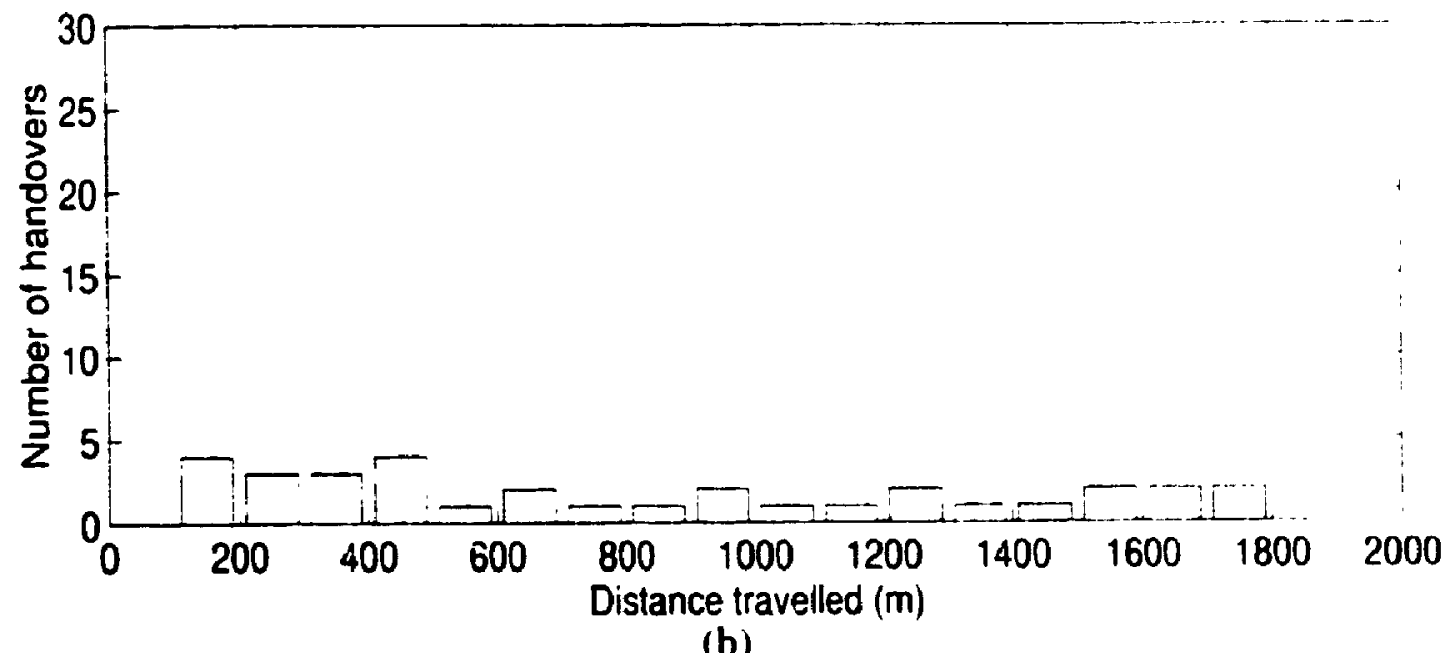

(b)

Figure 4.37 a) Short term (b) long term handovers using fuzzy algorithm for shadowing parameter $S=12 \mathrm{~dB}$ 


\subsection{Performance with signal strength and $\mathrm{CIR}$}

The signal strength measurements were obtained as described in section 4.1.1. CIR measurements were obtained using procedure described in section 4.1.2. In conventional algorithm using CIR measurements it is assumed that handover occurs when the CIR measurement falls below a specified factor which is termed as the protection ratio. The simulations were performed for protection ratios $R=6.9 .12$. and $18 \mathrm{~dB}$. In using fuzzy technique. the membership functions of signal strength and CIR were evaluated and combined using algebraic operation. The decision for handover is based on the combined membership function i.e if $\mu_{\mathrm{r}}$ is the membership function of the signal strength measurement and $\mu_{C}$ is the membership function of the CIR measurement. the combined membership function $\mu_{T}$ is given by

$$
\mu_{r}=\mu_{s}-\mu_{C}-\mu_{s} \mu_{C}
$$

The performance was assessed by investigating the number of handovers for different shadowing parameters.

Figure 4.38 shows the results using conventional algorithm for signal strength measurements. Figure 4.39 shows the results obtained with CIR measurements using conventional algorithm. The results using combined membership function are shown in figure 4.40 and it can be observed that the number of handovers is significantly reduced when compared to tigures 4.38 and 4.39 . The results also indicate low average number of handovers is obtained for protection ratio $R=6$ and $9 \mathrm{~dB}$ and therefore these will be suitable values to be used in the handover process. 


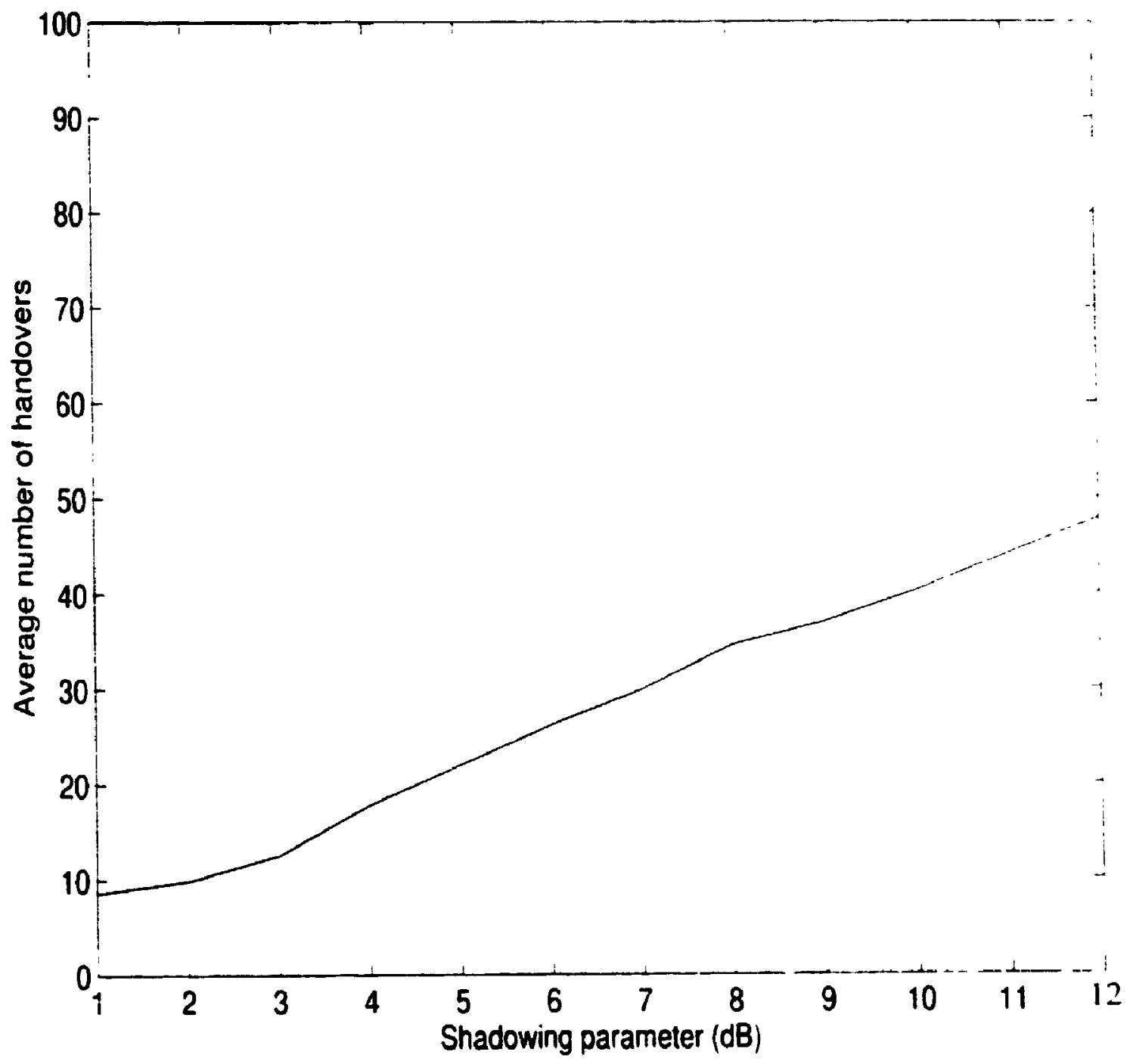

Fi,_lre 4.38 Handover variation with shadowing using conventional algorithm for signal strength measurements. 


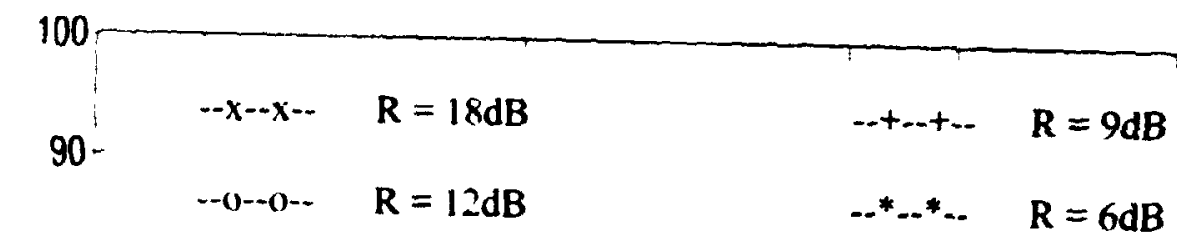

$80-$

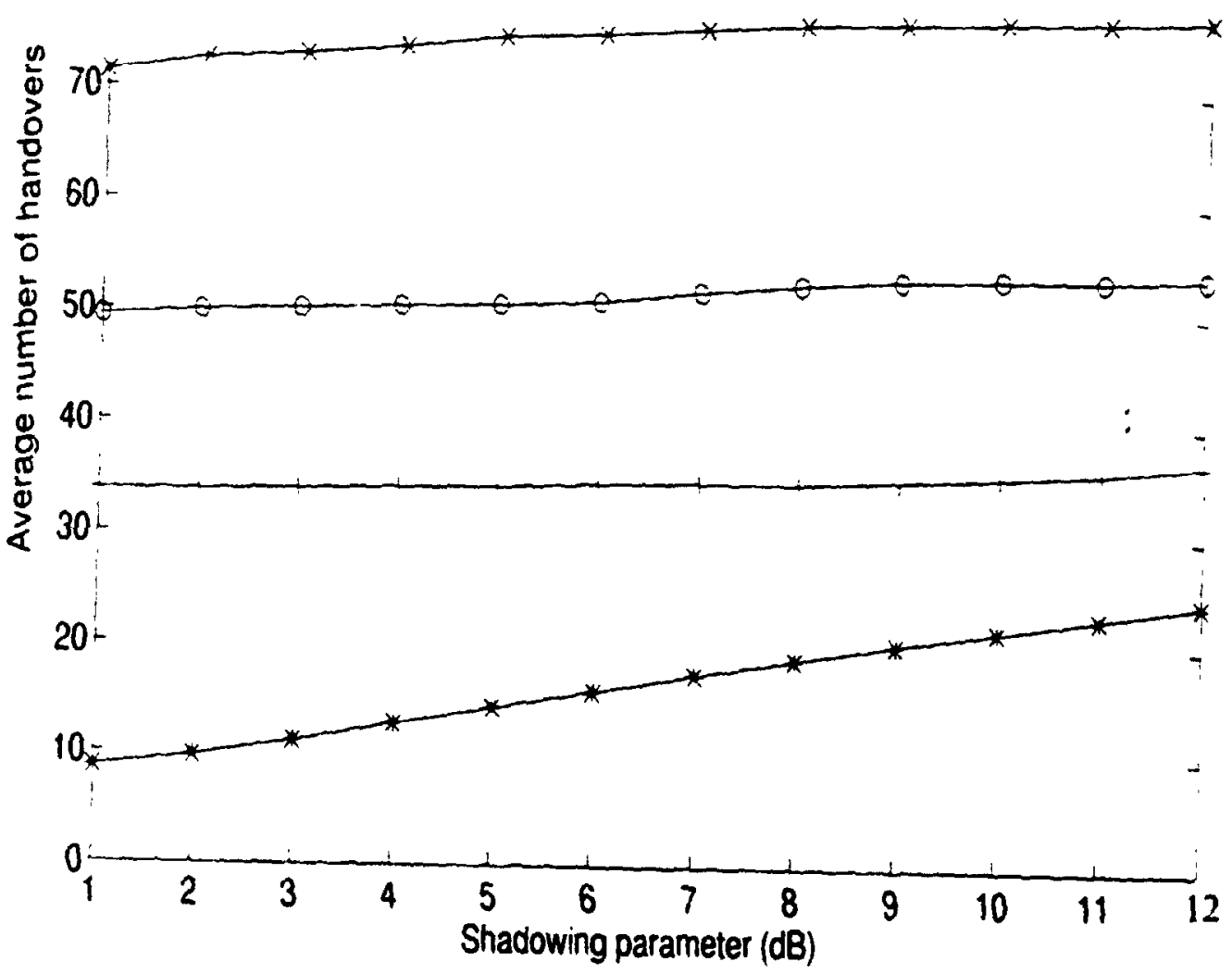

Figure 4.39 Mandover variation with shadowing using conventional algorithm for CIR measurements 


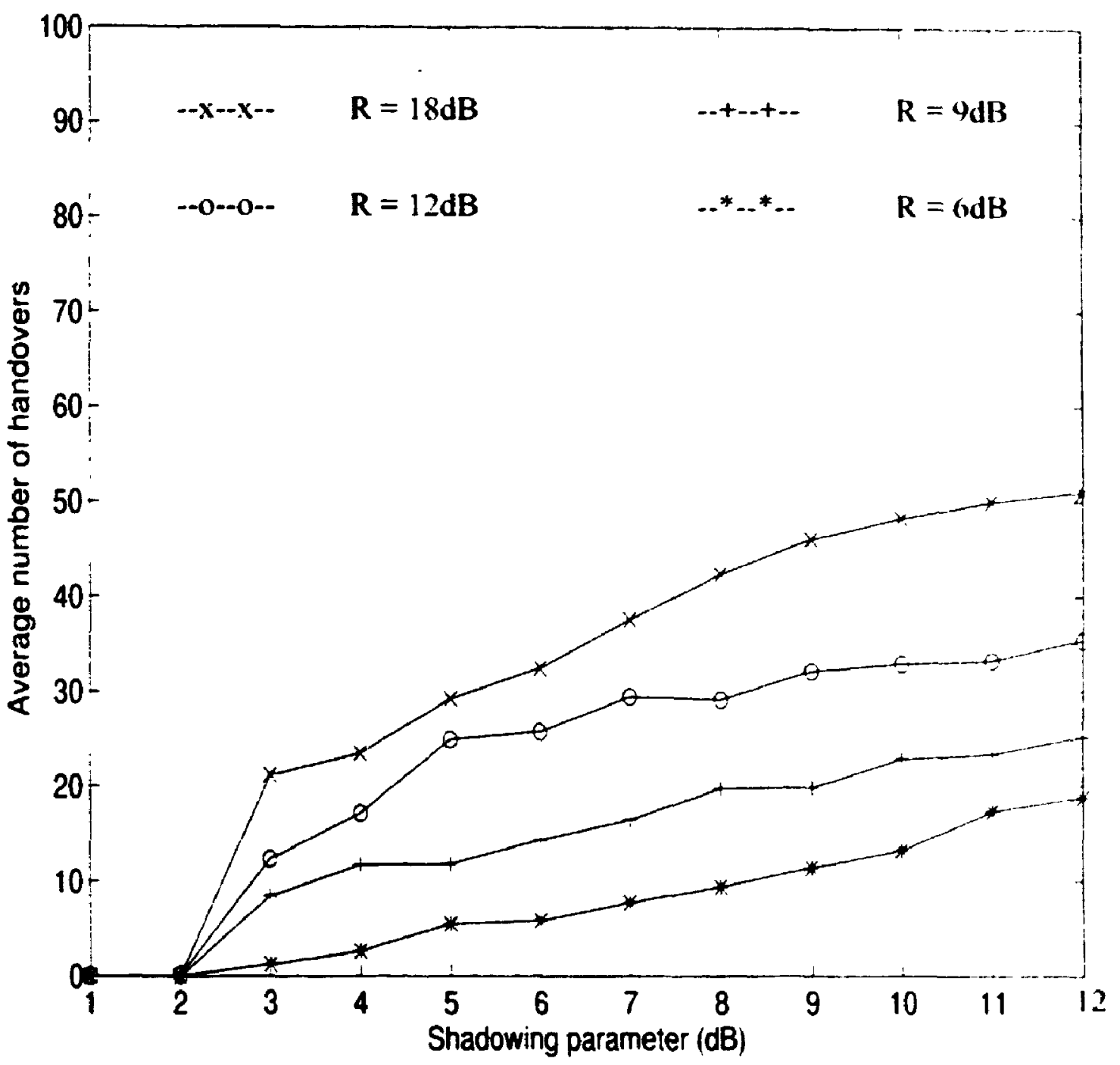

Figure 4.40 Handover variation with shadowing for combined signal strength and CIR measurements using fuzzy techniques 
The results presented in this chapter have demonstrated the improvement obtained in the performance of handover process when fuzzy algorithm is used. The results indicate fuzzy algorithm allows the reduction of the number of handovers in the Rayleigh fading environment. Significant reduction is observed in the boundary region where a large number of handovers is concentrated when using conventional algorithm. Average number of handovers was reduced to approximately $63 \%$. The algorithm also provides improvement in shadowing which is found to be very significant for a shadowing parameter $S=6 \mathrm{~dB}$. The reduction of approximately $48 \%$ was observed for a shadowing parameter $S=6 \mathrm{~dB}$ and averaging distance of $10 \mathrm{~m}$ "Horeover. fuzzy algorithm indicates better performance with fewer number of handovers as compared to the conventional algorithm with hysteresis. In addition. the results also indicate fuzzy techniques can be used for two decision parameter such as signal strength and CIR when the two decision parameters show the requirement for handover at the same time. The results show a better performance for protection ratios $R=6$ and $9 \mathrm{~dB}$. 


\section{Chapter 5}

\section{Conclusions}

\subsection{Conclusions}

This thesis research examined the handover process applicable to the future wireless technology for the development of Universal PCS. Handover processes using exısting algorithms investigated in this thesis show inability to control a large number of handovers. Therefore, a new fuzzy algorithm is proposed to provide improvement in the performance of handover process. The results show' that fuzzy algorithm is capable of reducing a large number of handovers occurring in the cell boundary which is the target arca for handovers.

An overview of handover process is provided in chapter 2 in which service concept and control procedure are described. Chapter 3 introduces the concept of fuzzy logic and describes some operations and its applications. One of the main application in the theory of fuzzy logic is in pattern recognition from which fuzzy algorithm implemented in this thesis emerged.

The performance was evaluated in Rayleigh fading environment with several shadowing parameters. It has been shown that fewer number of handovers is observed when fuzry algorithm was implemented as compared to existing (conventional) algorithms under Rayleigh fading environment. The results also indicate handovers can be significantly reduced by increasing averaging distance. 
Evaluation of handover process "as also performed for conventional and fuzzy algorithms with several shadowing parameters. Simulation results indicate increasing shadowing parameter causes a wider spatial spread of handovers. It was also observed that there were fewer number of handovers when fuzzy algorithm was used. In addition, it was shown that most handovers occur over relative short distance when conventional algorithm was used whereas fewer handovers were observed when fuzzy algorithm was used. The results also indicate improvement in the number of handovers can be achieved by using fuzzy technique to combine two handover criteria. Therefore. simulation results have show'n that the proposed fuzzy algorithm has the ability to reduce a large number of handovers as compared to conventional algorithm.

\subsection{Suggestions for Future Investigations}

The following are some suggestions for future investigations related to this thesis.

\section{Multiple cell handover performance}

The analysis using signal strength in this thesis has assumed that handover occurs between two adjacent cells. Usually, a microcellular system is represent by the cell clusters that are repeated all over the service area and each cell is surrounded by a number of neighboring cells. It will be of interest to study the possibility of handover to any of the neighboring cells.

\section{Fuzzy network directed handover}

In this thesis, we did not consider handover based on the network criterion. However, it is possible in future Universal PCS that handover will exist between the networks. This suggests that a study can be done to observe the impact of fuzzy logic in the network directed handover in the context of multioperator PCS and to reduce network congestion. 
Multiple fuzzy handover algorithm

In this thesis we used .uzzy .echnique to combine two criteria. The work can be extended to investigate possibili y of combining different criteria that are atailable in the system using fuzzy logic. for example CIR. signal strength. distance and network criterion. 


\section{References}

[1] D.C Cox. "Universal Digital Portable Radio Communications", IEEE proceedings. Vol.7, No. 4. April 1987. pp 436-477.

[2] S. Ginn. "Personal Communication Services: Expanding the Freedom to Communicate", IEEE Communication Magazine. Feb. 1991.

[3] R.M. Singer, D.A. Irwin, Hopkins and Sutter, "Personal Communication Services: The next Technological Revolution", IEEE Communication Magazine, Feb. 1991.

[4] R.J. Potter. "PCN: Son of Cellular? The Challenges of Providing PCN Services", IEEE Communication Magazine. Feb. 1991.

[5] A.R. Potter, "Implementation of PCN using DCs1800", IEEE Communication Magazine. Dec. 1992.

[6] L.J. Greensten. N. Amitay. T. Chu, L.J. Cimin. G.J. Foschini. M.J. Gans. A. ChinLiu. A.J. Rustako, R.A. Valenzuela and G. Vannucci, "Microcells in Personal Communications Systems", IEEE Communication Magazine, Dec. 1992.

[7] R.S. Swain and D.W.J. Holmes, "The Digital Cordless Telecommunications Common Air Interface". British Telecom Technologi. Journai, Jan. 1990, pp 12-18

[8] H. Ochsner, "Digital European Cordless Telecommunications", IEEE 39th Vehicular Technologr Conference, Vol. 2. May 1990, pp 718-721.

[9] "WorldWide Personal Communication: Call for an Industry Vision", In Comforum (Rye Brook NY). June 10-11, 1991.

[10] D.C. Cox. "Wireless Access for Personal Communications", IEEE Communication Magazine, Dec. 1992.

[11] P. Carpenter, "From Mobile to Personal Communicators", Third Nordic Seminar on Digital Land Mobile Radio Communication. Copenhagen, Norway, Scpt. 1215,1988 .

[12] K. Yakamoto and A. Nakajima. "The Signalling Protocol Structure on the Radio Link for the Digital Mobile Communication System", 40th IEEE Vehicular Technologi. Conference. May 6-9. 1990, pp 487-491.

[13] T. Kanai and Y. Furuya. "Handoff Control Process for Microcellular Systr.ıns", 3 isth IEEE Vehicular Techmologr Conference, 1988.

[14] E.A. French and C.L. Mesquid. "Cellular Models and Handoff Criteria". 39th IEEE lehicular Technologi Conference, 1989.

[15] J.D. Parson and J.G. Gardiner."Mobile Communication Systems". John Wiley and Sons. New York. 1989, pp 266-271. 
[16] T. Kanai. M. Taketsugu and S. Kondo. “Experimental Digital Cellular Systems for Microcellular Handoff'. IEEE Vehicular Technologr Confèrenc'e. 1990.

[17] M. Háta and T. Nagatsu, "Mobile Location using Signal Strength Measurements in Cellular System", IEEE Transaction on Vehicular Technologi: V'T-29. No 2, May 1980. pp 245-252.

[18] G.D. Oh, "Vehicle Location in Cellular Mobile Radio Systems". IEEE Transaction on Vehicular Technologn: Vol. VT-26. No. 1. Feb., 1977. pp 43-46.

[19] W.G. Figel, N.H. Sheperd and W.F. Trammel, "Vehicle Location by Signal Attenuation Method", IEEE Transaction on Vehicular Technologi; Vol. VT-1s. Nov...1969.

[20] D.M. Black and D.O. Reudink, "Some Characteristics of Radio Propagation at $800 \mathrm{MHz}$ in the Philadelphia Area", IEEE Transactions on Vehicular Te'chnology: Vol. VT-21, May 1972, pp 45-51.

[21] D.C. Cox and R.P. Leck. "Distributions of Multipath delay Spread and Average Excess delay for 910MHz Urban Mobile Radio Paths", IEEE Transaction on Antenna Propagation, March 1975, pp 206-213.

[22] M. Greiner. K. Low and R.W. Lorenz, "Cell Boundary Detection in the German Cellular Mobile Radio: System C", IEEE Journal on Selected Areas in Communication, Vol. Sac-5, No. 5 June 1987.

[23] ETSI, GSM Technical Specification doc. 05.08, March 1992.

[24] ETSI. GSM Technical Specification doc. 03.09. July 1994.

[25] R. Beck and F.W. Ho. "Evaluation and Performance of Field Strength Related Handover Strategies for Microcellular Systems", Proceeding of Third Nordic Seminar on Digital Land Mobile Radio Communication. Copenhagen, Sept. 12-15. 1988.

[26] M. Gudmundson. "Analysis of Handover Algorithms", IEEE Proceeding. 1991.

[27] R. Vijayan and J.M. Holtzman, "Analysis of Handoff Algorithm using Nonstationary Signal Strength Measurements", IEEE Globecom, 1992.

[28] S.T.S. Chia and R.J. Warburton, "Handover Criteria for City Microcellular Radio Systems", IEEE Vehicular Technological Conference, 1990.

[29] L.A. Zadeh, "Fuzzy Sets". Information and Control, Vol. 8, 1965, pp 338-353.

[30] H.J. Zimmermann. "Fuzzy Set Theory and its Applications", Kluwer Academic, 1991. 
[31] D. Dubois and H. Prade, "Fuzzy Sets and Systems: Theory and Applications". 1980a.

[32] R.R. Yager and L.A. Zadeh, "An Introduction to Fuzzy Logic Applications in Intelligent Systems", Kluwer Academic. 1992.

[33] A. Kandel, "Fuzzy Techniques in Pattem Recognition". John Wiley and Suns. 1982.

[34] S.K. Pal and D.K.D. Majumder, "Fuzzy Mathematical Approach to Pattern Recognition". Wiley Eastern. 1986.

[35] J.C. Bezdek and S.K. Pal. "Fuzzy Models for Pattern Recognition". IEEE Press. 1992.

[36] M. Hata, "Empirical Formula for Propagation Loss in Land Mobile Radio Services". IEEE Transactions on Vehicular Technologr: Vol. VT-29. No. 3. August 1980.

[37] W. C. Jakes. "Microwave Mobile Communications". John Wiley and Sons. New York. 1973.

[38] F. Handessi. "On the Theory of FRESH-DFE and its Application in Digital Cellular Radio Systems", Ph. D Thesis. Carleton University. Sept. 1994. 

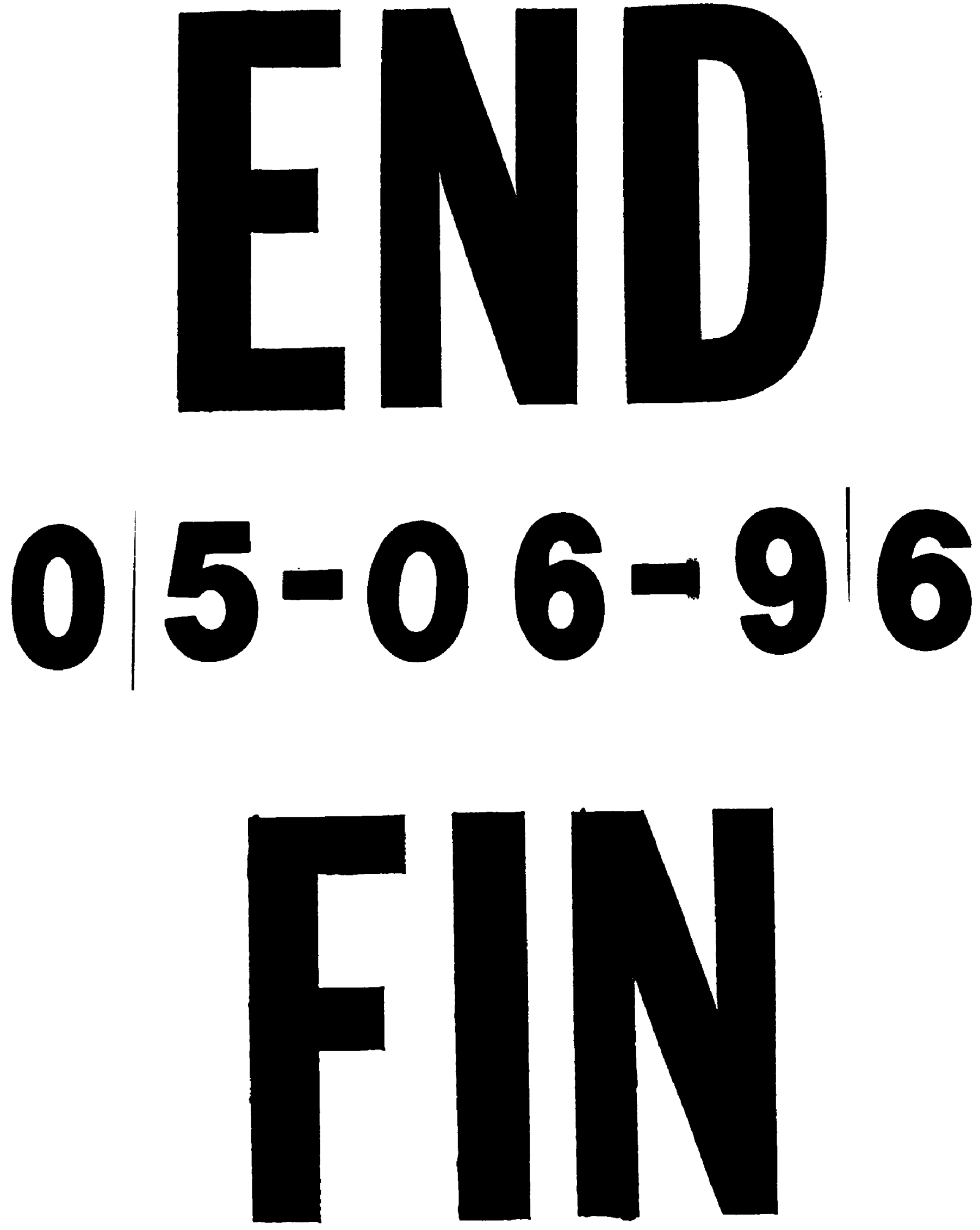